University of Tennessee Health Science Center

UTHSC Digital Commons

\title{
$5-2011$
}

\section{A Behavioral and Anatomical Analysis of Conditioned Taste Aversion in C57BL/6J and DBA/2J Mice}

April Rebecca Glatt

University of Tennessee Health Science Center

Follow this and additional works at: https://dc.uthsc.edu/dissertations

Part of the Neurosciences Commons

\section{Recommended Citation}

Glatt, April Rebecca , "A Behavioral and Anatomical Analysis of Conditioned Taste Aversion in C57BL/6J and DBA/2J Mice" (2011). Theses and Dissertations (ETD). Paper 101. http://dx.doi.org/10.21007/ etd.cghs.2011.0113.

This Dissertation is brought to you for free and open access by the College of Graduate Health Sciences at UTHSC Digital Commons. It has been accepted for inclusion in Theses and Dissertations (ETD) by an authorized administrator of UTHSC Digital Commons. For more information, please contact jwelch30@uthsc.edu. 


\title{
A Behavioral and Anatomical Analysis of Conditioned Taste Aversion in C57BL/ $6 \mathrm{~J}$ and DBA/2J Mice
}

\begin{abstract}
Conditioned taste aversion (CTA) has been commonly used as a model of learning and memory. Traditionally, CTA approaches have used a paradigm that follows the model of classical conditioning. This involves presentation of a novel tastant, such as sucrose (conditioned stimulus, CS), followed by an intraperitoneal injection of lithium chloride that induces gastric malaise (unconditioned stimulus, US), which results in the aversion of sucrose (conditioned response, CR). However, a more natural classical conditioning paradigm involves the consumption, rather than injection, of the US by using a self-administration paradigm that allows for time-dependent analysis of formation, generalization, and extinction of CTA as it would occur naturally.

An appreciation of the anatomy of the taste pathway is critical in understanding CTA, as the learning is dependent on salient gustatory cues. Taste information begins with taste buds on the tongue and is sent to the brainstem via three cranial nerves: facial, glossopharyngeal, and the vagus. The first synapse of these cranial nerves is in the nucleus of the solitary tract, where gustatory and visceral information are processed separately. From here, taste information is sent to the parabrachial nucleus, where gustatory and visceral information have been shown to overlap. Therefore, the parabrachial nucleus is a key site of investigation concerning CTA, as it may be the first area where taste and gastrointestinal cues converge, leading to a learning event. Electrophysiology and immunohistochemistry techniques have been used to show changes in neuronal activity in taste nuclei in conditioned taste aversion, including the use of c-Fos as a method of labeling neurons that respond to a specified behavior.
\end{abstract}

The use of inbred strains of mice, specifically the common strains C57BL/6J (B6) and DBA/2J (D2), allows for the investigation of phenotypic variation and specific genes underlying the various components of CTA. B6 and D2 mice have previously been characterized in terms of various ingestive behaviors, making these mice ideal for this study. Learning-based differences between B6 and D2 mice have been seen in various tasks, including types of conditioning. Therefore, the following studies investigated the hypothesis that these two strains differ in various aspects of CTA, a form of learning and memory. First, we hypothesized that D2 mice will make a stronger association between the taste and malaise compared to B6 mice, and that such strain differences would be evident in both a behavioral and anatomical analysis. Second, we hypothesized that any strain differences seen in behavior will also be evident in c-Fos labeling following a CTA.

The following experiments tested the hypothesis that D2 mice would condition a stronger taste aversion than B6 mice, and that this strain difference would be evident in behavioral measures as well as in patterns of neuronal activation. We used a self-administration paradigm to condition a taste aversion to lithium chloride, and then tested the CTA the following day, where the CTA generalized to sodium chloride. More alterations in measures of licking behavior were seen in D2 mice as a result of a CTA, suggesting D2 mice conditioned a stronger aversion than B6 mice. Using c-Fos as a neuronal marker, we then compared patterns of activation in the parabrachial nucleus between the strains following various types of stimulation (visceral, gustatory, or combination). Results showed no strain differences except following the generalization test, where D2 showed overall more c-Fos than B6, and specifically showed more c-Fos in the external medial nucleus, which has been associated with aversive stimuli. These results suggest that $\mathrm{NaCl}$, a previously palatable stimulus, had shifted to an aversive stimulus due to a CTA, but only in D2 mice.

\section{Document Type}

Dissertation 


\section{Degree Name}

Doctor of Philosophy (PhD)

\section{Program}

Biomedical Sciences

\section{Research Advisor}

John D. Boughter, Jr., Ph.D.

\section{Keywords}

Aversion, c-Fos, Conditioning, Genetic, Parabrachial Nucleus, Taste

\section{Subject Categories}

Medical Sciences | Medicine and Health Sciences | Neurosciences 


\title{
A BEHAVIORAL AND ANATOMICAL ANALYSIS OF CONDITIONED TASTE AVERSION IN C57BL/6J AND DBA/2J MICE
}

\author{
A Dissertation \\ Presented for \\ The Graduate Studies Council \\ The University of Tennessee \\ Health Science Center
}

\author{
In Partial Fulfillment \\ Of the Requirements for the Degree \\ Doctor of Philosophy \\ From The University of Tennessee
}

By

April Rebecca Glatt

May 2011 
Copyright @ 02011 by April Rebecca Glatt All right reserved 


\section{DEDICATION}

I would like to dedicate this dissertation to my parents, Donna and Edward Glatt. You have been there for me my entire life, with truly

unconditional love and support, and always believed I could do anything I wanted. So here's to you - I wouldn't be who I am, or where I am, without you. 


\section{ACKNOWLEDGMENTS}

I would like to acknowledgement and thank my mentor, Dr. John Boughter, for all his guidance, patience, and understanding over the years.

I would like to acknowledge my committee, Dr. Cantrell, Dr. McDonald, Dr. Steketee, and Dr. Waters, for all your assistance and expertise.

I would like to thank my lab mate, Jennifer Saputra, for always being there to help and make the day brighter. Also I'd like to thank Dr. Tokita, for all his assistance and expertise on the PBN and immunohistochemistry.

Lastly, an acknowledgement to my fellow graduate students, for moral support and help over the years. We did it! 


\section{ABSTRACT}

Conditioned taste aversion (CTA) has been commonly used as a model of learning and memory. Traditionally, CTA approaches have used a paradigm that follows the model of classical conditioning. This involves presentation of a novel tastant, such as sucrose (conditioned stimulus, CS), followed by an intraperitoneal injection of lithium chloride that induces gastric malaise (unconditioned stimulus, US), which results in the aversion of sucrose (conditioned response, CR). However, a more natural classical conditioning paradigm involves the consumption, rather than injection, of the US by using a self-administration paradigm that allows for time-dependent analysis of formation, generalization, and extinction of CTA as it would occur naturally.

An appreciation of the anatomy of the taste pathway is critical in understanding CTA, as the learning is dependent on salient gustatory cues. Taste information begins with taste buds on the tongue and is sent to the brainstem via three cranial nerves: facial, glossopharyngeal, and the vagus. The first synapse of these cranial nerves is in the nucleus of the solitary tract, where gustatory and visceral information are processed separately. From here, taste information is sent to the parabrachial nucleus, where gustatory and visceral information have been shown to overlap. Therefore, the parabrachial nucleus is a key site of investigation concerning CTA, as it may be the first area where taste and gastrointestinal cues converge, leading to a learning event. Electrophysiology and immunohistochemistry techniques have been used to show changes in neuronal activity in taste nuclei in conditioned taste aversion, including the use of c-Fos as a method of labeling neurons that respond to a specified behavior.

The use of inbred strains of mice, specifically the common strains C57BL / 6J (B6) and DBA / 2J (D2), allows for the investigation of phenotypic variation and specific genes underlying the various components of CTA. B6 and D2 mice have previously been characterized in terms of various ingestive behaviors, making these mice ideal for this study. Learning-based differences between B6 and D2 mice have been seen in various tasks, including types of conditioning. Therefore, the following studies investigated the hypothesis that these two strains differ in various aspects of CTA, a form of learning and memory. First, we hypothesized that D2 mice will make a stronger association between the taste and malaise compared to B6 mice, and that such strain differences would be evident in both a behavioral and anatomical analysis. Second, we hypothesized that any strain differences seen in behavior will also be evident in c-Fos labeling following a CTA.

The following experiments tested the hypothesis that D2 mice would condition a stronger taste aversion than B6 mice, and that this strain difference would be evident in behavioral measures as well as in patterns of neuronal activation. We used a self-administration paradigm to condition a taste aversion to lithium chloride, and then tested the CTA the following day, where the CTA generalized to sodium chloride. More alterations in measures of licking behavior 
were seen in D2 mice as a result of a CTA, suggesting D2 mice conditioned a stronger aversion than B6 mice. Using c-Fos as a neuronal marker, we then compared patterns of activation in the parabrachial nucleus between the strains following various types of stimulation (visceral, gustatory, or combination). Results showed no strain differences except following the generalization test, where D2 showed overall more c-Fos than B6, and specifically showed more c-Fos in the external medial nucleus, which has been associated with aversive stimuli. These results suggest that $\mathrm{NaCl}$, a previously palatable stimulus, had shifted to an aversive stimulus due to a CTA, but only in D2 mice. 


\section{TABLE OF CONTENTS}

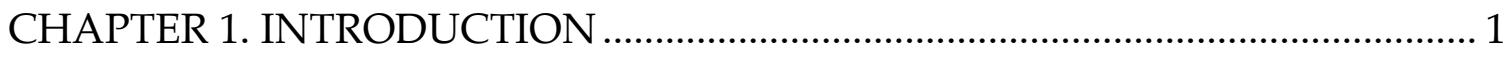

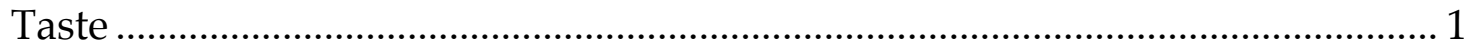

Conditioned Taste Aversion.................................................................................. 1

Genetic Differences in Learning and Memory........................................................ 4

Brain Regions Involved in CTA …………………................................................ 7

c-Fos and Conditioned Taste Aversion............................................................... 12

CHAPTER 2. GENERAL METHODS ……………........................................... 15

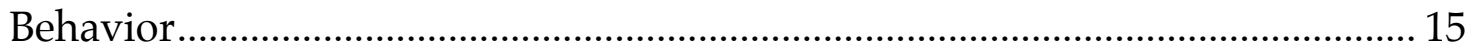

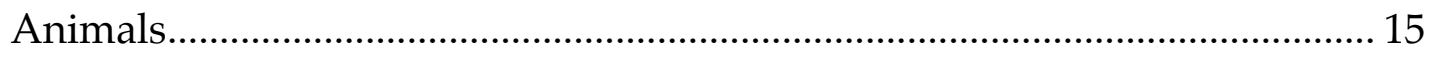

Lickometer................................................................................................... 15

Brief-Access Tests............................................................................................ 15

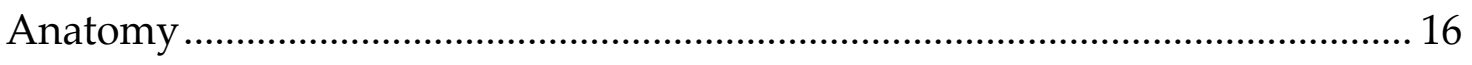

c-Fos Immunohistochemistry with DAB ........................................................ 16

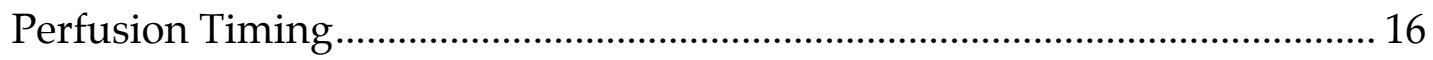

\section{CHAPTER 3. MOUSE STRAIN DIFFERENCES IN CONDITIONED TASTE} AVERSION FORMATION, GENERALIZATION, AND EXTINCTION USING A SELF-ADMINISTRATION PARADIGM .................................................. 20

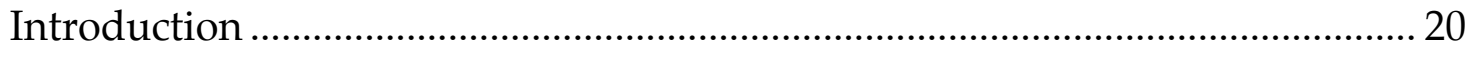

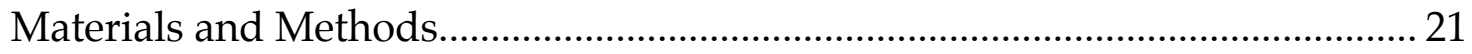

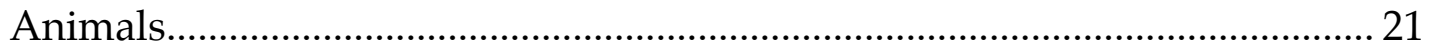

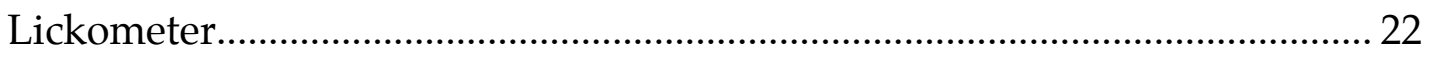

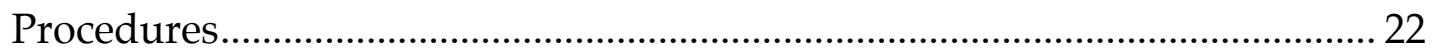

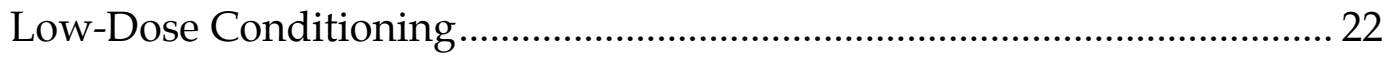




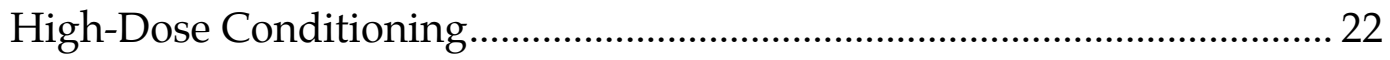

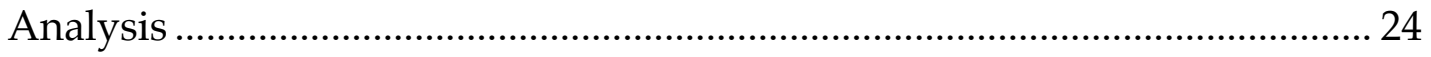

Licks and Volume per Lick (VPL) ................................................................ 24

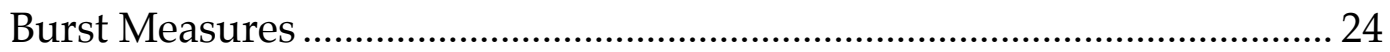

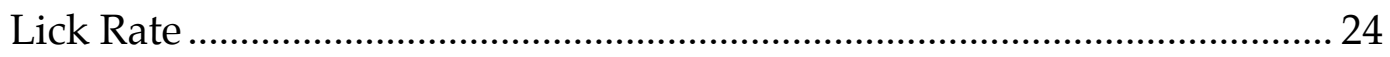

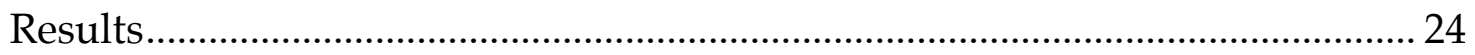

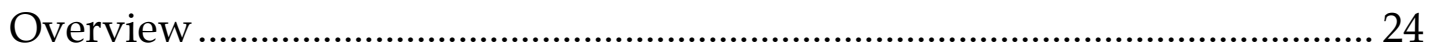

Low-Dose Experiment................................................................................. 25

Conditioning: Minute-by-Minute Analysis of Licks....................................... 25

Generalization: Minute-by-Minute Analysis of Licks ................................... 28

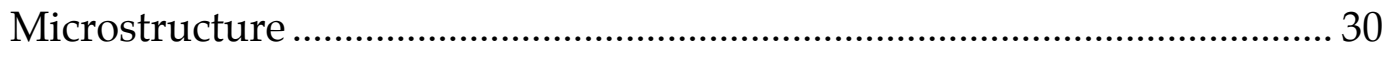

High-Dose Experiment.......................................................................................... 35

Conditioning: Minute-by-Minute Analysis of Licks....................................... 35

Generalization: Minute-by-Minute Analysis of Licks ................................... 37

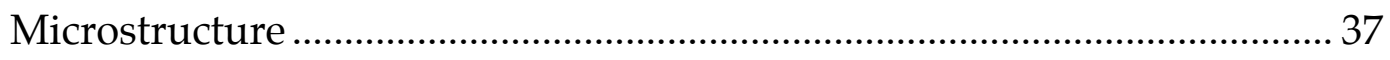

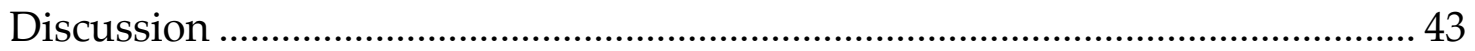

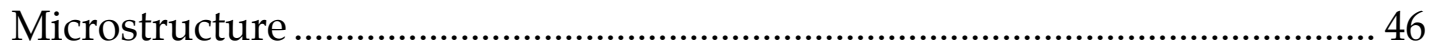

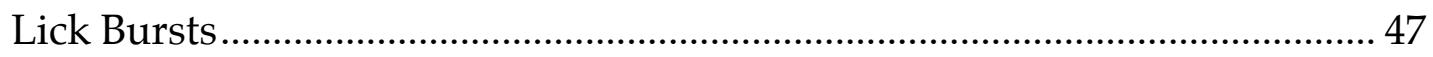

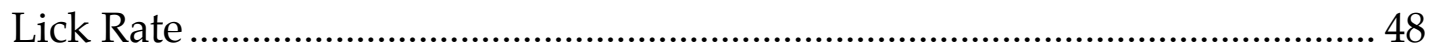

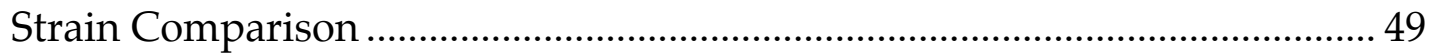

CHAPTER 4. IMMUNOHISTOCHEMICAL DETECTION OF C-FOS, TO DETERMINE ANATOMICAL BRAIN AREAS RESPONSIBLE FOR STRAIN DIFFERENCES SEEN IN ACQUISITION AND EXTINCTION OF A

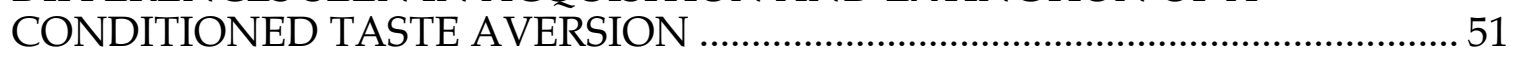

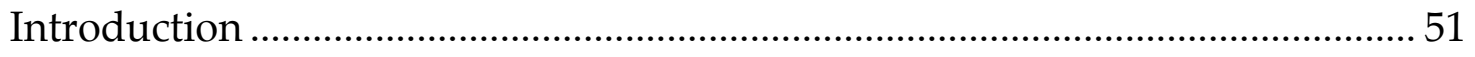

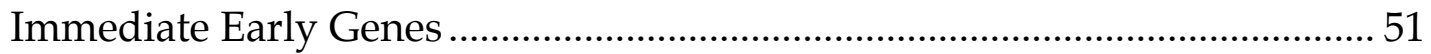


Taste and Visceral-evoked c-Fos..................................................................... 51

Conditioned Taste Aversion in the PBN ........................................................... 52

Materials and Methods........................................................................................... 53

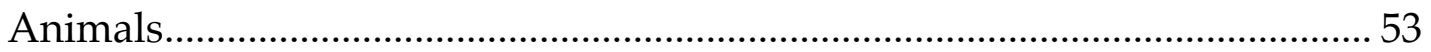

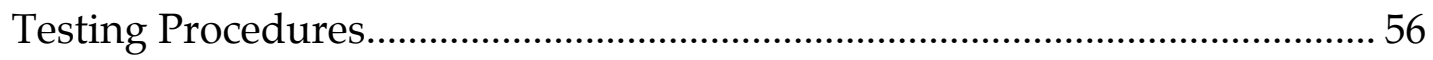

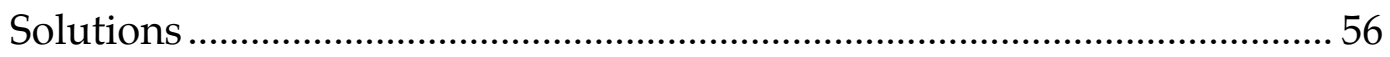

Intraperitoneal Injections ............................................................................... 56

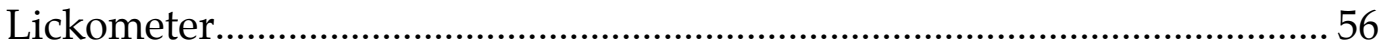

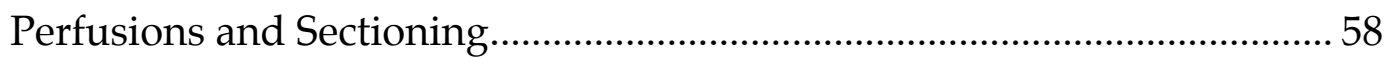

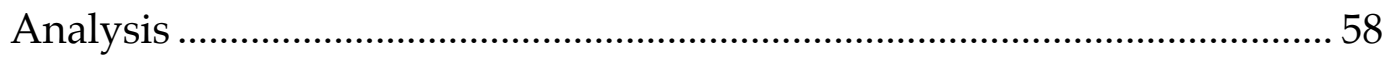

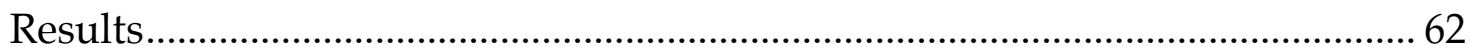

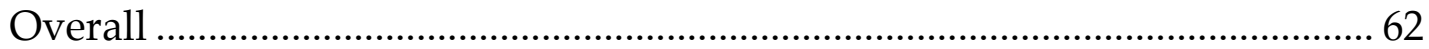

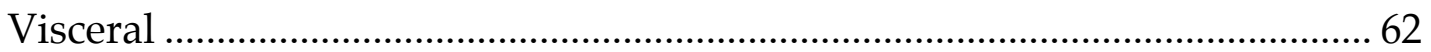

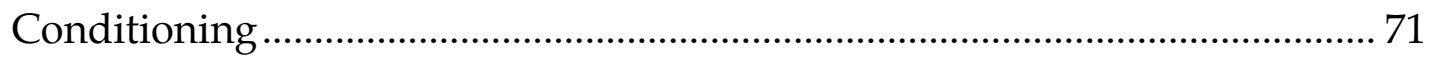

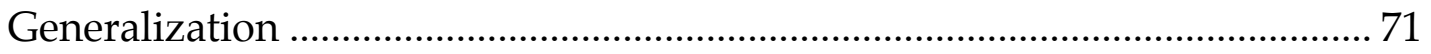

Conditioning to Generalization ........................................................................... 74

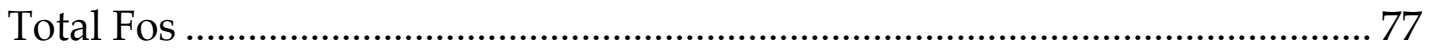

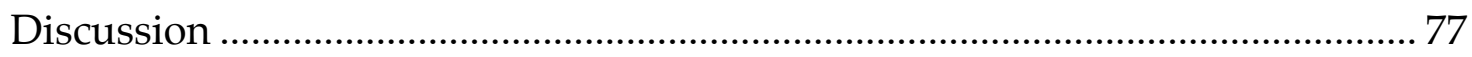

CHAPTER 5. FINAL SUMMARY AND OVERALL CONCLUSIONS ................... 83

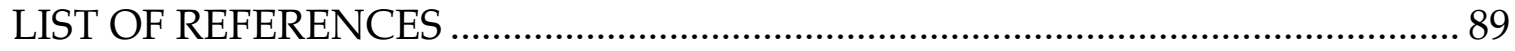

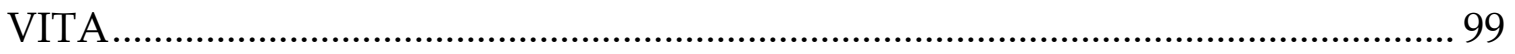




\section{LIST OF TABLES}

Table 1-1. B6 and D2 learning and memory differences...................................5

Table 1-2. Summary of lesion studies of major brain regions possibly involved in CTA - PBN most severely affected................................... 9

Table 3-1. Average percent of original body weight from low concentration

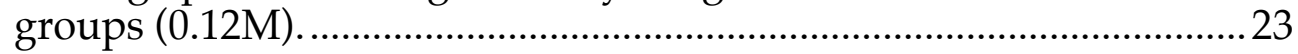

Table 3-2. Average percent of original body weight from high

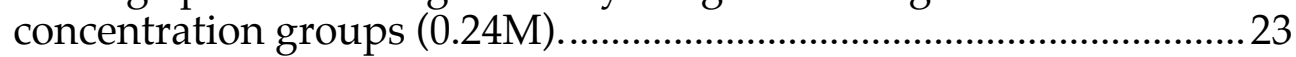

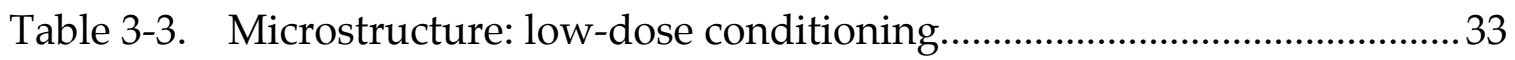

Table 3-4. Microstructure: low-dose generalization.......................................... 34

Table 3-5. Microstructure: high-dose conditioning. .......................................... 41

Table 3-6. Microstructure: high-dose generalization........................................ 42

Table 4-1. Test groups for immunohistochemistry........................................54

Table 4-2. Summary of groups, stimulus, and method of application...............55

Table 4-3. Immunohistochemistry steps for labeling c-Fos.................................60 


\section{LIST OF FIGURES}

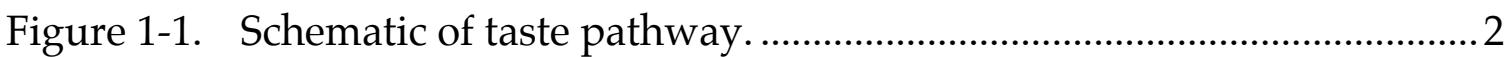

Figure 1-2. Representation of possible convergence areas in the PBN, leading to a conditioned taste aversion.

Figure 2-1. Example of quantification of c-Fos expression in the PBN after perfusion, either 30 minutes or 2 hours following the start of $\mathrm{NaCl}$ consumption in $\mathrm{B} 6$

Figure 2-2. Examples illustrating $\mathrm{LiCl}$ dose is related to number of c-Fos positive nuclei in the external lateral subnucleus of the PBN.

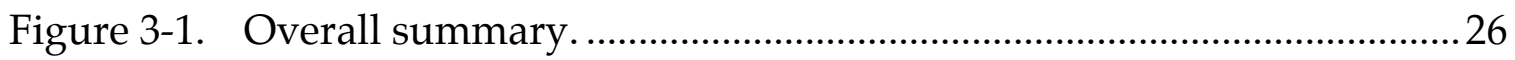

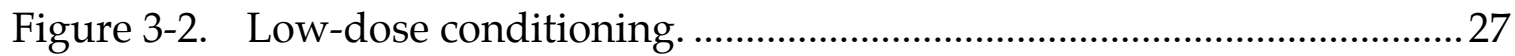

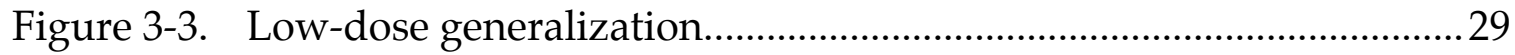

Figure 3-4. Inter-lick interval distribution during $0.12 \mathrm{M}$ conditioning................31

Figure 3-5. Inter-lick interval distribution during $0.12 \mathrm{M}$ generalization. ............31

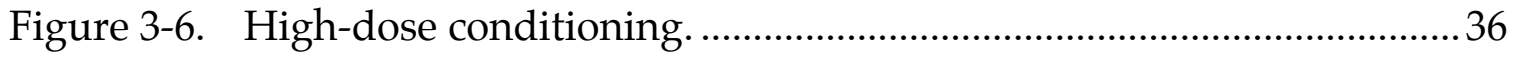

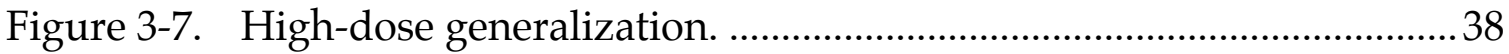

Figure 3-8. Inter-lick interval during $0.24 \mathrm{M}$ conditioning....................................... 40

Figure 3-9. Inter-lick interval during $0.24 \mathrm{M}$ generalization. .................................... 40

Figure 4-1. Comparison of dose $(\mathrm{mg} / \mathrm{kg})$ mice received of $0.15 \mathrm{M} \mathrm{LiCl}$ injected via i.p. and $0.24 \mathrm{M} \mathrm{LiCl}$ self-administered in lickometer. ....57

Figure 4-2. c-Fos staining and antibody controls....................................................59

Figure 4-3. Representative sections of the PBN used for quantification..............61

Figure 4-4. Plots of c-Fos quantification (labeling) in the PBN following water intake.

Figure 4-5. Plots of c-Fos quantification in the PBN following i.p. NaCl............64

Figure 4-6. Plots of c-Fos quantification in the PBN following $\mathrm{NaCl}$ intake. ..... 64

Figure 4-7. Plots of c-Fos quantification in the PBN following i.p. LiCl. ............65

Figure 4-8. Plots of c-Fos quantification in the PBN following $\mathrm{LiCl}$ intake........ 65 
Figure 4-9. Summary of c-Fos quantification for B6 mice.

Figure 4-10. Summary of c-Fos quantification for D2 mice...................................68

Figure 4-11. Comparisons of c-Fos expression following intraperitoneal injections of $\mathrm{NaCl}$ or $\mathrm{LiCl}$. .70

Figure 4-12. Comparisons of c-Fos expression following $\mathrm{NaCl}$ or $\mathrm{LiCl}$ intake in B6 and D2 mice.

Figure 4-13. Comparison of c-Fos expression following generalization. .73

Figure 4-14. Amount of c-Fos expression on conditioning day compared to generalization day in C57BL/6J mice. .75

Figure 4-15. Amount of c-Fos expression on conditioning day compared to generalization day in DBA/2J mice. .....................................................76

Figure 4-16. Total c-Fos amounts in the PBN in B6 and D2 mice following visceral, conditioning, and generalization testing.

Figure 4-17. Illustration of c-Fos labeling results following stimulation by injection, conditioning, and generalization 


\section{LIST OF ABBREVIATIONS}

$\mathrm{ABC}$

AP

B6

BLA

BST

CeA

CLS

CMS

CTA

D2

DAB

DLS

DNA

ELS

EMS

FLI

IC

IEG

ILI

I/O
Avidin-biotin complex (kit)

Area postrema

C57BL / 6J inbred mice

Basolateral amygdala

Bed nucleus of the stria terminalis

Central nucleus of the amygdala

Central lateral subnucleus

Central medial subnucleus

Conditioned taste aversion

DBA / 2J inbred mice

Diaminobenzidine

Dorsal lateral subnucleus

Deoxyribonucleic acid

External lateral subnucleus

External medial subnucleus

Fos-like immunoreactivity

Insular cortex

Immediate early gene

Inter-lick interval

Intra-oral 


\begin{tabular}{|c|c|}
\hline i.p. & Intraperitoneal \\
\hline IX & Cranial nerve 9 \\
\hline LH & Lateral hypothalamus \\
\hline $\mathrm{LiCl}$ & Lithium chloride \\
\hline $\mathbf{M}$ & Medial \\
\hline $\mathrm{MgCl}$ & Magnesium chloride \\
\hline MPI & Mean primary lick interval \\
\hline $\mathrm{NaCl}$ & Sodium chloride \\
\hline NST & Nucleus of the solitary tract \\
\hline PBN & Parabrachial nucleus \\
\hline PBS & Phosphate buffered saline \\
\hline SCP & Superior cerebellar peduncle \\
\hline SOA & Sucrose octaacetate \\
\hline STT & Sipper tube training \\
\hline TT & Trial training \\
\hline VII & Cranial nerve 7 \\
\hline VLS & Ventral lateral subnucleus \\
\hline VPL & Volume per lick \\
\hline VPMpc & Ventral posteromedial nucleus of the thalamus \\
\hline Wa or $W$ & Waist area of PBN \\
\hline $\mathbf{x}$ & Cranial nerve 10 \\
\hline
\end{tabular}




\section{CHAPTER 1. INTRODUCTION}

\section{Taste}

Conditioned taste aversion (CTA) is a phenomenon that occurs when an association is made between a taste and symptoms of malaise caused by toxins. For example, following ingestion of spoiled food, a subject will associate the taste of the food with the sickness induced from it being spoiled, leading the subject to avoid the food in the future. Before one can study conditioned taste aversion though, the sense of taste and its pathway must first be understood. As is illustrated in Figure 1-1, taste is considered a form of chemoreception, and in the rodent, detection of stimuli begins with the taste buds where taste receptor cells are located. The three cranial nerves, which carry this information to the brain, innervate specific taste buds. Cranial nerve VII, the facial nerve, innervates fungiform papillae (anterior tongue) and foliate papillae (sides of the tongue) (Boughter, J. D., Jr. et al. 2002). Cranial nerve IX, the glossopharyngeal nerve, innervates vallate and foliate papillae (posterior tongue). Lastly, cranial nerve $\mathrm{X}$, the vagus nerve, innervates portions of the upper esophagus and epiglottis.

From the cranial nerves, the first central relay in the gustatory pathway is the nucleus of the solitary tract (NST). The fibers of the facial nerve synapse in the rostral NST; fibers of the glossopharyngeal synapse at intermediate levels of the NST; and fibers of the vagus synapse in more caudal NST. Taste (gustatory) information is sent from taste buds to the rostral NST, also known as the gustatory zone. In the caudal NST, visceral (ingestive) input is received from the stomach. The vagus nerve is known to densely innervate the body, including the abdominal region and stomach (Johnson, L.R. 2006). The afferent input from the vagus nerve is then thought to be "sorted" in the NST, which subsequently regulates projections to the stomach (Johnson, L. R. 2006). Therefore, at the level of the NST, while both gustatory and visceral (ingestive) information are being received, it remains separate. However, at the next level of the gustatory pathway, the parabrachial nucleus (PBN), it is thought that visceral and gustatory information first converge. Gustatory information is conveyed to the PBN parallel to general visceral information coming from the caudal NST. From the PBN, the taste pathway divides into thalamocortical and limbic forebrain projections. The latter includes direct reciprocal connections between the PBN and the central nucleus of the amygdala (CeA), lateral hypothalamus (LH), and the bed nucleus of the stria terminalis (BST).

\section{Conditioned Taste Aversion}

The ability to acquire a conditioned taste aversion is an important survival trait. In nature, an animal must be able to recognize toxic food by either taste or smell, and learn to reject it to protect itself against fatal poisoning. This is accomplished by developing a CTA to potentially toxic foods. Studying CTA not only allows insight into possible mechanisms of learning and memory, but also 


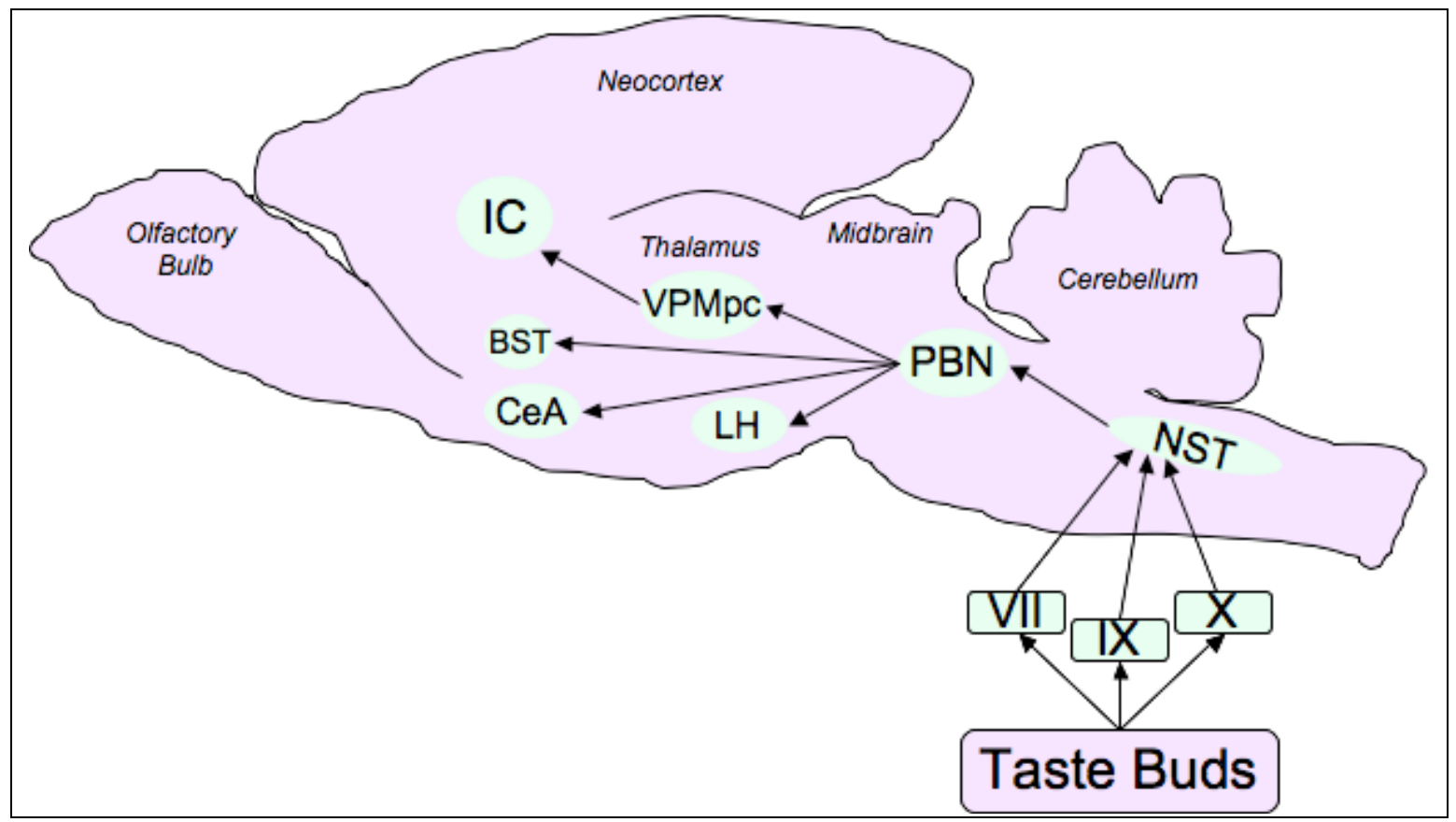

Figure 1-1. Schematic of taste pathway.

Notes: Abbreviations: VII =cranial nerve VII, facial nerve; IV = cranial nerve IV, glossopharyngeal nerve; $X=$ cranial nerve $X$, vagus nerve; NST = nucleus of the solitary tract; $\mathrm{PBN}=$ parabrachial nucleus; $\mathrm{LH}=$ lateral hypothalamus; $\mathrm{CeA}=$ central nucleus of the amygdala; BST = bed nucleus of the stria terminalis; $\mathrm{VPMpc}=$ ventral posteromedial nucleus of the thalamus; IC = insular cortex. 
into the complexity of the taste system. Understanding the anatomy of the taste pathway is critical in understanding the neural substrate for CTA, as taste and visceral information project to common brain regions, where at some point, an association between the two types of information is made (Welzl, H. et al. 2001). One possible site for this association is the PBN, where specific subnuclei are known to receive visceral and / or gustatory information (Karimnamazi, H. et al. 2002). Lesions of the PBN, but not the NST, have been found to abolish CTA (Spector, A. C. et al. 1992). Studies using both electrophysiology (Chang, F. C. et al. 1984; Yamamoto, T. et al. 1989) and immunohistochemistry to label the immediate early gene, c-Fos (Yamamoto, T. et al. 1993; Houpt, T. A. et al. 1994; Swank, M. W. et al. 1994; Swank, M. W. et al. 1995; Houpt, T. A. et al. 1996; Navarro, M. et al. 2000; Schafe, G. E. et al. 2000; Purves, D. 2008; Clark, E. W. et al. 2009) have shown changes in neuronal activity in the PBN following the formation of a CTA, and it's been suggested that these changes occurred as the result of learning (Welzl, H. et al. 2001).

Conditioned taste aversion has been well studied as a model of learning and memory. Traditionally, CTA approaches have used a paradigm that follows a model of behavior modification known as classical conditioning. Classical conditioning resulting in a CTA typically involves presentation of a novel tastant, such as sucrose (conditioned stimulus, CS), followed by an intraperitoneal (i.p.) injection of lithium chloride $(\mathrm{LiCl})$ that induces gastric malaise (unconditioned stimulus, US), which results in behavioral avoidance of the tastant (conditioned response, CR) (Ingram, D. K. 1982; Chang, F. C. et al. 1984; Spector, A. C. et al. 1988; Meachum, C. L. et al. 1990; Risinger, F. O. et al. 2000; Foynes, M. M. et al. 2004). Another important aspect of CTA is generalization, which occurs when a CTA to a conditioned stimulus generalizes to a similar tasting stimulus. For example, an aversion to sucrose may generalize to other similar sweet tastes. There are many variations on this procedure, such as those manipulating the duration between US and CS, as well as the number of pairings used to condition the aversion. Although varied, these approaches ultimately result in the acquisition of a CTA via the US as an i.p. injection of LiCl.

A more natural classical conditioning paradigm involves the consumption, rather than injection, of the US: A study by Loy and Hall (2002) demonstrated that self-administered consumption of $\mathrm{LiCl}$ results in a conditioned taste aversion to salt, which generalizes to a presumably similartasting salt, $\mathrm{NaCl}$ (Loy, I. et al. 2002; Ishiwatari, Y. et al. 2009). A subsequent study by Baird and colleagues (2005) made use of this self-administration model in rats to show via a licking analysis that CTA development and generalization occur within an extremely rapid timeframe (9 min) (Baird, J. P. et al. 2005). Together, these studies show that a self-administered, single-trial of $\mathrm{LiCl}$ is sufficient to establish a CTA. Further, using such a self-administration paradigm allows for time-dependent analysis of formation, generalization, and extinction of CTA as it would occur naturally, rather than following the standard pairing of an ingested stimulus with injection. 


\section{Genetic Differences in Learning and Memory}

In our study, we compared two common, genetically characterized, inbred mouse strains, C57BL/6J (B6) and DBA/2J (D2). Using inbred strains allows for investigation of genetic differences underlying the components of various behaviors, including CTA, and these differences can in turn be exploited for the discovery of specific genes that underlie behavior. B6 and D2 mice have been well characterized in terms of taste and ingestive behavior, making these strains ideal for this study (Nelson, T. M. et al. 2003; Lewis, S. R. et al. 2005). While many CTA studies have focused on rats, they do not focus on genetic differences underlying CTA, whereas B6 and D2 mice have been used in other studies that test various learning and memory avenues. Table 1-1 summarizes learning and memory studies and the performance level of B6 and D2 mice on different tasks (better performance by B6 indicated by blue; $\mathrm{D} 2$ by green).

Differences between B6 and D2 mice have been seen in the Morris water maze, where B6 mice solve the hidden platform task at 24 days old, while D2 mice never solve this task (Upchurch, M. et al. 1988; Paylor, R. et al. 1994; D'hooge, R. et al. 2001); better performance by B6, compared to D2, in the standard radial arm maze (Ammassari-Teule, M. et al. 1993); contextual fear conditioning, where B6 mice are among the strains exhibiting the highest level of freezing and retain this fear memory for 60 days, while D2 mice show some of the lowest levels of freezing and significantly decrease their retention by 60 days (Paylor, R. et al. 1994; Bothe, G. W. et al. 2004); and rotorod performance, again with B6 mice showing the highest, and D2 showing the lowest, levels of motor learning (Mcfadyen, M. P. et al. 2003). While it may appear B6 perform better in learning and memory tasks, it is important to note these tasks measure various types of learning and memory that take place in different brain regions.

Tasks including the radial arm maze, Morris water maze, and contextual fear conditioning, test spatial learning and memory, which are based in the hippocampus (Siegfried, B. et al. 1989; Brown, R. E. et al. 2007). Object recognition tasks are among those to test learning and memory roles of the rhinal cortex (Zhu, X. O. et al. 1995). Finally, the amygdala is thought to be a brain area with a critical role in aversive learning (a form of classical conditioning where an association between an aversive event and the stimulus that predicted the event is made), which has been tested through conditioned fear response, place avoidance and active avoidance conditioning (Maren, S. 2001). It has been widely associated with aversive learning in previous literature (Mcgaugh, J. L. 1989; Davis, J. D. et al. 1992; Ledoux, J. E. 2000; Calder, A. J. et al. 2001; Davis, M. et al. 2001; Maren, S. 2001, 2003). Unlike the above studies, which found B6 to have stronger responses, the opposite appears to be true for these amygdala-related tasks. Place aversion, conditioned using various doses of $\mathrm{LiCl}$, reveals D2 mice develop a stronger aversion than B6 mice (Risinger, F. O. et al. 2000). A study by Siegfried and Frischknecht (1989) shows that place avoidance learning, conditioned with bites from an aggressive mouse, results in D2 mice showing avoidance of the place of the attack, while B6 show no avoidance (Squire, L. R. 2004). 
Table 1-1. B6 and D2 learning and memory differences.

\begin{tabular}{|c|c|c|c|c|}
\hline Task & Goal & B6 Performance & D2 Performance & $\begin{array}{l}\text { Type of Learning } \\
\text { and Brain Region }\end{array}$ \\
\hline Morris water maze $^{1}$ & $\begin{array}{l}\text {-Locate hidden platform } \\
\text {-Distal cues } \\
\text {-Proximal cues }\end{array}$ & -Solve at 24 days old & -Never solve & $\begin{array}{l}\text {-Spatial learning } \\
\text {-Hippocampus }\end{array}$ \\
\hline Barnes circular maze $^{2}$ & $\begin{array}{l}\text {-Find drop box } \\
\text {-Bright light and loud } \\
\text { noise = aversive } \\
\text { motivation }\end{array}$ & -Approx 4 errors, day 4 & -Approx 9 errors, day 4 & $\begin{array}{l}\text {-Visuo-spatial } \\
\text {-Hippocampus }\end{array}$ \\
\hline Rotorod $^{3}$ & $\begin{array}{l}\text {-Latency to fall off during } \\
\text { acceleration }\end{array}$ & -Improvement about 20s & -Improvement about 3s & $\begin{array}{l}\text {-Motor learning } \\
\text {-Cerebellum, basal ganglia }\end{array}$ \\
\hline $\begin{array}{l}\text { Contextual fear } \\
\text { conditioning }\end{array}$ & $\begin{array}{l}\text {-Associate context }+ \text { shock } \\
- \text { Show fear in context }\end{array}$ & $\begin{array}{l}\text {-Highest levels of freezing } \\
\text {-Retain memory } 60 \text { days }\end{array}$ & $\begin{array}{l}\text {-Lowest levels of freezing } \\
\text {-Significant decrease in } \\
\text { retention at } 60 \text { days }\end{array}$ & $\begin{array}{l}\text {-Spatial and conditioning - } \\
\text {-Hippocampus and } \\
\text { amygdala }\end{array}$ \\
\hline Object recognition $^{5}$ & -Spatial: displaced objects & $\begin{array}{l}\text {-Recognized object had } \\
\text { been moved }\end{array}$ & $\begin{array}{l}\text {-Did not recognize objects } \\
\text { had been moved }\end{array}$ & $\begin{array}{l}\text {-Spatial } \\
\text {-Hippocampus }\end{array}$ \\
\hline Object recognition $^{5}$ & -Non-spatial: novel object & $\begin{array}{l}\text {-No increase in time spent } \\
\text { exploring novel object }\end{array}$ & $\begin{array}{l}\text {-Significant increase in } \\
\text { time exploring novel object }\end{array}$ & -Non-spatial \\
\hline Place avoidance $^{6}$ & $\begin{array}{l}\text {-Conditioned with bites } \\
\text { from aggressive mouse }\end{array}$ & $\begin{array}{l}\text {-No avoidance of place of } \\
\text { attack }\end{array}$ & $\begin{array}{l}\text {-Avoidance of place of } \\
\text { attack }\end{array}$ & $\begin{array}{l}\text {-Classical conditioning } \\
\text {-Amygdala }\end{array}$ \\
\hline Avoidance $\operatorname{task}^{7}$ & $\begin{array}{l}\text {-Moves to neighboring } \\
\text { compartment to avoid } \\
\text { shock }\end{array}$ & $\begin{array}{l}\text {-Acquisition: avoid less } \\
\text { than } 20 \% \text { of shocks }\end{array}$ & $\begin{array}{l}\text {-Acquisition: avoid about } \\
80 \% \text { of shocks }\end{array}$ & $\begin{array}{l}\text {-Classical conditioning } \\
\text {-Amygdala }\end{array}$ \\
\hline $\begin{array}{l}\text { Conditioned taste } \\
\text { aversion }^{8}\end{array}$ & $\begin{array}{l}\text {-Associate malaise with } \\
\text { taste } \\
\text {-Avoid taste }\end{array}$ & $\begin{array}{l}\text {-Decrease } \mathrm{NaCl} \text { intake } \\
\text { only after highest i.p. LiCl } \\
\text { dose }\end{array}$ & $\begin{array}{l}\text {-Decrease } \mathrm{NaCl} \text { intake } \\
\text { after } 3 \text { of } 4 \mathrm{LiCl} \text { doses: } \\
\text {-Develop CTA lower doses } \\
\text { and fewer trials }\end{array}$ & $\begin{array}{l}\text {-Classical conditioning } \\
\text {-Amygdala }\end{array}$ \\
\hline
\end{tabular}




\section{Table 1-1. (continued).}

Notes: Blue highlights indicate better performance by B6; green highlights indicate better performance by D2. Each study directly compares B6 and D2 mice at the same time and under the same conditions. Better performance is specific to each study presented here, and varying parameters could yield other results.

Sources: ${ }^{1}$ (Upchurch, M. et al. 1988; D'hooge, R. et al. 2001); ${ }^{2}$ (Brown, R. E. et al. 2011); ${ }^{3}$ (Mcfadyen, M. P. et al. 2003); ${ }^{4}$ (Paylor, R. et al. 1996; Bolivar, V. J. et al. 2001; Bothe, G. W. et al. 2004); ${ }^{5}$ (Orsini, C. et al. 2004) ${ }^{6}$ (Siegfried, B. et al. 1989); ${ }^{7}$ (Bovet, D. et al. 1969); ${ }^{8}$ (Ingram, D. K. 1982; Risinger, F. O. et al. 2000). 
Finally, in conditioned taste aversion, which is an example of classical conditioning, D2 mice have been shown to develop stronger aversions and be more resistant to extinction than B6 mice (Ingram, D. K. 1982; Risinger, F. O. et al. 2000).

In this study, we compared B6 and D2 mice using the oral selfadministration model previously developed (Loy, I. et al. 2002; Baird, J. P. et al. 2005), as opposed to following intake (forced or free choice) with i.p. injections of LiCl (Ingram, D. K. 1982; Chang, F. C. et al. 1984; Spector, A. C. et al. 1988; Meachum, C. L. et al. 1990; Risinger, F. O. et al. 2000; Foynes, M. M. et al. 2004). We allowed the subjects to self-administer $\mathrm{LiCl}$, which served as both the conditioned stimulus (induced malaise) and unconditioned stimulus (salty taste). Using a microstructural analysis of licking, we looked at changes in behavior throughout 20-minute trials on acquisition and expression days. Overall, it appears D2 mice condition a stronger aversion than B6, with significant, yet subtle, results. Further, we found conditioning with a higher concentration of $\mathrm{LiCl}$ resulted in stronger aversions in both $\mathrm{B} 6$ and D2 mice.

\section{Brain Regions Involved in CTA}

A number of lesion studies have been conducted and the results suggest several brain regions that may play a role in CTA. The area postrema (AP), which is thought to detect the unconditioned stimulus (US) as a toxic substance in the blood or through afferent nerves, appears to have an important role in the acquisition of a CTA (Bures, J. et al. 1998). Lesions in the AP result in disruption in the acquisition of a CTA when using $\mathrm{LiCl}$ as the unconditioned stimulus (Ritter, S. et al. 1980; Rabin, B. M. et al. 1983; Ladowsky, R. L. et al. 1986; Kosten, T. et al. 1989; Curtis, K. S. et al. 1994).

The nucleus of the solitary tract receives both gustatory and visceral information, making it an important site for CTA. Visceral inputs are mainly received in the caudal NST and relay to the lateral parabrachial nucleus (PBN). Lesions in the NST result in impairment of taste preference and aversion, but the animals are still able to form a CTA from other taste cues (Bures, J. et al. 1998). This was shown in rats with electrolytic lesions in the rostral NST, which resulted in rats responding the same to sucrose as to water, as well as impaired aversion (Shimura, T. et al. 1997; Bures, J. et al. 1998). Alanine was paired with i.p. $\mathrm{LiCl}$, and rats with rostral NST lesions reduced their intake to half as that of controls (Shimura, T. et al. 1997). The reason offered for the rats still being able to form an aversion, although impaired, was that taste cues remained in the caudal NST, possibly providing enough recognition to distinguish "taste" from "no taste" (Shimura, T. et al. 1997; Bures, J. et al. 1998).

The next relay in the gustatory pathway is the PBN. It has been shown that visceral and gustatory information project to mainly separate areas of the NST, but then converge in the PBN (Hermann, G. E. et al. 1983; Bures, J. et al. 1998). The exact dispersion of information in the PBN is still being studied, but previous work has suggested roles for various areas. The caudal PBN is known 
to receive primarily gustatory information and the rostral PBN to receive primarily visceral information, whereas the intermediate region of the PBN receives overlapping gustatory and visceral input (Yamamoto, T. 1993; Yamamoto, T. et al. 1994; Karimnamazi, H. et al. 2002). This highlights the PBN as possibly a more critical brain region regarding CTA, as it may be where visceral and gustatory information are first processed together, leading to an aversion (Yamamoto, T. 1993). Lesions in the PBN result in disruption of acquisition and retention of a CTA. When comparing specific regions of the PBN, it has been shown that lesions in the medial PBN result in a loss of neophobia (here, neophobia refers to fear of a new taste), and acquisition and retention of a CTA, whereas lesions in the lateral PBN result in disruption of acquisition, but only slightly affect retention, and did not affect neophobia (Sakai, N. et al. 1997). This work suggests a role in the medial PBN for various aspects of CTA, while the lateral PBN may be important regarding acquisition (Bures, J. et al. 1998). These results can be seen in Table 1-2.

A diagram examining the possible role the PBN plays in CTA is shown in Figure 1-2, illustrating inputs of both visceral and gustatory information to various subnuclei, and where and how this information may be integrated. This schematic is based on the taste-elicited c-Fos mapping studies of Yamamoto (1993).

Hedonics, the study of pleasurable and unpleasurable sensations, is used in taste studies that differentiate between positive hedonic processing (information processed in the brain regarding a tastant which the subject finds pleasurable, or tastes good) and negative hedonic processing (information processed in the brain regarding a tastant which the subject finds unpleasurable, or tastes bad). Following oral presentation of an appetitive stimulus such as saccharin, neuronal activation is seen in the central lateral subnucleus (CLS) of the PBN, thought to be involved in taste quality (i.e. sweet, sour, bitter, salty and umami) discrimination, and in the dorsal lateral subnucleus (DLS), thought to be involved in positive hedonic processing (Figure 1-2A). Weaker projections are also sent to the caudal region of the external lateral subnucleus (ELS), thought to be involved in the processing of negative hedonics. Since saccharin tastes more hedonically positive than negative, the rat ingests the stimulus. Figure 1-2B shows the pattern of activation following an i.p. injection of LiCl. Visceral information (information being received in the brain, from the viscera, such as the intestines and stomach) projects to the rostral ELS. This stimulus also activates the caudal ELS, thought to be involved in negative hedonic processing. Figure 1-2C shows what may occur when saccharin is ingested as the CS and the US is an i.p. injection of LiCl. Yamamoto (1993) suggests that the US potentiates the CS signal being sent to the caudal ELS (increasing the message of negative hedonics of saccharin) and simultaneously depresses the CS signal being sent to the DLS (decreasing the hedonic value of saccharin). Ultimately convergence of gustatory and visceral information in the ELS and DLS would result in behavioral aversion of saccharin. 
Table 1-2. Summary of lesion studies of major brain regions possibly involved in CTA - PBN most severely affected.

\begin{tabular}{|c|c|c|c|c|c|}
\hline Brain Area & Inputs & Outputs & CTA Role & Type of Lesion & Lesion Results \\
\hline Area Postrema & $\begin{array}{l}\text {-Vagal nerve (i.e. } \\
\text { visceral info) } \\
\text {-Hypothalamus }\end{array}$ & $\begin{array}{l}\text {-NST } \\
\text {-PBN } \\
\text {-Dorsal motor nucleus of } \\
\text { vagus } \\
\text {-Other brainstem }\end{array}$ & $\begin{array}{l}\text {-Detects US directly as toxic } \\
\text { substance or indirectly via } \\
\text { visceral nerves }\end{array}$ & $\begin{array}{l}\text {-Electrolytic } \\
\text { before acquisition } \\
\text {-Electrolytic, } \\
\text { after acquisition }\end{array}$ & $\begin{array}{l}\text {-Acquisition deficits } \\
\text {-No effect on retention }\end{array}$ \\
\hline NST & $\begin{array}{l}\text {-Vagal, visceral (toxins } \\
\text { in GI) } \\
\text {-AP } \\
\text {-Vestibular system (i.e. } \\
\text { motion sickness) } \\
\text {-Gustatory (tongue) }\end{array}$ & $\begin{array}{l}\text {-Gustatory project to } \\
\text { medial PBN } \\
\text {-Visceral project to lateral } \\
\text { PBN }\end{array}$ & $\begin{array}{l}\text { - Residual taste neurons in } \\
\text { cNST enough to recognize } \\
\text { taste or no taste } \\
\text {-Neurons in rNST make fine } \\
\text { discriminations of intensity } \\
\text { and flavor }\end{array}$ & -Electrolytic & $\begin{array}{l}\text {-Deficits in gustatory } \\
\text { preference } \\
\text {-Deficits in aversion } \\
\text {-Can still use taste cues to } \\
\text { learn aversion }\end{array}$ \\
\hline PBN & $\begin{array}{l}\text {-rNST, gustatory } \\
\text {-cNST, visceral } \\
\text {-AP }\end{array}$ & $\begin{array}{l}\text {-Ventral forebrain: } \\
\text {-Amygdala } \\
\text {-Lateral hypothalamus } \\
\text {-Bed nucleus of stria } \\
\text { terminalis } \\
\text {-Thalamus }\end{array}$ & $\begin{array}{l}\text { - PBNmed (taste) needed for } \\
\text { acquisition and retention } \\
\text {-PBNlat, visceral and taste- } \\
\text { visceral associations, crucial } \\
\text { for acquisition } \\
\text {-Convergence gustastoy and } \\
\text { visceral }\end{array}$ & $\begin{array}{l}\text {-Bilateral ibotenic acid } \\
\text { whole PBN } \\
\text {-Electrolytic, mPBN } \\
\text {-Lateral PBN }\end{array}$ & $\begin{array}{l}\text {-Severe impairment of } \\
\text { acquisition } \\
\text {-Disrupt acquisition } \\
\text {-No neophobia } \\
\text {-Impaired retention } \\
\text {-Disrupt acquisition } \\
\text {-Slight disruption of } \\
\text { retention }\end{array}$ \\
\hline Thalamus & $\begin{array}{l}\text {-PBNmed, gustatory to } \\
\text { VMPpc } \\
\text {-PBNlat, visceral to } \\
\text { VPLpc }\end{array}$ & -Insular cortex & $\begin{array}{l}\text {-Possible that surrounding } \\
\text { regions important in } \\
\text { acquisition, but not VMPpc } \\
\text { alone }\end{array}$ & $\begin{array}{l}\text {-Electrolytic VMPpc } \\
\text {-Excitotoxic VMPpc } \\
\text {-Electrophysiological }\end{array}$ & $\begin{array}{l}\text {-No neophobia } \\
\text {-Impaired acquisition } \\
\text {-Impaired retention } \\
\text {-Little effect acquisition } \\
\text {-No effect acquisition }\end{array}$ \\
\hline
\end{tabular}


Table 1-2. (continued).

\begin{tabular}{|c|c|c|c|c|c|}
\hline Brain Area & Inputs & Outputs & CTA Role & Type of Lesion & Lesion Results \\
\hline Hypothalamus & -PBN & -Area postrema & $\begin{array}{l}\text {-Unknown } \\
\text {-LH regulates feeding } \\
\text {-VMH regulates satiety }\end{array}$ & $\begin{array}{l}\text {-Ibotenic acid, LH and } \\
\text { VMH } \\
\text {-Electrolytic VMH } \\
\text {-LH lesion }\end{array}$ & $\begin{array}{l}\text {-No effect acquisition } \\
\text {-Stronger aversion } \\
\text {-More resistant to } \\
\text { extinction } \\
\text {-Failure to learn new } \\
\text { aversion }\end{array}$ \\
\hline Amygdala & $\begin{array}{l}\text {-Hypothalamus } \\
\text {-Thalamus } \\
\text {-All sensory } \\
\text {-Limbic system }\end{array}$ & -Lateral hypothalamus & $\begin{array}{l}\text {-Associative process of } \\
\text { learning tasks } \\
\text {-CTA, visceral associations } \\
\text {-Learning and memory of } \\
\text { CTA } \\
\text {-CeA important in } \\
\text { acquisition and retention } \\
\text {-Conflicting studies }\end{array}$ & $\begin{array}{l}\text {-Large permanent } \\
\text {-Electrolytic, BLA } \\
\text {-NMDA lesion, BLA }\end{array}$ & $\begin{array}{l}\text {-Disrupt aversion } \\
\text {-Disrupt acquisition and } \\
\text { retention } \\
\text {-No effect on CTA }\end{array}$ \\
\hline
\end{tabular}

Notes: Green highlights the PBN, indicating the brain region with the most severe effects on CTA following lesions, supporting the aim to analyze this specific region for evidence of CTA effects. Abbreviations: $\mathrm{AP}=\mathrm{area}$ postrema; $\mathrm{BLA}=$ basolateral nucleus; $\mathrm{CeA}=$ central nucleus of the amygdala; $\mathrm{cPBN}=$ caudal parabrachial nucleus; $\mathrm{GI}=$ gastrointestinal; $\mathrm{LH}=$ lateral hypothalamus; NMDA = N-Methyl-D-aspartic acid; NST = nucleus of the solitary tract; PBN = parabrachial nucleus; PBNlat = lateral parabrachial nucleus; PBMmed = medial PBN; rPBN = rostral PBN; VMH = ventromedial hypothalamus; VMPpc = ventroposteromedial nucleus of the thalamus. 


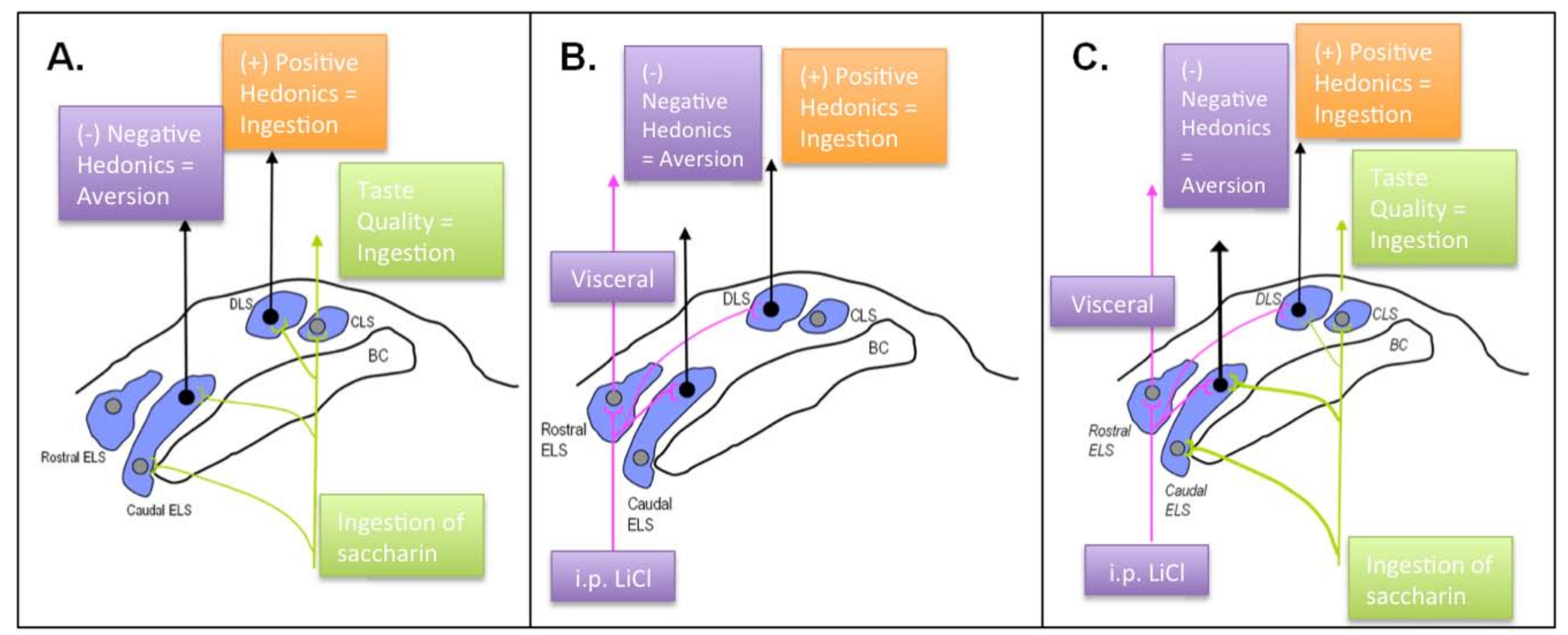

Figure 1-2. Representation of possible convergence areas in the PBN, leading to a conditioned taste aversion.

Notes: A) Following ingestion of saccharin, most information is projected to the CLS, for taste quality, and the DLS, for positive hedonics. Weak projections send information to the caudal ELS as well, for any negative hedonics. B) LiCl i.p. injections result in projections mostly to the rostral ELS, for visceral information, and the caudal ELS, for negative hedonics. Weak projections are sent to the dells. C) Possible convergence of gustatory and visceral information occurs in the ELS and DLS. It is hypothesized that the US potentiates the CS signal sent to the caudal ELS, and depresses the CS signal to the DLS, resulting in more negative hedonics than positive, therefore avoiding the CS.

Adapted by permission: Yamamoto, T., T. Shimura, et al. (1993). "c-Fos expression in the parabrachial nucleus after ingestion of sodium chloride in the rat." Neuroreport 4(11): 1223-1226. 


\section{c-Fos and Conditioned Taste Aversion}

It has been previously shown that $\mathrm{D} 2$ mice develop stronger $\mathrm{LiCl}$ conditioned taste aversions than B6 in a place aversion paradigm (Risinger, F. O. et al. 2000). It has also already been shown that D2 mice appear more resistant to extinction (Ingram, D. K. 1982). However, it is still unknown as to why these strain differences occur. It is possible that $\mathrm{D} 2$ mice are more sensitive to the visceral effects of $\mathrm{LiCl}$, therefore becoming more ill than $\mathrm{B} 6$, and subsequently developing stronger aversions. It is also possible that neuronal processes in the brain are responsible. For example, CTA is a form of classical conditioning, and the amygdala has been shown to have a role in form of learning and memory (Yamamoto, T. et al. 1994; Spray, K. J. et al. 2000). Therefore, if D2 mice are forming stronger aversions as a result of higher responses in the amygdala or neuronal response in the PBN, then evidence of this may be seen via immunohistochemistry techniques.

Although the amygdala has been implicated in playing a role in classical conditioning (Mcgaugh, J. L. 1989; Davis, M. 1992; Schafe, G. E. et al. 1998; Ledoux, J. E. 2000; Davis, M. et al. 2001; Maren, S. 2001, 2003), it has been shown that method of delivery during conditioning results in varying neuronal activation (Navarro, M. et al. 2000; Spray, K. J. et al. 2000). A possible explanation for this focuses on defining "true" Pavlovian conditioning (Maren, S. 2003). True Pavlovian conditioning has been defined as a conditioning paradigm where the animal does not control the delivery of the stimuli (Maren, S. 2003). Shafe et al (1998) compared the effects on CTA of amygdala lesions in two conditioning methods: in the first method, rats were conditioned by following $30 \mathrm{~min}$ access to saccharin with i.p. $\mathrm{LiCl}$, and in the second method rats were conditioned by following intra-oral (I/O) infusion of saccharin with i.p. LiCl (Schafe, G. E. et al. 1998). It was shown that rats conditioned and tested via I/O methods showed the same preference to saccharin over water in a 2-bottle test as controls (Schafe, G. E. et al. 1998). However, if rats condition a taste aversion via $30 \mathrm{~min}$ access to a bottle and then tested in a 2-bottle choice test on the same stimulus, they show a CTA (Schafe, G. E. et al. 1998). Therefore it was concluded that these results show that if the animal is required to make a response to obtain the CS (approaching a bottle), lesions in the basolateral amygdala (BLA) have no affect on CTA; while if the CS is administered by the experimenter (I/O infusion), BLA lesions affect CTA (Schafe, G. E. et al. 1998; Maren, S. 2003). Therefore, one possibility for various results may lie in whether the paradigm is true classical conditioning (where the experimenter controls administration of CS) or not true classical conditioning (where the animal controls administration of the CS). In addition, since the study presented here includes a paradigm that may not be considered "true" classical conditioning based on the above results, there was no expectation that neuronal changes would be seen in the amygdala following conditioning or generalization in these studies. Further, our research specifically focuses on the $\mathrm{PBN}$, as it is the proposed first site of integration of taste and visceral information. Future studies could investigate possible neuronal labeling in other areas, including the amygdala, within such a CTA paradigm, but this area is not addressed in this research. 
Regarding immunohistochemistry, it has been shown that Fos-like immunoreactivity (FLI) counts are correlated to the strength of an aversion, seen by comparing single-trial and 3-trial learning protocols (Navarro, M. et al. 2000). Both conditioning designs were able to condition an aversion, determined behaviorally by the latency of rejection of the conditioned stimulus (Navarro, M. et al. 2000). This same measure, latency, also revealed behaviorally that 3 conditioning trials resulted in a stronger aversion than a single trial (Navarro, M. et al. 2000).

In addition, increase in FLI in the NST was found following single-trial learning, but no increases were found in the PBN or amygdala. However, following 3 conditioning trials, a significant increase in FLI was seen in all 3 areas (NST, PBN, and amygdala) (Navarro, M. et al. 2000). Therefore as the authors concluded, the strength of aversion (as defined by latency to reject the stimulus) is correlated to amount of c-Fos induced in the PBN and amygdala (Navarro, M. et al. 2000).

Another relevant study involves the comparison of conditioning methods. Spray et al. (2000) conducted an experiment comparing CTA developed by using intra-oral cannulas versus bottles (Spray, K. J. et al. 2000). Interestingly, both methods conditioned similar strength aversions (again displayed by the latency to reject the conditioned stimulus), but only in the I/O method did the authors see increased FLI in the NST (Spray, K. J. et al. 2000). This study concluded that conditioning method plays a role in c-Fos induction. However, the reason for this difference in c-Fos activation is not clear, and was speculated to be a result of other, unknown, conditioned responses occurring during the I/O method. Also, it is important to note that this study used single-trial conditioning, and were only looking at the NST, not the PBN - Navarro and colleagues (2000) also only saw increased FLI following a single I/O trial in the NST, but in no other CTA areas. Further, all above studies condition an aversion via i.p. injections of $\mathrm{LiCl}$, and method of delivery only applies to the unconditioned stimulus being administered. Finally, with so many variations in CTA paradigms, it is difficult to directly compare previous literature.

Due to evidence of differences between B6 and D2 mice in other learning and memory paradigms, and their common use in research in taste and behavior studies, we have chosen these two strains to compare as a method of studying conditioned taste aversion. Specifically based on the previous literature discussed regarding learning and memory, we expected to see a strain difference in the strength of an aversion formed. Further, based on select studies on D2 mice and how quickly they learn in classical conditioning designs compared to B6, we expected the D2 strain to develop a stronger CTA. The stronger CTA was expected to be evident in such measures as longer avoidance of the conditioned stimulus, more changes in behavior when responding to the CS, and how quickly the mice began avoidance. We utilized behavioral methods to obtain measures of the response before, during, and after conditioning a taste aversion, and subsequently used immunohistochemical methods to measure the neuronal response in these strains in different phases of a CTA (such as conditioning and generalization). In the first set of experiments, mice were tested in a lickometer 
and conditioned by self-administration of $\mathrm{LiCl}$. The mice associated the salty taste of $\mathrm{LiCl}$ to the malaise it induced, resulting in a CTA. The following day mice were tested again in the lickometer with $\mathrm{NaCl}-\mathrm{a}$ similar tasting solution to $\mathrm{LiCl}$. This day was referred to as generalization day and served as the test of learning. Immediate avoidance of the solution demonstrated mice had conditioned a taste aversion to $\mathrm{LiCl}$, and that it had generalized to $\mathrm{NaCl}$. This behavioral paradigm using self-administration allowed us to obtain both gross and detailed measures related to licking behavior. Changes in this behavior, latency to lick, and how long the mice avoided the $\mathrm{NaCl}$ were all indications of the strength of the CTA formed.

In the second set of experiments, we used c-Fos as a neuronal marker of activated neurons in response to a stimulus. Various groups were tested to assess activation following visceral, gustatory, and a combination of types of stimulation in the brain. We focused on the PBN as previously discussed, based on literature supporting the concept that the $\mathrm{PBN}$ is one of the most critical regions regarding CTA. Also, it is possibly the first site of convergence of taste and visceral information, an event that has to occur for an association to be made and a CTA formed. We expected that any strain differences seen behaviorally would be reflected in neuronal activation - in other words, if D2 mice indeed conditioned a stronger aversion we expected to see a different pattern of c-Fos activated in the PBN compared to B6 mice.

Therefore, the overall hypothesis was that B6 and D2 differ in their ability to condition a taste aversion, with the expectation that D2 mice would develop a stronger CTA. Further, it was hypothesized that these differences would be evident in c-Fos patterns in the PBN, with D2 showing a different pattern of activation, reflective of their stronger aversion. 


\title{
CHAPTER 2. GENERAL METHODS
}

\author{
Behavior
}

\section{Animals}

All mice used for these studies were either C57BL / 6J or DBA / 2J males and females purchased from Jackson Laboratory (Bar Harbor, ME). Mice were 35 months old, and were group housed prior to testing in standard plastic shoebox cages $(28 \times 17.5 \times 13 \mathrm{~cm})$. See methods and materials of each chapter for details regarding group numbers, sex, age, and food and water for each experiment.

\section{Lickometer}

Brief-access testing procedures were conducted using an MS-160 computer-controlled lickometer (DiLog Instruments, Inc., Tallahassee, FL), and were similar to those recently described (Boughter, J. D., Jr. et al. 2002; Nelson, T. M. et al. 2003; Boughter, J. D., Jr. et al. 2005). Briefly, mice were placed in a test chamber $(30 \times 14.5 \times 16 \mathrm{~cm})$ with a stainless-steel mesh floor, and could access taste stimuli or water via a small opening at the front of the chamber. A trial began when a shutter opened to allow access to a stainless steel drinking tube, and ended after a defined period when the shutter closed. Licks were counted via a high-frequency AC contact circuit.

\section{Brief-Access Tests}

The apparatus used in this paradigm is a Davis Rig lickometer (DiLog Instruments, Inc., Tallahassee, FL). The lickometer consists of a testing chamber, which is a plexiglass box, with a wire grid floor. In front of the chamber is a panel that holds a number of sipper tubes, and the panel moves to a given tube based on the protocol entered into the computer. The animal stands on a wire floor, therefore when it contacts the metal sipper tube to lick, an electrical circuit is connected and the computer counts a lick. Via computer software, the number of licks and intervals between licks are collected. There are several basic testing days involved in a brief-access concentration series paradigm. First, the animals undergo sipper tube training (STT), where one tube of water is presented for 20 minutes. The next day, the animals undergo trial training (TT), where they are presented with 16, 5 second trials of water. The water is presented in the form of random trials from 4 tubes. This helps acclimate the animal to the sound and movement of the lickometer as will occur during the concentration series. For a concentration series, the tubes are presented in a random order, with each concentration being presented multiple times. If the experiment requires the animals to be water-deprived throughout the testing period, a water supplement schedule is implemented - animals are given free access to 15 minutes of water in 
their home cage at the end of a specified day. Testing, trial times, stimuli, and water deprivation are specified for each experiment.

\section{Anatomy}

\section{c-Fos Immunohistochemistry with DAB}

First, mice are behaviorally tested in the lickometer, followed by perfusion (see below for details of perfusion timing), at which time mice are anesthetized with $25 \%$ urethane and perfused with $50 \mathrm{ml}$ of $0.1 \mathrm{M}$ phosphate-buffered saline (PBS), followed by $50-100 \mathrm{ml}$ of $10 \%$ formalin solution (Fischer Scientific, Pittsburgh, PA). Sections are post-fixed overnight. The next day, sections are cryoprotected overnight in 30\% sucrose-phosphate buffer. The brains are cut into $40 \mu \mathrm{m}$ thick floating coronal sections on a sliding microtome, placed in PBS, and subsequently stained. Sections were first pre-treated in 3\% hydrogen peroxide, then blocked in $4 \%$ normal goat serum (for the inhibition of non-specific binding) and incubated overnight with the primary antibody (anti c-Fos, 1:10,000). Floating sections were then washed in PBS and incubated with secondary biotinylated anti-rabbit IgG (Jackson, 1:1000) for $1 \mathrm{~h}$. After washing with PBS, Vectastain $A B C$ reagent (Vector Labs, Burlingame, $C A$ ) was added. Sections were stained with DAB (Vector Labs, Burlingame, CA) substrate for $10 \mathrm{~min}$, washed in distilled water, mounted on slides, dried, dehydrated, and cover-slipped.

\section{Perfusion Timing}

First, we addressed the concern of timing between testing and perfusion of the animals. Following taste stimulation (defined as direct chemical stimulation of taste buds in the oral cavity) or i.p. injection of $\mathrm{LiCl}$, other studies vary perfusion times including 30 minutes (including unpublished findings by Boughter and Tokita) (Rinaman, L. et al. 1997), 45 minutes (Chan, C. Y. et al. 2004; Travers, J. B. et al. 2007), 75 minutes (Travers, S. P. et al. 2007), 90 minutes (Yasoshima, Y. et al. 2006; St Andre, J. et al. 2007), and 2 hours post-stimulation (Swank, M. W. et al. 1995; Navarro, M. et al. 2000; Spray, K. J. et al. 2000; Grancha, M. L. et al. 2002; Chan, C. Y. et al. 2004; Yasoshima, Y. et al. 2006; St Andre, J. et al. 2007; Travers, J. B. et al. 2007; Travers, S. P. et al. 2007). Even though the literature varies on wait time before perfusion, a majority of studies wait $2 \mathrm{~h}$ before perfusion. To verify that $2 \mathrm{~h}$ was optimal, a study was conducted comparing $30 \mathrm{~min}$ and $2 \mathrm{~h}$ wait times from stimulation to perfusion. As mentioned, I selected these 2 intervals to test because each time could be easily justified for these experiments. First, the 30 min interval was ideal because of the efficiency of the experiment which would allow time to perfuse more animals in one day, as well as it had been shown that quantifiable c-Fos was detected at this short time interval (including unpublished findings by Boughter and Tokita) (Rinaman, L. et al. 1997). Also, transcriptional activation of c-Fos begins within minutes of stimulation and the mRNA peaks around 30-40 minutes (Harris, J. A. 
1998). However, levels of the protein, Fos, being labeled, peak around $2 \mathrm{~h}$ poststimulation (Harris, J. A. 1998). Therefore, we compared a 30 min wait time (efficient and does show c-Fos expression) and $2 \mathrm{~h}$ wait time (known to be the peak time for Fos protein expression) for this experiment. For this preliminary experiment, we compared $4 \mathrm{~B} 6$ and $4 \mathrm{D} 2$ male mice, perfused at either $30 \mathrm{~min}$ or $2 \mathrm{~h}$ from the start of an intake test with sodium chloride $(\mathrm{NaCl})$. No other time periods were tested - we focused on what is widely considered the optimal time until perfusion $(2 \mathrm{~h})$, and what may be a more efficient time that still yields appropriate results (30 $\mathrm{min})$.

In this preliminary study, both B6 and D2 mice showed comparable overall c-Fos labeling following intake, therefore only results from B6 mice are shown here. More labeled neurons were seen in mice perfused at $2 \mathrm{~h}$ compared to $30 \mathrm{~min}$ following $\mathrm{NaCl}$ intake (Figure 2-1). It is clear there were more labeled neurons in the mouse perfused at $2 \mathrm{~h}$, which agreed with the vast majority of CTA-related studies in both mice (Swank, M. W. et al. 1994; Koh, M. T. et al. 2003) and rats (Swank, M. W. et al. 1995; Navarro, M. et al. 2000; Spray, K. J. et al. 2000; Grancha, M. L. et al. 2002; Tokita, K. et al. 2007). Further, this $2 \mathrm{~h}$ wait time is used to analyze c-Fos elicited following both intra-oral taste stimulation (Swank, M. W. et al. 1994; Navarro, M. et al. 2000; Spray, K. J. et al. 2000; Tokita, K. et al. 2007), as well as i.p. injections of the most common drugs used to condition an aversion (Swank, M. W. et al. 1995; Grabus, S. D. et al. 2004).

Next, in order to be able to compare the degree to which both strains respond viscerally to $\mathrm{LiCl}$, i.e. how sick the mice become, it was imperative to show that stronger doses produced more c-Fos staining. To test the hypothesis of variation in visceral response to $\mathrm{LiCl}$, we tested $\mathrm{B} 6$ mice with two doses of $\mathrm{LiCl}$. We compared mice receiving an i.p. injection of $0.15 \mathrm{M} \mathrm{LiCl}$ at a dose of either 20 $\mathrm{ml} / \mathrm{kg}$ (which is approximately the amount received in our paradigm and other CTA studies) or $40 \mathrm{ml} / \mathrm{kg}$. All animals were food and water deprived to eliminate possible interference and activation of the external lateral subnucleus (of the PBN) from ingestion. All animals were perfused $2 \mathrm{hrs}$ following i.p. injection.

As shown in Figure 2-2, it was evident that B6 mice demonstrate higher numbers of FLI-positive neurons in the ELS of the PBN following the $40 \mathrm{ml} / \mathrm{kg}$ dose compared to the $20 \mathrm{ml} / \mathrm{kg}$ dose. These results agree with a previous study comparing various $\mathrm{LiCl}$ doses that concluded that higher doses resulted in corresponding increases in c-Fos labeling (Sakai, N. et al. 1997). As shown in previous literature, stronger CTAs elicit more c-Fos (Navarro, M. et al. 2000). Also, it has been shown that a higher dose of $\mathrm{LiCl}(0.3 \mathrm{M}$ compared to $0.15 \mathrm{M})$ is more effective at inducing malaise (Ding, H. K. et al. 2008). LiCl induces malaise by irritating the gastrointestinal tract and modulating gastric acid. Therefore, the more $\mathrm{LiCl}$ ingested, the harsher these effects, and the sicker the animal becomes. Due to an increased severity of illness, it is reasonable to assume inputs from the gastrointestinal tract increase, resulting in increased c-Fos in appropriate brain regions. Therefore the results of this study suggest that stronger malaise was induced by $40 \mathrm{ml} / \mathrm{kg}$ of $\mathrm{LiCl}$, and elicited more c-Fos: i.e., visceral FLI in the ELS is dose dependent. 


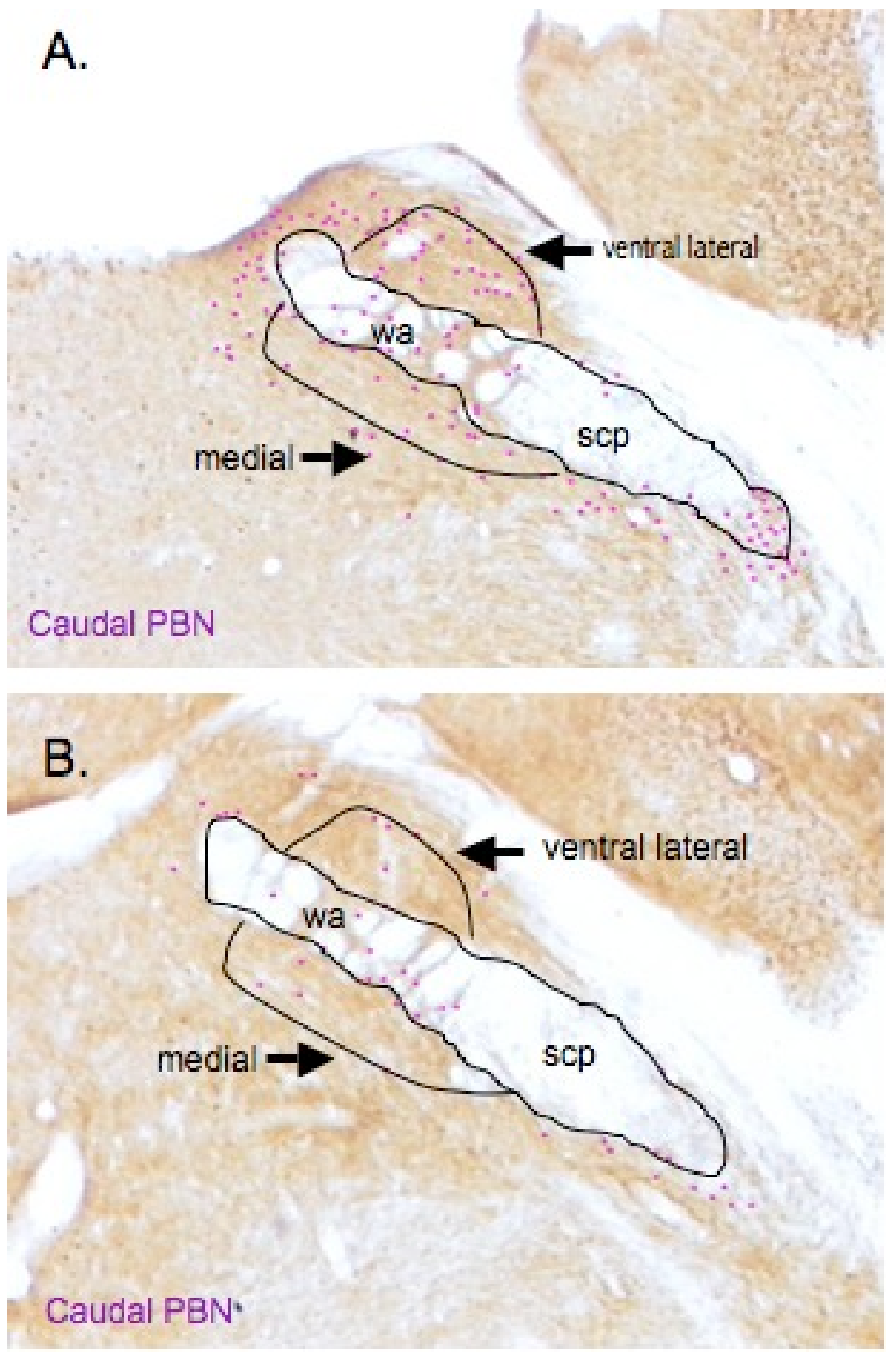

Figure 2-1. Example of quantification of c-Fos expression in the PBN after perfusion, either 30 minutes or 2 hours following the start of $\mathrm{NaCl}$ consumption in B6.

Notes: Top panel pictures (A) are from a B6 mouse perfused $2 \mathrm{~h}$ following the start of stimulation with $\mathrm{NaCl}$. Bottom two panels (B) are from a B6 mouse perfused $30 \mathrm{~min}$ following start of stimulation with $\mathrm{NaCl}$. Blue dots represent Fos positive nuclei counted with NIH ImageJ. Results from D2 mice were similar, with comparable increases in c-Fos expression following $2 \mathrm{~h}$ compared to $30 \mathrm{~min}$, and therefore are not shown. 


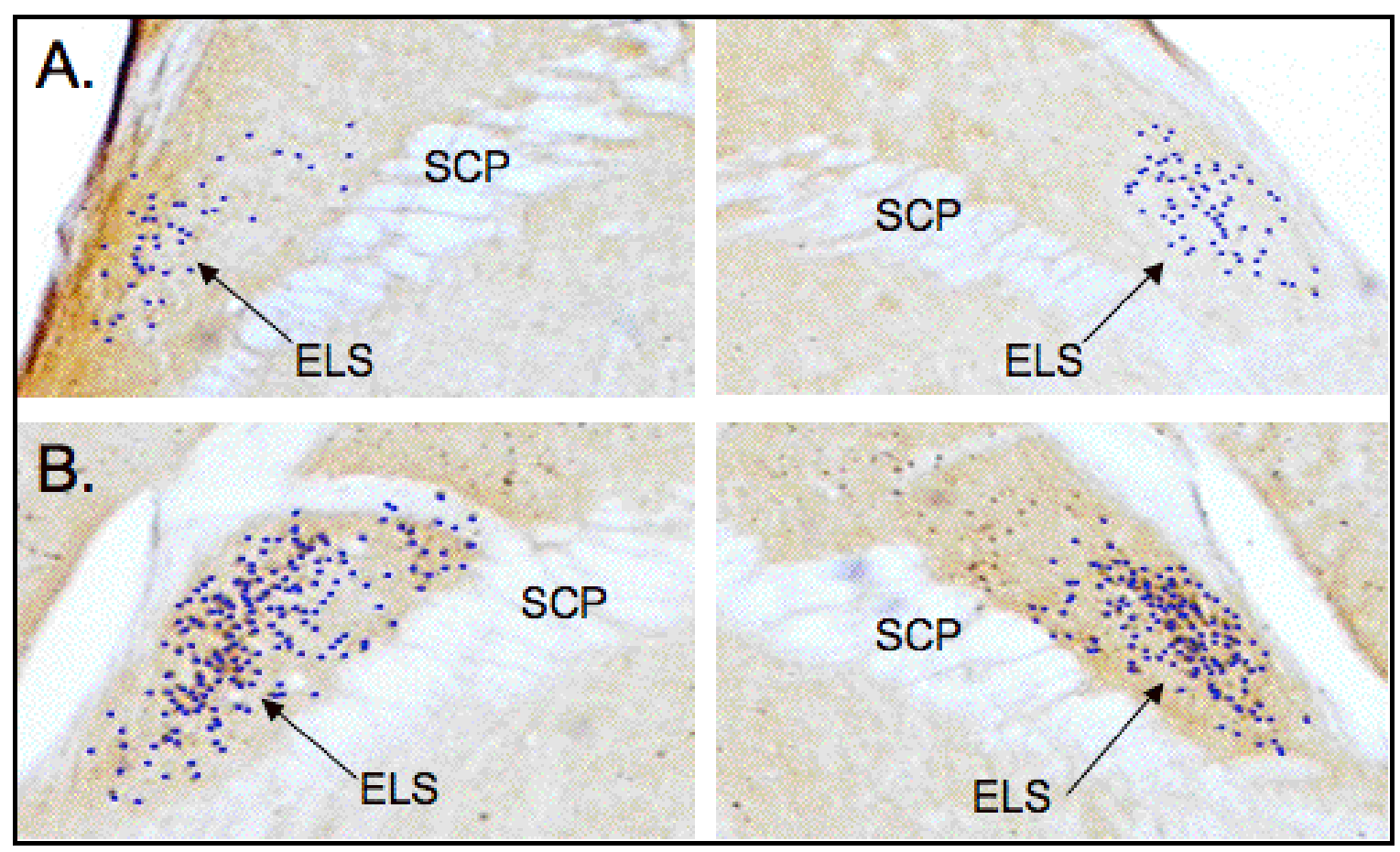

Figure 2-2. Examples illustrating $\mathrm{LiCl}$ dose is related to number of $\mathrm{c}-\mathrm{Fos}$ positive nuclei in the external lateral subnucleus of the PBN.

Notes: Top panel pictures (A) show counted c-Fos results following a dose of 20 $\mathrm{ml} / \mathrm{kg} \mathrm{LiCl} \mathrm{i.p.} \mathrm{injection.} \mathrm{Bottom} \mathrm{panel} \mathrm{pictures} \mathrm{(B)} \mathrm{show} \mathrm{counted} \mathrm{c-Fos} \mathrm{results}$ following a dose of $40 \mathrm{ml} / \mathrm{kg} \mathrm{LiCl}$ i.p. injection. Blue dots represent Fos positive nuclei counted using NIH ImageJ. It is clear that the stronger dose, which is expected to elicit more malaise, results in much higher counts of activated neurons. Visceral activation is known to be seen in the rostral ELS of the PBN, shown here. Results from D2 mice were similar, with comparable increases in cFos expression following $2 \mathrm{~h}$ compared to $30 \mathrm{~min}$, and therefore are not shown. $\mathrm{SCP}=$ superior cerebellar peduncle; ELS = external lateral subnucleus. 


\section{CHAPTER 3. MOUSE STRAIN DIFFERENCES IN CONDITIONED TASTE AVERSION FORMATION, GENERALIZATION, AND EXTINCTION USING A SELF-ADMINISTRATION PARADIGM}

This chapter covers experiments from specific aim 1 - to determine if there is behavioral evidence of strain differences in CTA. The following analysis includes behavior and licking microstructure analyses.

\section{Introduction}

Conditioned taste aversion has been commonly used as a model of learning and memory. Traditionally, CTA approaches have used a paradigm that follows the model of classical conditioning, and involves presentation of a novel tastant, such as sucrose (conditioned stimulus), followed by an i.p. injection of $\mathrm{LiCl}$ that induces gastric malaise (unconditioned stimulus), which results in the aversion of sucrose (conditioned response) (Ingram, D. K. 1982; Chang, F. C. et al. 1984; Spector, A. C. et al. 1988; Meachum, C. L. et al. 1990; Risinger, F. O. et al. 2000; Foynes, M. M. et al. 2004). There are many variations on this procedure, such as the duration between US and CS, or the number of US-CS pairings, but the common endpoint is that the animals develop an aversion to the tastant based on the conditioning received. However, a more natural classical conditioning paradigm involves the consumption, rather than injection, of the US: A study by Loy and Hall (2002) demonstrated that self-administered consumption of $\mathrm{LiCl}$ results in a conditioned taste aversion to salt, which generalized to a presumable similar-tasting salt, $\mathrm{NaCl}$ in rats (Loy, I. et al. 2002). A subsequent study by Baird and colleagues (2005) made use of this selfadministration model in rats to show via a licking analysis that CTA development and generalization occur within an extremely rapid timeframe ( 9 min) (Baird, J. P. et al. 2005). Using the self-administration paradigm allows for time-dependent analysis of formation, generalization, and extinction of CTA as it would occur naturally, rather than following the standard pairing of ingested stimulus with injection. In this paradigm of self-administration, the method of conditioning is a form of classical conditioning, as an association is being made between a taste and sickness, which leads to modification of behavior (avoidance of the taste). However, in this test model, $\mathrm{LiCl}$ provides both the unconditioned stimulus (malaise) and the conditioned stimulus (salty taste), compared to more traditional studies which use a tastant such as sucrose for the conditioned stimulus and inject $\mathrm{LiCl}$ to induce the subsequent malaise (Ingram, D. K. 1982; Chang, F. C. et al. 1984; Spector, A. C. et al. 1988; Meachum, C. L. et al. 1990; Risinger, F. O. et al. 2000; Foynes, M. M. et al. 2004).

In our study, we compared two common, well-studied, inbred mouse strains, C57BL/6J and DBA/2J. Using inbred strains allows for investigation of genetic differences underlying the various components of CTA. Specifically, B6 and D2 mice have previously been successfully compared in ingestive behavior, making these mice ideal for this study (Boughter, J. D., Jr. et al. 2005; Boughter, J. D., Jr. et al. 2007a). While many CTA studies have focused on rats and have not 
yet offered any clear results regarding genetic influences on taste aversion (such as strain differences in aspects of CTA), B6 and D2 mice have been used in other studies that test various learning and memory avenues. Differences between B6 and D2 mice have been seen in the Morris water maze, where B6 mice solve the hidden platform task at 24 days old, while D2 mice never solve this task (Paylor, R. et al. 1996; D'hooge, R. et al. 2001); better performance by B6, compared to D2, in the standard radial arm maze (Ammassari-Teule, M. et al. 1993); contextual fear conditioning, where B6 mice are among the strains exhibiting the highest level of freezing and retain this fear memory 60 days later, while D2 mice show some of the lowest levels of freezing and significantly decrease their retention by 60 days (Paylor, R. et al. 1994; Bolivar, V. J. et al. 2001; Balogh, S. A. et al. 2002; Balogh, S. A. et al. 2003; Bothe, G. W. et al. 2004); trace fear conditioning (Holmes, A. et al. 2002); and rotorod performance, again with B6 mice showing the highest, and D2 showing the lowest, levels of motor learning (Mcfadyen, M. P. et al. 2003). It may appear that B6 mice perform better regarding learning and memory tasks, but it is important to note these tasks measure different types of learning and memory in different brain regions.

Tasks including the radial arm maze, Morris water maze, and contextual fear conditioning, test spatial learning and memory, which is based in the hippocampus (Purves, D. 2008). Object recognition tasks are among those to test learning and memory roles of the rhinal cortex (Purves, D. 2008). Finally, classical conditioning is considered a way to test learning and memory associated with the amygdala, and therefore this type of learning is tested through conditioned fear response, place avoidance and active avoidance conditioning (Purves, D. 2008). Unlike the above studies, which found B6 to perform better, the opposite appears to be true for amygdala-related tasks. Place aversion, conditioned using various doses of $\mathrm{LiCl}$, reveals D2 mice develop a stronger aversion than B6 mice (Risinger, F. O. et al. 2000). A study by Siegfried and Frischknecht (1989) shows that place avoidance learning, conditioned with bites from an aggressive mouse, results in D2 mice showing avoidance of the place of the attack, while B6 show no avoidance (Siegfried, B. et al. 1989). Finally, in conditioned taste aversion, an example of classical conditioning and therefore a form of learning and memory associated with the amygdala, D2 mice have been shown to develop stronger aversions and be more resistant to extinction than B6 mice (Siegfried, B. et al. 1989).

\section{Materials and Methods}

\section{Animals}

A total of 80 naïve mice from inbred strains C57BL/6J (B6) and DBA2/J (D2) were used for all experiments. Approximate equal numbers of sex and strain were used in these experiments (see Methods and Materials section in appropriate chapter for details for each experiment) and all mice were purchased from the Jackson Laboratory (Bar Harbor, ME). Prior to testing, mice were group housed according to sex in standard plastic shoebox cages $(28 \times 17.5 \times 13 \mathrm{~cm})$ with 
ad libitum chow and water. At time of testing, mice were approximately 3-5 months old. Approximately $24 \mathrm{~h}$ prior to testing, mice were water deprived and individually housed with ad libitum chow. Animals were treated according to a protocol approved by the University of Tennessee Health Science Center Institutional Animal Care and Use Committee.

\section{Lickometer}

All brief-access testing procedures were conducted using a Davis Rig, also known as a MS-160 computer-controlled lickometer (Dilog Instruments, Inc., Tallahassee, FL), and were similar to those recently described (Boughter, J. D., Jr. et al. 2002; Nelson, T. M. et al. 2003; Boughter, J. D., Jr. et al. 2005). Briefly, mice were placed in a test chamber $(30 \times 14.5 \times 16 \mathrm{~cm})$ with a stainless-steel mesh floor, and could access taste stimuli or water via a small opening at the front of the chamber. A trial began when a shutter opened to allow access to a stainless steel sipper tube, and ended after a defined period when the shutter closed. Licks were counted via a high-frequency AC contact circuit.

\section{Procedures}

\section{Low-Dose Conditioning}

A total of 40 naïve mice, 20 from each strain (10 males, 10 females), were tested using a 2-week protocol to examine acquisition and generalization of a conditioned taste aversion to salt taste using 20 minute, single-bottle test sessions in the lickometer (one session per day). Mice were placed under water restriction $24 \mathrm{~h}$ prior to the first test session. The first two days of testing consisted of $20 \mathrm{~min}$ trials with distilled water; on day 3 (CTA acquisition), mice were either given a 20 minute session with $0.12 \mathrm{M} \mathrm{LiCl}$ (CTA mice; $\mathrm{n}=10$ per strain) or $0.12 \mathrm{M} \mathrm{NaCl}$ (control mice; $\mathrm{n}=10$ per strain). On day 4 (generalization), all mice were tested with $0.12 \mathrm{M} \mathrm{NaCl}$. Following testing on days 2 and 3, mice were given a $15 \mathrm{~min}$ water supplement in the home cage. Body weight was monitored throughout testing and can be seen in Table 3-1 - all mice maintained above $80 \%$ of their original body weight.

\section{High-Dose Conditioning}

A total of 40 naïve mice, 20 from each strain (10 males, 10 females) were tested using the same protocol used in experiment 2 . The first two days of testing consisted of 20 min trials with distilled water; on day 3 (CTA acquisition), mice were either given a 20 minute session with $0.24 \mathrm{M} \mathrm{LiCl}$ (conditioned mice; $\mathrm{n}=15$ per strain) or $0.24 \mathrm{M} \mathrm{NaCl}$ (control mice; $\mathrm{n}=6$ per strain). On day 4 (generalization) all mice were tested with $0.24 \mathrm{M} \mathrm{NaCl}$. As in the previous experiment, after testing on days 2 and 3, mice were given a 15 min water supplement in home cages. Body weight was monitored and is in Table 3-2. 
Table 3-1. Average percent of original body weight from low concentration groups $(0.12 \mathrm{M})$.

\begin{tabular}{lllll}
\hline Group & Day 1 & Day 2 & Day 3 & Day 4 \\
\hline B6 Controls & $88.10 \%$ & $85.00 \%$ & $86.31 \%$ & $90.84 \%$ \\
D2 Controls & $91.33 \%$ & $86.12 \%$ & $85.50 \%$ & $87.20 \%$ \\
B6 CTA & $89.73 \%$ & $86.11 \%$ & $89.01 \%$ & $90.15 \%$ \\
D2 CTA & $89.49 \%$ & $84.27 \%$ & $84.06 \%$ & $85.87 \%$ \\
\hline
\end{tabular}

Table 3-2. Average percent of original body weight from high concentration groups $(0.24 \mathrm{M})$.

\begin{tabular}{lllll}
\hline Group & Day 1 & Day 2 & Day 3 & Day 4 \\
\hline B6 Controls & $88.00 \%$ & $83.63 \%$ & $83.38 \%$ & $86.14 \%$ \\
D2 Controls & $89.18 \%$ & $89.12 \%$ & $83.42 \%$ & $85.88 \%$ \\
B6 CTA & $89.23 \%$ & $86.23 \%$ & $83.96 \%$ & $82.13 \%$ \\
D2 CTA & $90.07 \%$ & $85.68 \%$ & $83.94 \%$ & $81.72 \%$ \\
\hline
\end{tabular}




\section{Analysis}

\section{Licks and Volume per Lick (VPL)}

During behavioral testing, lick contacts and inter-lick intervals are recorded via computer software. Lick data are reported as mean lick counts for each experimental group. We also measured consumption for each mouse by weighing each test bottle prior to and after the completion of a trial. By subtracting the end weight from the start weight, we are able to determine the amount of fluid consumed during testing. Further, by dividing that volume by the total number of licks in the trial we are then able to calculate the VPL.

\section{Burst Measures}

A lick burst is defined as a series of licks bounded by intervals of $1 \mathrm{~s}$ (Boughter, J. D., Jr. et al. 2007b). Looking at bursts allow the investigator to see the overall licking and pausing behavior over the entire trial. Analyzing licks per minute, or per second, only quantifies intake behavior, while it is the pauses in between the licks, and how those pauses are dispersed, that indicated aversive behavior. Burst size is the number of licks per bursts. We also quantified the number of bursts per test session (burst count). Changes in burst counts and sizes reflect whether or not the stimulus is appetitive or aversive; for example, rats possess longer bursts to a highly preferred stimulus such as sucrose as compared to a neutral stimulus such as water. Longer bursts indicate sustained intake of the preferred stimulus (Spector et al., 1998). Visits were defined as sequences of licking bounded by intervals of $1 \mathrm{~min}$. Ube3a-deficient mice, a model for Angelman's syndrome, possessed abnormally long visits, reflective of deficits in overall motor coordination, or perhaps attention (Heck et al., 2008).

\section{Lick Rate}

Primary lick rate refers to the mean inter-lick interval (ILI) occurring between 50-160 ms (Boughter, J. D., Jr. et al. 2007a). Intra-burst lick rate refers to the mean inter-lick interval occurring between 40 and $1000 \mathrm{~ms}$. Inter-lick interval greater than $1000 \mathrm{~ms}$ represent pauses between bursts; intervals less than $40 \mathrm{~ms}$ are presumably too brief to represent actual pauses between licks, and are likely artifacts. Intervals this small were rare.

\section{Results}

\section{Overview}

Licking behavior was measures by looking at mean licks for the 20 min trial, mean licks in a minute-by-minute fashion, then through microstrucutral 
measures described later. All analysis focuses on either comparing controls to CTA mice within strains, or comparing the strains where appropriate. We chose not to analyze sex differences due to small sample size (5 males and 5 females) and lack of previous effects. For example, previous studies have not shown any effects of sex on sucrose octaacetate (SOA) preference (Whitney, G. et al. 1991; Harder, D. B. et al. 1992) or quinine aversion (Lush, I. E. 1984).

Figure 3-1 shows an overall summary of mean licks throughout both the low-dose and high-dose CTA experiments. The first 2 days of testing mice received only water in 20 min trials, as these were training days to allow mice to acclimate to the lickometer. B6 mice showed significantly more mean licks to water than D2, in the low-dose test group shown in Figure 3-1A, [Day 1, F(1,36) = 39.636, $p \leq .00001$; Day 2, F(1,36) = 25.056, $p \leq .00001]$, as well as in the high-dose test group shown in Figure 3-1B [Day 1, F(1,34)=11.704, $p \leq .001$; Day 2, F(1,37) = $15.193, p \leq .0004]$. During conditioning with $0.12 \mathrm{M} \mathrm{LiCl}$, shown in Figure 3-1C, CTA mice of both strains show significantly fewer licks compared to controls, who are receiving $0.12 \mathrm{M} \mathrm{NaCl}[\mathrm{B} 6, \mathrm{~F}(1,17)=195.15, p \leq .00001 ; \mathrm{D} 2, \mathrm{~F}(1,18)=$ $52.654, p \leq .00001]$. This suppression in licks indicates the aversive properties of $\mathrm{LiCl}$ compared to $\mathrm{NaCl}$. The following day, all mice received $0.12 \mathrm{M} \mathrm{NaCl}$. Again, both strains show fewer mean licks to the stimulus compared to controls [B6, F $(1,18)=9.5962, p \leq .006 ; \mathrm{D} 2, \mathrm{~F}(1,18)=15.327, p \leq .001]$. Figure 3-1D illustrates similar results for high-dose solutions. Both strains show a significant suppression of licks in response to $0.24 \mathrm{M} \mathrm{LiCl}$ during conditioning $[\mathrm{B} 6, \mathrm{~F}(1,22)=68.722, p \leq$ $.00001 ; \mathrm{D} 2, \mathrm{~F}(1,23)=34.131, p \leq .00001]$. The following day, as the CTA is being expressed, CTA mice of both strains have significantly fewer licks compared to controls $[\mathrm{B} 6, \mathrm{~F}(1,22)=61.004), p \leq .00001 ; \mathrm{D} 2, \mathrm{~F}(1,23)=17.418, p \leq .0004]$. In addition, a strain difference was found in conditioning with $0.24 \mathrm{M} \mathrm{NaCl}[\mathrm{F}(1,17)$ $=11.951, p \leq .003]$, and generalization controls $[\mathrm{F}(1,17)=18.654, p \leq .0005\}$.

\section{Low-Dose Experiment}

\section{Conditioning: Minute-by-Minute Analysis of Licks}

As described in detail above, for conditioning, mice were set in the lickometer, and allotted a $20 \mathrm{~min}$, single trial, to lick either $0.12 \mathrm{M} \mathrm{NaCl}$ (controls) or $0.12 \mathrm{M} \mathrm{LiCl}$ (CTA). At the end of testing, mice received a $15 \mathrm{~min} \mathrm{dH} 2 \mathrm{O}$ supplement. Minute-by-minute mean lick counts are shown for the entire $20 \mathrm{~min}$ session in Figure 3-2.

To begin with an overall analysis of these experiments, that included both low and high-dose experiments (high-dose is described in detail later), for the entire 20 min session, a repeated measures ANOVA was conducted on data from conditioning day with between subjects factors for strain, stimulus, and concentration $(2 \times 2 \times 2)$ and within subjects factors for time $(x 20)$. Results showed significant effects of stimulus $[\mathrm{F}(1,77)=261.711, p \leq 0.0001]$, strain $[\mathrm{F}(1,77)=$ 


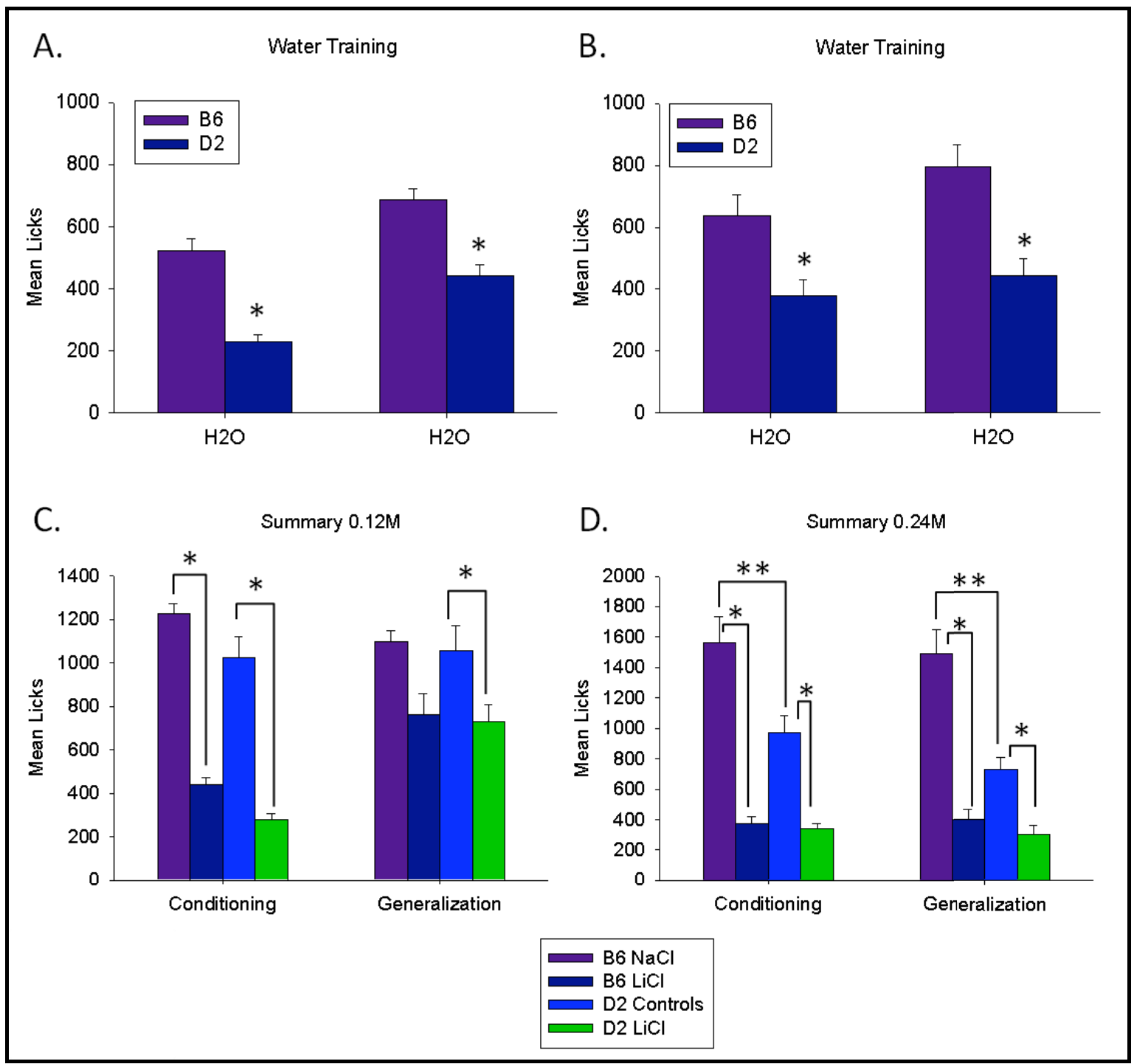

\section{Figure 3-1. Overall summary.}

Notes: A \& B) Mean licks to water for B6 and D2 during sipper tube training from the low-dose (A) and high-dose (B) test groups. Both groups of D2 mice show significantly fewer licks to water than B6. C) Low-Dose Summary. During conditioning, mice received $0.12 \mathrm{M}$ of either $\mathrm{NaCl}$ (controls) or $\mathrm{LiCl}$ (CTA). Both strains show significantly fewer licks in response to $\mathrm{LiCl}$ during conditioning. During generalization, only D2 mice show a significant suppression in mean licks compared to controls. D) High-Dose Summary. During conditioning, mice received either $0.24 \mathrm{M} \mathrm{NaCl}$ or $\mathrm{LiCl}$. Both strains show significantly fewer mean licks to $\mathrm{LiCl}$ compared to $\mathrm{NaCl}$. Also, $\mathrm{B} 6$ controls had significantly higher mean licks than $\mathrm{D} 2$ controls drinking $0.24 \mathrm{M} \mathrm{NaCl}$. During generalization, both strains show a significant suppression in licks to $\mathrm{NaCl}$, illustrating a CTA. Again, B6 control mice have significantly higher mean licks than D2 controls. 


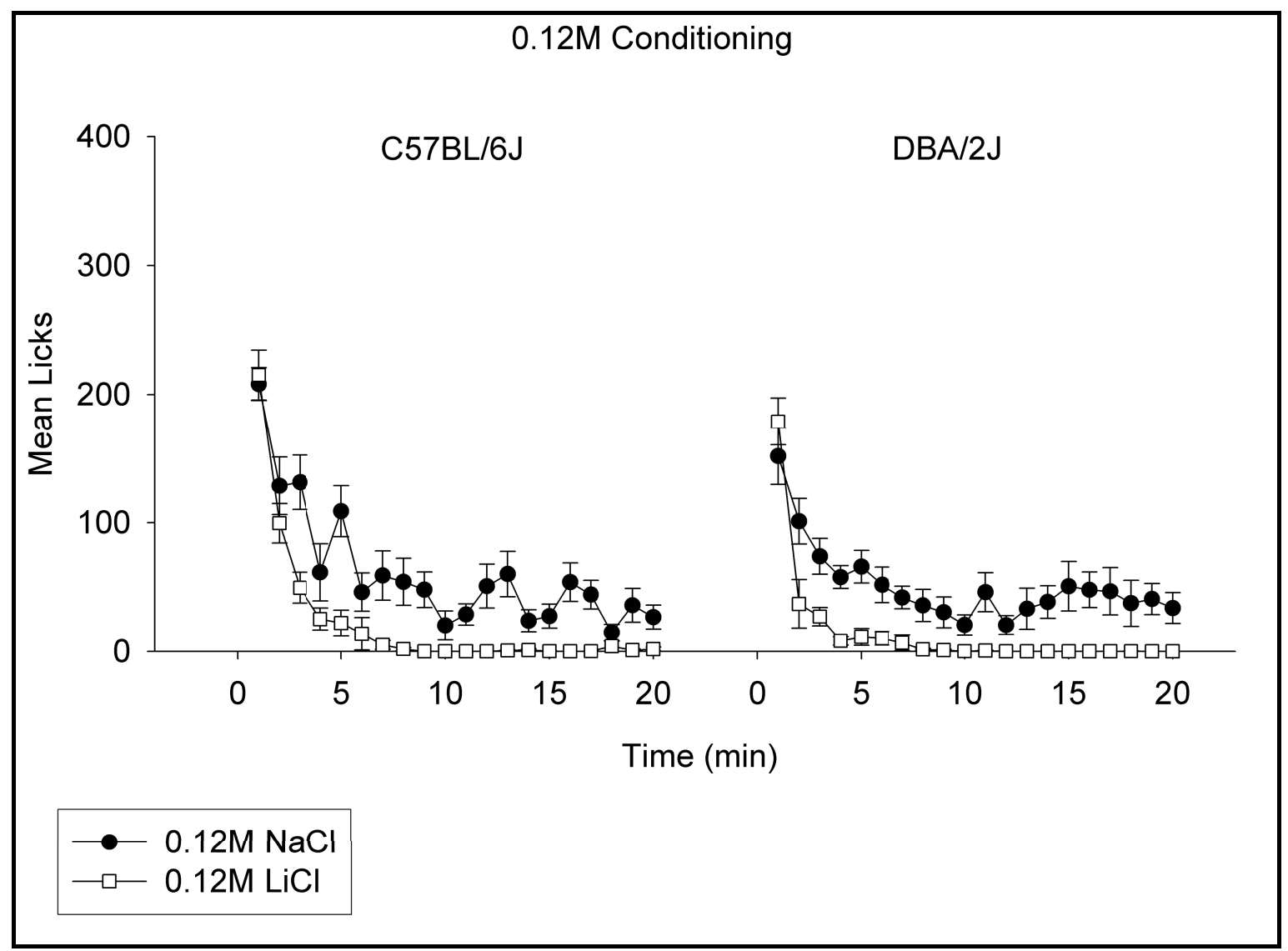

Figure 3-2. Low-dose conditioning.

Notes: Mean licks to either $0.12 \mathrm{M} \mathrm{NaCl}$ (controls) or $0.12 \mathrm{M} \mathrm{LiCl}$ (CTA). B6 mice are shown to the left, and D2 mice are shown to the right. Controls are shown in black and CTA mice shown in white. 
$21.643, p \leq 0.0001]$, and time $[\mathrm{F}(19,1463)=113.750, p \leq .00001]$. Significant interactions were found between stimulus and strain $[\mathrm{F}(1,77)=6.231, p \leq .014]$ time (individual minutes) and concentration $[\mathrm{F}(19,1463)=2.466, p \leq 0.0004]$; time and stimulus $[\mathrm{F}(19,1463)=7.097, p \leq 0.0001]$; time and $\operatorname{strain}[\mathrm{F}(19,1463)=3.137, p$ $\leq 0.0001]$; and time by concentration by strain $[\mathrm{F}(19,1463)=3.299, p \leq 0.0001]$ were found.

It is evident in minute 1 that mice find $\mathrm{NaCl}$ and $\mathrm{LiCl}$ similar in taste, as their mean lick response is comparable. Similar to brief-access lick tests, evaluation of the initial lick behavior (prior to the onset of post-ingestive feedback) is widely accepted as a hedonic evaluation of taste, as is duration of lick bursts (Travers, J. B. et al. 1986; Grill, H. J. et al. 1987; Davis, J. D. et al. 1992; Davis, J. D. et al. 1993; Spector, A. C. et al. 1998a; Baird, J. P. et al. 1999). By minute 2, there was a rapid decline in mean licks in mice receiving $\mathrm{LiCl}$, in both strains, compared to their own controls. Planned comparisons showed that B6 mice licking $\mathrm{LiCl}$ had significantly fewer licks in minutes 3 ( $p \leq .004), 5$ ( $p \leq .002)$, and 7 $(p \leq .02)$. After minute 7, B6 CTA and control mice remained significantly different from one another at each minute except in minute 10 and 18. However, D2 mice licking $\mathrm{LiCl}$ showed significantly fewer licks to their controls right away in minute $2(p \leq .02)$, and remained significantly different from controls for the rest of the trial (with the exception of minutes 13 and 18). Therefore, D2 mice appear to respond to the $\mathrm{LiCl}$ right away in minute 2, where $\mathrm{B} 6$ mice are inconsistently different from their controls for minutes 3-7, then finally taper off as the D2 mice do, after minute 7.

A repeated measures ANOVA for B6 mice revealed significant effects of stimulus $[\mathrm{F}(1,17)=195.15, p \leq 0.00001]$ and time $[\mathrm{F}(19,342)=29.127, p \leq 0.00001]$. For D2 mice, a repeated measures ANOVA also revealed significant effects of stimulus $[\mathrm{F}(1,18)=52.654, p \leq 0.00001]$ and time $[\mathrm{F}(19,342)=20.102, p \leq 0.00001]$.

\section{Generalization: Minute-by-Minute Analysis of Licks}

Figure 3-3 illustrates minute-by-minute mean licks for the 20 min test trial for generalization. On this test day, all mice received $0.12 \mathrm{M} \mathrm{NaCl}$. Mice that received $\mathrm{NaCl}$ previously are controls and mice that were conditioned with $\mathrm{LiCl}$ are CTA mice. B6 mice are to the left and D2 mice are to the right in the figure.

An overall repeated measures was conducted on data from generalization day for both the low-dose and high-dose groups (high-dose is described in detail later), for the entire $20 \mathrm{~min}$ session, with between subjects factors for strain, stimulus, and concentration $(2 \times 2 \times 2)$ and within subjects factors for time $(\times 20)$. Results showed significant effects of stimulus $[\mathrm{F}(1,81)=90.612, p \leq .000001]$, time $[\mathrm{F}(19,1539)=14.308, p \leq .000001]$, and strain $[\mathrm{F}(1,81)=16.572, p \leq .0001]$. Significant interactions were found between concentration and stimulus $[\mathrm{F}(1,81)=$ $5.5263, p \leq .02]$, time and stimulus $[\mathrm{F}(19,1539)=19.928, p \leq .00001]$, concentration, 


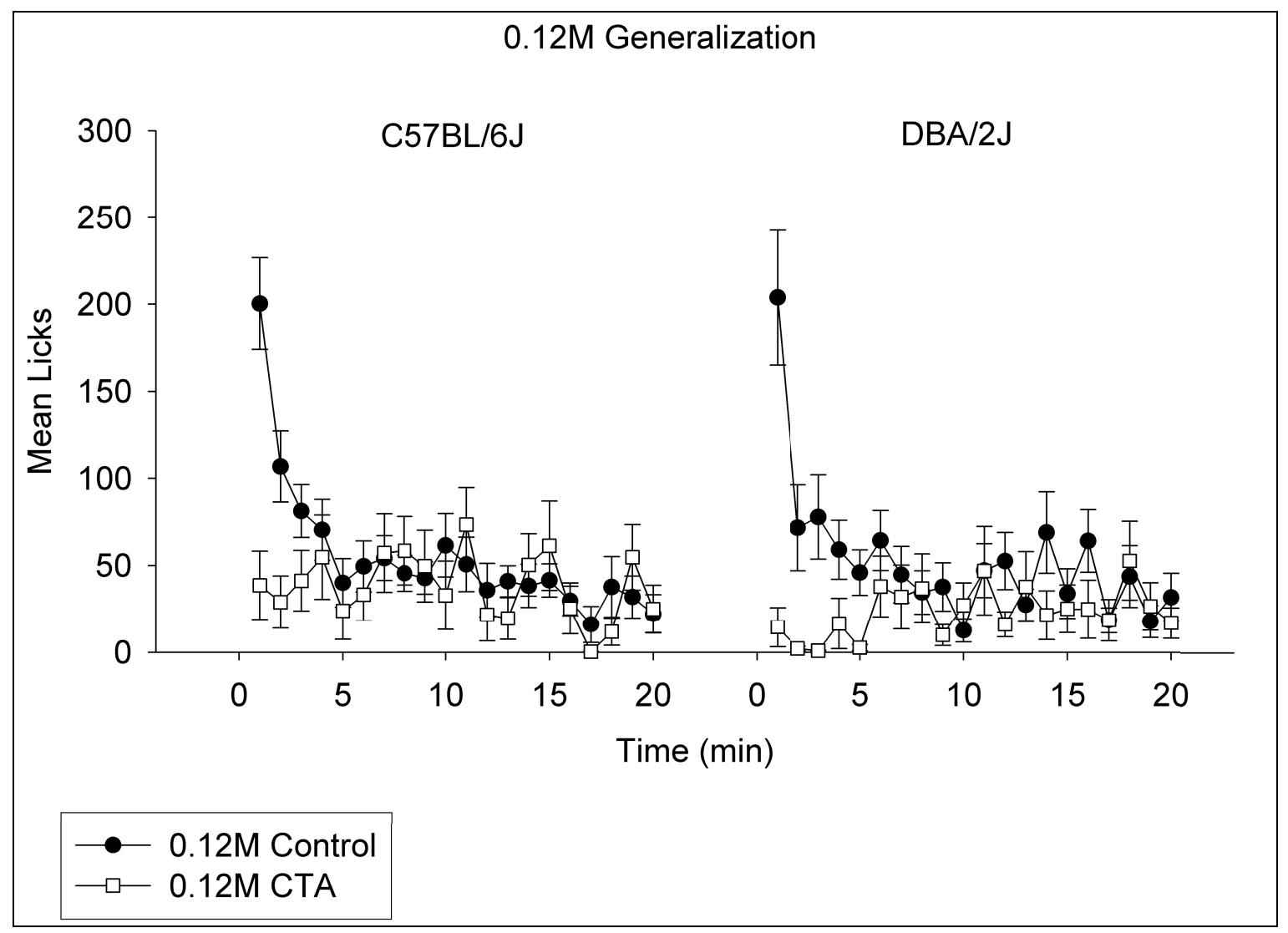

\section{Figure 3-3. Low-dose generalization.}

Notes: Mean licks to $0.12 \mathrm{M} \mathrm{NaCl}$ across a single, 20 min trial $24 \mathrm{~h}$ after conditioning in B6 (left plot) and D2 (right plot) mice. Controls, conditioned with $\mathrm{NaCl}$ the previous day are in black, and CTA mice, conditioned with $\mathrm{LiCl}$, are in white. 
stimulus, and strain $[\mathrm{F}(1,81)=8.9567, p \leq .004]$, and time, concentration, and stimulus $[\mathrm{F}(19,1539)=1.9932, p \leq .006]$.

At the start of the session, in minutes 1-5 (approximately), for both strains, a large suppression of licks was seen in CTA mice compared to controls. After this time, however, lick rates for CTA mice generally matched those of controls. Specifically, planned comparisons revealed B6 CTA mice had a significant suppression of licks compared to controls for minutes $1(p \leq .0001)$ and $2(p \leq .007)$, and D2 CTA mice showed significantly fewer licks compared to controls in minutes $1(p \leq .0001), 2(p \leq .01), 3(p \leq .005)$ and $5(p \leq .004)$. These results show that D2 CTA mice avoided $\mathrm{NaCl}$ longer into the 20 min trial than B6 CTA mice. For B6 mice, a repeated measures ANOVA revealed significant effects of stimulus $[\mathrm{F}(1,18)=9.5962, p \leq .006]$, time $[\mathrm{F}(19,342)=4.1014, p \leq .0000]$, and an interaction of stimulus and time $[\mathrm{F}(19,342)=3.3021, p \leq .00001]$. A repeated measures ANOVA for D2 mice also showed significant effects of stimulus $[\mathrm{F}(1,18)=15.327$, $p \leq .001]$, time $[\mathrm{F}(19,342)=3.0044, p \leq .00003]$, and an interaction of stimulus and time $[\mathrm{F}(19,342)=4.2265, p \leq .00001]$.

\section{Microstructure}

To further investigate the behavior exhibited during conditioning and generalization of conditioned taste aversion, we considered several microstructural measures as part of the analysis, including inter-lick intervals, bursts, volume, and lick rate. Microstructure is commonly used to analyze licking behavior, and has been considered a more sensitive method of finding differences, compared to more gross measures such as total consumption or lick counts (Baird, J. P. et al. 2005). A model of this analysis can be seen by Baird, et al (2005), who researched CTA self-administration behavior in rats, and found similar results as we did in mice

Inter-lick intervals measure the time from the beginning of one lick to the start of the next lick. The primary or local lick rate is defined as the mean ILI from $50-160 \mathrm{~ms}$, and the majority of ILIs fall into this time range. ILIs longer than 160 ms represent pauses in a train of licks, which are often expressed while an animal is licking an aversive stimulus. Figures 3-4 and 3-5 illustrate the ILI distributions for B6 and D2 mice. In Figure 3-4A, during conditioning it is apparent that B6 mice receiving $\mathrm{NaCl}$ show a similar distribution of ILIs as $\mathrm{B} 6$ mice receiving $\mathrm{LiCl}$. However, D2 mice receiving $\mathrm{LiCl}$ tend to possess longer ILIs, manifested as an increase in ILIs in the range of 160-319ms (Figure 3-4B). Both B6 and D2 mice acquired a CTA to $\mathrm{LiCl}$, and generalized the aversion to the similarly salty tasting solution of $\mathrm{NaCl}$.

Figure 3-5 shows ILI distribution during generalization for both strains. In panel A, B6 mice show a slight increase in ILIs that are 160-319 ms, while D2 mice demonstrate a more substantive increase in ILIs in this range, reflecting greater aversion to the stimulus in this strain. During conditioning, the increased pauses 


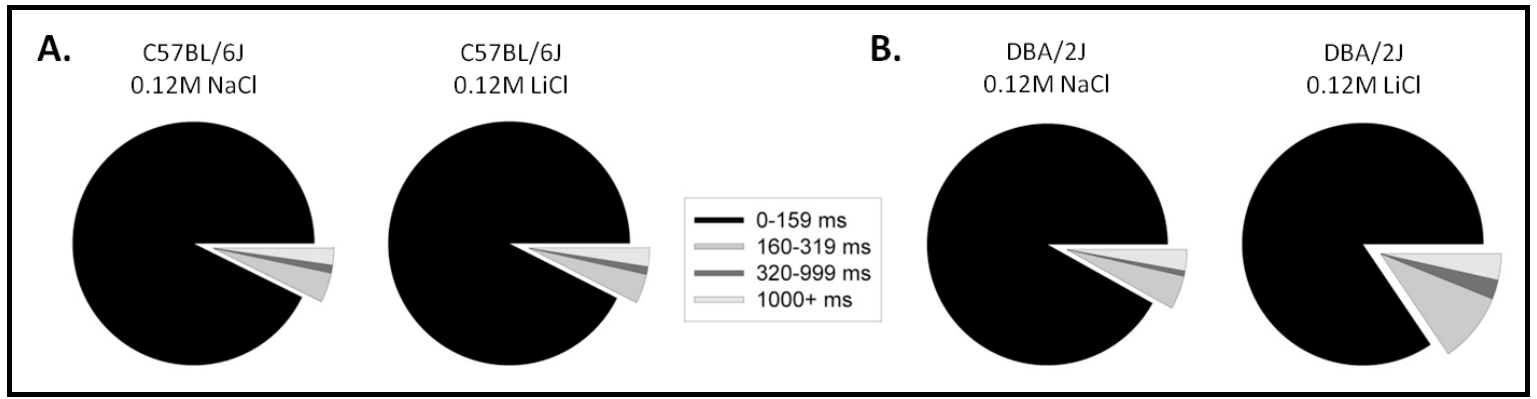

Figure 3-4. Inter-lick interval distribution during $0.12 \mathrm{M}$ conditioning.

Notes: Distribution of ILI ranges during low-dose conditioning. A) B6 mice show generally matching ILI profiles when responding to $\mathrm{NaCl}$ or LiCl. B) D2 mice licking $\mathrm{LiCl}$ show an increase in ILIs between $160-319 \mathrm{~ms}$, indicating longer pauses between licks. These results suggest D2 mice were responding more to the malaise of $\mathrm{LiCl}$ than $\mathrm{B} 6$ mice.

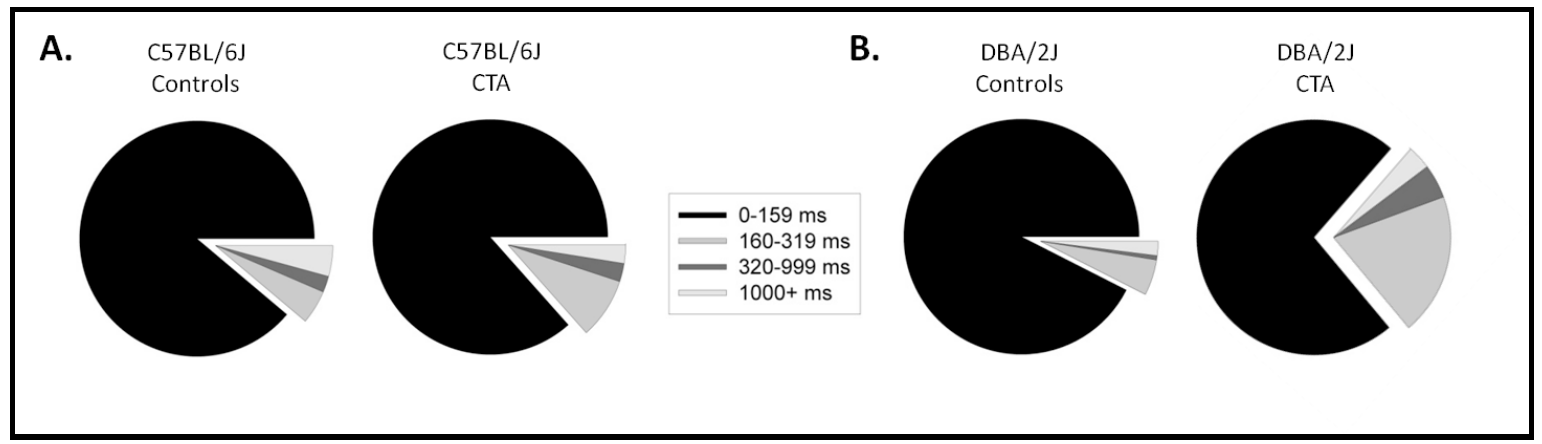

Figure 3-5. Inter-lick interval distribution during 0.12M generalization.

Notes: Distribution of ILI ranges during low-dose generalization. A) B6 CTA mice show a slight increase in ILIs falling between $160-319 \mathrm{~ms}$. This increase is similar to the D2 ILI distribution during conditioning. B) D2 CTA mice show a substantive increase in ILIs falling between $160-319 \mathrm{~ms}$, and a slight increase in ILIs 320-999ms. This large of an increase in ILI is only seen in D2 mice, and suggests evidence that D2 were expressing a stronger CTA compared to B6 mice. 
are likely due to the malaise being experienced. Therefore according to ILI data, B6 do not suffer enough from the malaise of $\mathrm{LiCl}$ to affect their licking structure while D2 mice do. During generalization, increases are likely due to a conditioned taste aversion, as mice are showing more hesitant behavior to $\mathrm{NaCl}$ due to the aversion generalized from $\mathrm{LiCl}$. Accordingly, ILI data for generalization suggests that both strains are exhibiting a conditioned taste aversion, but that D2 mice have developed a much stronger aversion than B6, as was hypothesized.

Other microstructure measures are compiled in Tables 3-3 (low-dose conditioning) and 3-4 (low-dose generalization). The tables show results from a comprehensive analysis comparing controls to CTA mice within each strain. Microstructure measures that were analyzed include: lick count, the total number of licks during the 20 min trial; volume per lick (VPL), the amount of fluid consumed divided by the number of licks, and is used to quantify consumption; initial lick rate, the number of licks in the first minute of the trial; burst count, the number of bursts within the 20 min test session; mean burst size, the average number of licks per burst; burst size, $1^{\text {st }}$ half, which is the average burst size during the first 10 minutes of the 20 minute test session; burst size, $2^{\text {nd }}$ half, which is the average size during the last 10 minutes of the test session; intra-burst lick rate, the mean inter-lick interval between 60-1000ms (which are intervals that occur within bursts); primary lick rate, the mean inter-lick interval between 50$160 \mathrm{~ms}$; number of visits, the total number of times the mouse visited the spout; and latency to first lick, which measures the time it took for the mouse to initiate the first lick of the trial.

Tables 3-3 and 3-4 show these results for B6 and D2 mice in the low-dose experiment. Data highlighted in pink marks significant differences between controls and CTA mice that are indicative of a CTA based on previous literature (e.g., Baird, J. P. et al. 2005). Data that are highlighted in gray mark differences that are statistically significant ( $p s \leq .05)$, but do not match previous literature indications of a CTA in rats. During conditioning with $0.12 \mathrm{M} \mathrm{LiCl}, \mathrm{B} 6$ mice demonstrate a decrease in mean lick count and burst count, measures possibly associated with CTA formation. However, in the absence of other changes (such as in VPL, burst size, or lick rate), the decrease in licks is most likely due to malaise being experienced during the trial, resulting in decreased licks, which leads to fewer bursts. D2 mice show these same results, but also have an increase in intra-burst lick rate. However, these alterations occur in the presence of malaise, and therefore are unlikely evidence of a CTA during conditioning.

During generalization, where all mice received $0.12 \mathrm{M} \mathrm{NaCl}, \mathrm{B} 6 \mathrm{CTA}$ mice possessed alterations in licking microstructure (vs. controls) indicative of a conditioned taste aversion. A decrease in burst count was seen in the absence of malaise, and as a result of the mice avoiding the $\mathrm{NaCl}$ during the first several minutes of the trial (see Figure 3-4). A decrease in lick count was also seen, but this measure was not significant. Also, a slight yet significant increase in intraburst lick rate was seen in B6 CTA mice, indicating longer pauses between licks. D2 CTA mice also possessed several characteristics suggesting a conditioned taste aversion was formed, and expressed during this test trial: A significant decrease 
Table 3-3. Microstructure: low-dose conditioning.

\begin{tabular}{llllll}
\hline Measure & \multicolumn{2}{c}{ C57BL/6J } & & \multicolumn{2}{c}{ DBA/2J } \\
\cline { 2 - 3 } \cline { 5 - 6 } & Control & CTA & & Control & CTA \\
\hline Lick Count & $1229.10^{*}$ & 464.8 & & $987.63^{*}$ & 290.63 \\
Volume per Lick (ml) & 1.15 & 1.16 & & 1.19 & 1.07 \\
Initial Lick Rate & 208.1 & 199 & & 146.18 & 175.5 \\
Burst Count & 32.5 & 12.8 & & 26 & 11.38 \\
Mean Burst Size & 42.66 & 39.26 & & 39.11 & 26.12 \\
Burst Size: 1st Half & 48.24 & 53.56 & & 44.99 & 39.84 \\
Burst Size: 2nd Half & 36.75 & 22.17 & & 32.81 & 11.55 \\
Intra-burst Lick Rate (ms) & $124.77^{*}$ & 129.84 & & $100.85^{*}$ & 124.29 \\
Primary Lick Rate (ms) & $115.90^{*}$ & $121.43^{*}$ & & $92.98^{*}$ & $99.93^{*}$ \\
Number of Visits & 6 & 3.4 & & 6.9 & 2.38 \\
Latency to First Lick (s) & 0.11 & 0.13 & & 0.13 & 0.21 \\
\hline
\end{tabular}

Notes: Pink cells indicate significant group (Control vs. CTA within strain) differences (factorial ANOVA, strain X group, followed by Bonferroni test, $p \leq$ 0.05) as expected in CTA formation (e.g. Baird et al., 2005). Asterisks indicate significant strain differences (compared within groups only). Abbreviations: CTA $=$ conditioned taste aversion; $\mathrm{ms}=$ milliseconds; $\mathrm{s}=$ seconds; $\mathrm{ul}=$ microliter. 
Table 3-4. Microstructure: low-dose generalization.

\begin{tabular}{llllll}
\hline Measure & \multicolumn{2}{c}{ C57BL /6J } & & \multicolumn{2}{c}{ DBA/2J } \\
\cline { 2 - 3 } \cline { 5 - 6 } & Control & CTA & & Control & CTA \\
\hline Lick Count & 1098.30 & 763.20 & & 1076.00 & 554.13 \\
Volume per Lick (ul) & 1.38 & 1.10 & & 1.33 & 1.12 \\
Initial Lick Rate & 200.40 & 38.70 & & 214.82 & 17.50 \\
Burst Count & 28.60 & 15.80 & & 21.45 & 15.50 \\
Mean Burst Size & 41.47 & 52.52 & & 51.08 & 33.95 \\
Burst Size: 1st Half & 45.28 & 41.29 & & 58.20 & 26.90 \\
Burst Size: 2nd Half & 33.34 & 64.17 & & 43.58 & 41.74 \\
Intra-burst Lick Rate (ms) & $129.18^{*}$ & 139.36 & & $98.90^{*}$ & 128.47 \\
Primary Lick Rate (ms) & $117.60^{*}$ & $118.60^{*}$ & & $91.15^{*}$ & $99.93^{*}$ \\
Number of Visits & 6.60 & 6.60 & & 7.36 & 7.25 \\
Latency to First Lick (s) & 0.10 & 0.16 & & 0.13 & 7.52 \\
\hline
\end{tabular}

Notes: Pink cells indicate significant group (Control vs. CTA within strain) differences (factorial ANOVA, strain X group, followed by Bonferroni test, $p \leq$ 0.05) as expected in CTA formation (e.g. Baird et al., 2005). Asterisks indicate significant strain differences (compared within groups only). Abbreviations: CTA $=$ conditioned taste aversion; $\mathrm{ms}=$ milliseconds; $\mathrm{s}=$ seconds; $\mathrm{ul}=$ microliter. 
in mean licks, initial lick rate, burst count, and an increase in intra-burst lick rate. These results are all indicators of behavior being exhibited in response to a conditioned taste aversion - including hesitation, longer pauses, fewer licks, and avoidance of the stimulus.

A factorial ANOVA analyzing strain X group, was followed by Bonferroni test, indicated several strain differences in licking microstructure. During conditioning, B6 controls possessed significantly higher lick counts, intra-burst lick rate, and primary lick rate. B6 CTA mice also demonstrated a significantly higher primary lick rate, which is characteristic for these strains - D2 mice are known to possess a faster lick rate than B6. Following generalization, B6 show a significantly higher intra-burst lick rate and primary lick rate; B6 CTA mice continue to show a significantly higher (slower) primary lick rate than D2.

In summary, even though B6 mice abruptly ceased licking of $0.12 \mathrm{M} \mathrm{LiCl}$ within a few minutes during conditioning with $0.12 \mathrm{LiCl}$, they did not express alterations in microstructure indicative of rapid CTA formation. Alterations in microstructure indicative of a CTA were expressed the following day. Meanwhile, D2 CTA mice showed more characteristics of CTA during conditioning, such as increased intra-burst lick rate (60 -1000 ms), and decreased number of licks and bursts. D2 CTA mice also appeared to fully express a CTA during the generalization session based on microstructural changes, similar to the B6 mice.

\section{High-Dose Experiment}

\section{Conditioning: Minute-by-Minute Analysis of Licks}

The same parameters were followed for conditioning as were executed for low-dose conditioning. Briefly, mice received a single, 20 min trial with either $0.24 \mathrm{M} \mathrm{NaCl}$ (controls) or $0.24 \mathrm{LiCl}$ (CTA). At the end of testing, mice received a 15 min $\mathrm{dH} 2 \mathrm{O}$ supplement. The results are shown in mean licks and illustrated in Figure 3-6. Mean licks are shown by minute, for the entire 20 min session. First, as was seen with low-dose conditioning, it is evident in minute 1 that mice find $\mathrm{NaCl}$ and $\mathrm{LiCl}$ similar in taste, as their mean lick response is comparable. As of minute 2 , one can see the rapid decline in mean licks by mice receiving $\mathrm{LiCl}$, in both strains, compared to their own controls. Planned comparisons showed that B6 mice licking LiCl had significantly fewer licks compared to controls by minute $2(p \leq .03)$, and maintained this significant difference until minute 13 . After this time point B6 CTA and controls were only significantly different at minutes 15 and 18. D2 mice licking $\mathrm{LiCl}$ show similar results, displaying significantly fewer licks by minute $2(p \leq .01)$ and maintaining this difference for most of the trial (significantly different from controls minutes 2-10, 12, 13, 16, 18, and 19). These results show both strains respond to the $\mathrm{LiCl}$ right away in minute 2 .

Compared to low-dose conditioning, B6 mice appear to acquire a CTA more quickly with the high-dose $\mathrm{LiCl}$, while $\mathrm{D} 2$ continue to show a rapid 


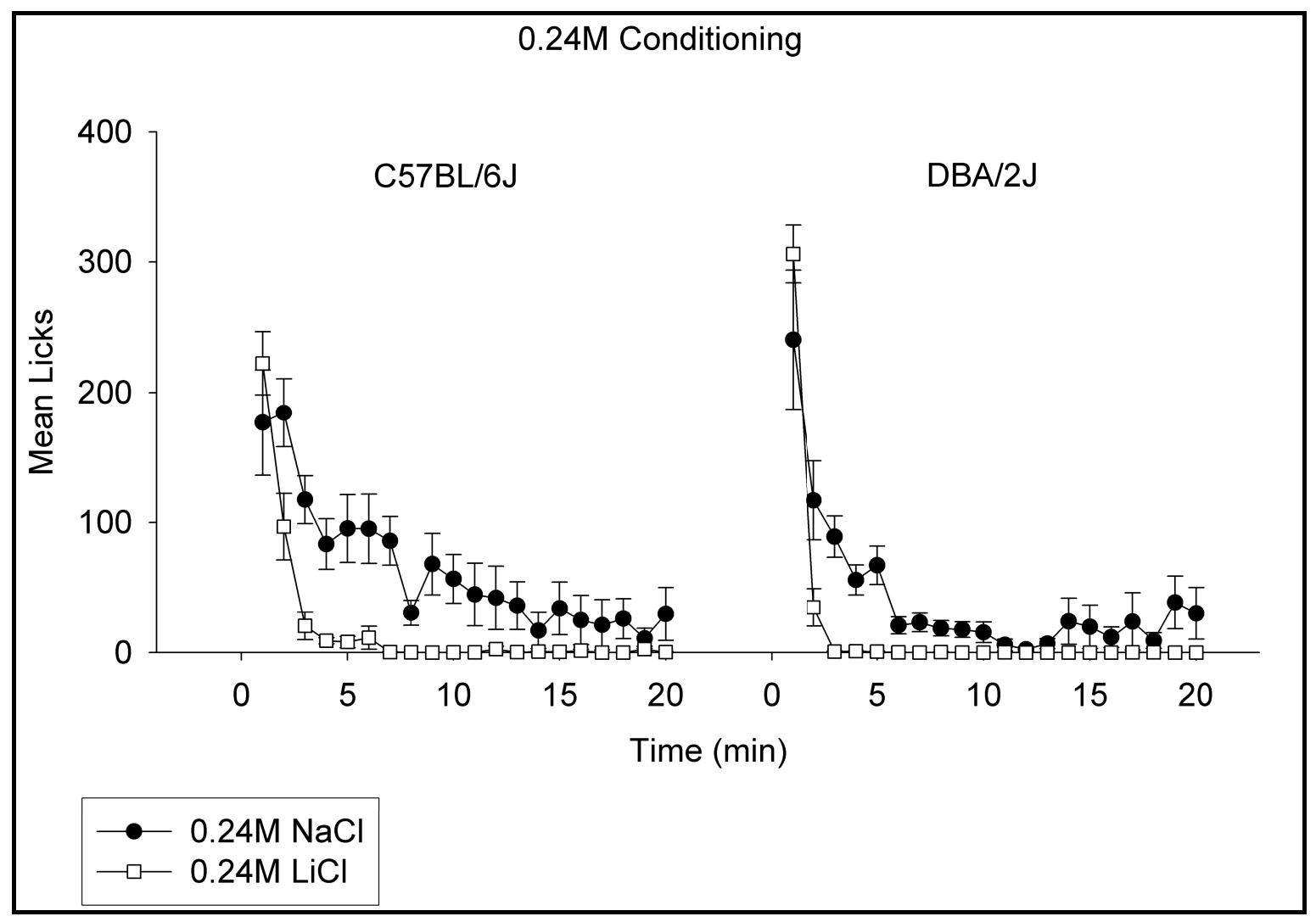

\section{Figure 3-6. High-dose conditioning.}

Notes: Mean licks to either $0.24 \mathrm{M} \mathrm{NaCl}$ (controls) or $0.24 \mathrm{M} \mathrm{LiCl}$ (CTA). B6 mice are shown to the left, and D2 mice are shown to the right. Controls are shown in black and CTA mice shown in white. 
development of CTA. A repeated measures ANOVA for B6 mice revealed significant effects of stimulus $[\mathrm{F}(1,22)=68.656, p \leqq 0.00001]$, time $[\mathrm{F}(19,418)=$ $24.065, p \leq 0.00001]$, and an interaction of time $\mathrm{x}$ stimulus $[\mathrm{F}(19,418=3.1914, p \leq$ .00001]. For D2 mice, a repeated measures ANOVA also revealed significant effects of stimulus $[\mathrm{F}(1,20)=45.439, p \leq 0.00001]$, time $[\mathrm{F}(19,380)=57.083, p \leq$ $0.00001]$, and an interaction of time $x$ stimulus $[\mathrm{F}(19,380)=4.0266, p \leq 0.00001]$.

\section{Generalization: Minute-by-Minute Analysis of Licks}

Figure 3-7 illustrates mean licks for the 20 min test trial for generalization. On this test day, all mice received $0.24 \mathrm{M} \mathrm{NaCl}$. Controls are mice that received $\mathrm{NaCl}$ previously and CTA mice were conditioned with $\mathrm{LiCl}$. $\mathrm{B} 6$ mice are to the left and D2 mice are to the right in the figure. As was seen in the low-dose groups, CTA mice of both strains showed a large suppression of licks immediately in minute 1, demonstrating a CTA. Planned comparisons showed B6 CTA mice had significantly fewer licks compared to controls for minutes 1 ( $p$ $\leq .0001), 2(p \leq .01), 3(p \leq .005)$ and $5(p \leq .004)$. However, D2 CTA mice showed significantly fewer licks compared to controls for the first 6 minutes ( $p s \leq .01$ ).

A repeated measures ANOVA for B6 mice revealed significant effects of stimulus $[\mathrm{F}(1,22)=60.954, p \leq 0.00001]$, time $[\mathrm{F}(19,418)=5.1300, p \leq 0.00001]$ and an interaction between time and stimulus $[\mathrm{F}(19,418)=7.9048, p \leq 0.0003]$. For D2, a repeated measures ANOVA revealed significant effects of stimulus $[\mathrm{F}(1,23)=$ $17.591, p \leq 0.00001]$, time $[\mathrm{F}(19,437)=5.5983, p \leq 0.003]$, and an interaction of time and stimulus $[\mathrm{F}(19,437)=9.5204, p \leq 0.00001]$. This avoidance of the $\mathrm{NaCl}$ solution clearly shows that the mice acquired a CTA to $0.24 \mathrm{M} \mathrm{LiCl}$, and then generalized the aversion to the similarly salty tasting solution of $0.24 \mathrm{M} \mathrm{NaCl}$. It appears that B6 mice show this aversion further into the trial compared to B6 mice conditioned with the lower $\mathrm{LiCl}$. For example, around minute 4, $\mathrm{B} 6$ mice conditioned with $0.12 \mathrm{M} \mathrm{LiCl}$ show lick rates that generally matched that of controls during the generalization trial; however it is not until minute 8 that B6 mice conditioned with $0.24 \mathrm{M} \mathrm{LiCl}$ being to show lick rates that generally matched controls. This suggests that B6 mice obtained a stronger CTA following the higher dose of $\mathrm{LiCl}$ compared to the lower dose. Interestingly though, D2 mice do not show these same results. In fact, it appears they obtained just as strong of a CTA in both conditioning situations, as CTA mice appear to return to normal licking approximately 6 minutes into the generalization trial. These results could suggest strain differences in acquisition and expression of conditioned taste aversion, or possibly differences in sensitivity to $\mathrm{LiCl}$ used for conditioning.

\section{Microstructure}

We repeated the same microstructure analysis done in the low-dose experiment and described in a previous section. To reiterate, inter-lick intervals 


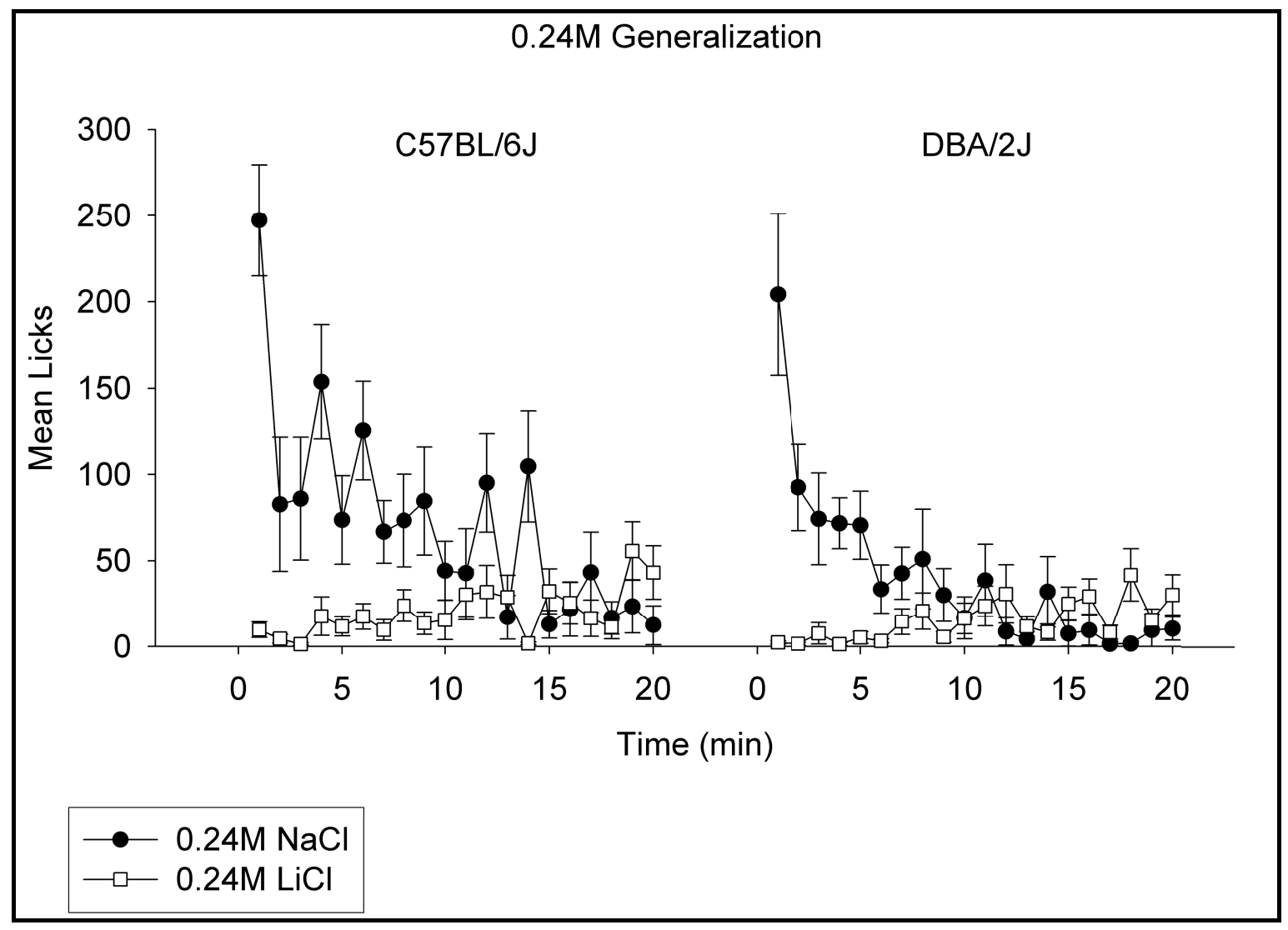

Figure 3-7. High-dose generalization.

Notes: Mean licks to $0.24 \mathrm{NaCl}$ across a single, $20 \mathrm{~min}$ trial. Controls, conditioned with $\mathrm{NaCl}$ the previous day are in black, and CTA mice, conditioned with $\mathrm{LiCl}$, are in white. 
measure the time from the beginning of one lick, to the start of the next lick. Primary lick rate is the mean ILI from $50-160 \mathrm{~ms}$, as it is within this range most ILIs fall, or peak. Also, based on intervals, we are able to determine whether subjects are taking longer pauses, as well as more or less pauses, which can be indicative of palatable and aversive tastes. Figures 3-8 and 3-9 illustrate the ILI breakdowns for B6 and D2 mice during $0.24 \mathrm{M}$ conditioning and generalization. During conditioning, it is apparent that $\mathrm{B} 6$ mice receiving $\mathrm{NaCl}$ show a similar distribution of ILIs as $\mathrm{B} 6$ mice receiving $\mathrm{LiCl}$, as was seen at the low-dose. However, D2 mice tend to possess longer ILIs, manifested as an increase in ILIs falling in the 160-319ms range, as is seen in Figure 3-8B.

Figure 3-9 shows ILI distribution during high-dose generalization for both strains. In panel A, B6 mice show a more substantive increases in longer ILIs in all ranges over $160 \mathrm{~ms}$, while D2 mice demonstrate even larger increases in these longer ILIs. As previously discussed, longer ILIs are indicative of longer pauses, reflecting greater aversion. During conditioning, the increased pauses are likely due to the malaise being experienced. Therefore, ILI data following $0.24 \mathrm{M} \mathrm{LiCl}$ suggests that D2 mice are being affected a great deal more by malaise than B6.

During generalization, increases are likely due to a conditioned taste aversion, as mice are showing more hesitant behavior to $\mathrm{NaCl}$ due to the aversion generalizing from $\mathrm{LiCl}$. Accordingly these results could suggest both strains have a much stronger aversion following $0.24 \mathrm{M} \mathrm{LiCl} \mathrm{compared} \mathrm{to} 0.12 \mathrm{M}$, and that D2 mice maintain a stronger CTA than B6.

Other microstructure measures are compiled in Tables 3-5 (conditioning) and 3-6 (generalization) for B6 and D2 mice. As was illustrated for low-dose microstructure results, the tables show results from a comprehensive analysis comparing controls to CTA mice within each strain. Data highlighted in pink marks significant differences between controls and CTA mice that are indicative of a CTA based on previous literature (e.g., Baird, J. P. et al. 2005). Data that is highlighted in gray mark differences that are statistically significant ( $p s \leq .05$ ), but do not match previous literature indications of a CTA.

As shown in Table 3-5, B6 CTA continue to only indicate malaise, and not necessarily acquisition of a CTA. Following $0.24 \mathrm{M} \mathrm{LiCl}, \mathrm{B} 6$ mice show a marked decrease in mean licks, and burst count, but no other alterations in microstructure (vs. controls). However, the following day during generalization to $0.24 \mathrm{M} \mathrm{NaCl}$, B6 CTA mice possessed alterations in licking microstructure indicative of conditioned taste aversion, including decreased mean licks, initial lick rate, burst count, mean burst size (specifically during the $1^{\text {st }}$ half of the test session, when the CTA was being expressed), and an increase in intra-burst lick rate and latency to first lick.

Following 0.24M LiCl, D2 CTA mice show similar results as B6, with decreased mean licks, burst count, and increased intra-burst lick rate. However, D2 CTA possessed additional changes in licking microstructure, such as increased burst size, and an increased burst size during the first half of the trial. 


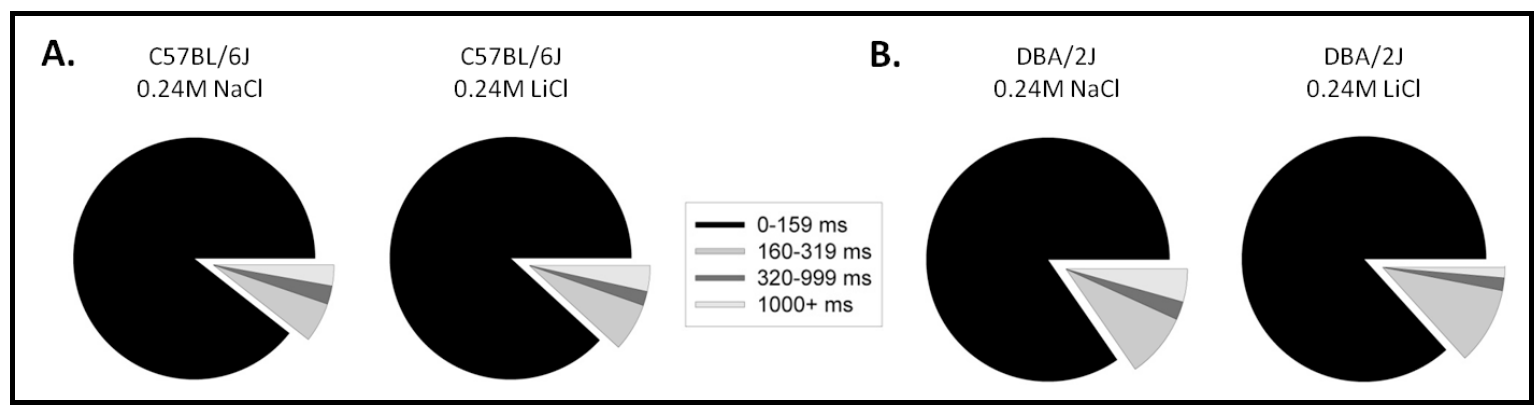

Figure 3-8. Inter-lick interval during $0.24 \mathrm{M}$ conditioning.

Notes: Distribution of ILIs following high-dose conditioning. A) Similar to lowdose results, B6 mice licking $\mathrm{LiCl}$ only show a subtle increase in ILIs 160-319ms, but generally appear the same as controls. B) D2 mice licking $\mathrm{NaCl}$ show increases ILIs compared to controls in the low-dose experiment, indicating the higher dose of $\mathrm{NaCl}$ may be less palatable to $\mathrm{D} 2$ mice. D2s licking $\mathrm{LiCl}$ show increased ILIs falling between 160-319ms compared to controls, and fewer ILIs over 1s.

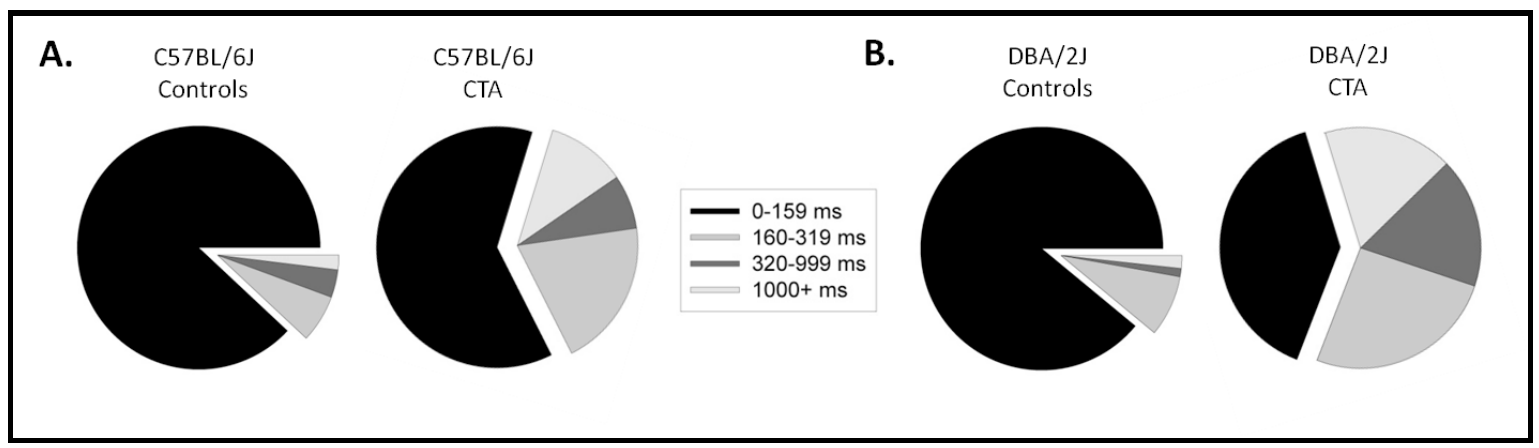

Figure 3-9. Inter-lick interval during 0.24M generalization.

Notes: Distribution of ILIs following high-dose conditioning. A) Compared to controls, B6 CTA mice show substantive increases in ILIs 160ms to 1s. This result is also a substantive increase compared to B6 CTA mice in the low-dose experiment. These results indicate B6 CTA mice acquired a stronger CTA with $0.24 \mathrm{M} \mathrm{LiCl}$ compared to $0.12 \mathrm{M} \mathrm{LiCl}$. B) D2 CTA mice show substantive increases in ILIs $160 \mathrm{~ms}$ to $1 \mathrm{~s}$. This increases are more so than what is seen in B6, suggesting evidence of a stronger CTA compared to B6, as well as a stronger CTA compared to $0.12 \mathrm{M} \mathrm{LiCl}$. 
Table 3-5. Microstructure: high-dose conditioning.

\begin{tabular}{llllll}
\hline Measure & \multicolumn{2}{c}{ C57BL / 6J } & & \multicolumn{2}{c}{ DBA /2J } \\
\cline { 2 - 3 } \cline { 5 - 6 } & Control & CTA & & Control & CTA \\
\hline Lick Count & $1283^{*}$ & 411.20 & & $779^{*}$ & 354.6 \\
Volume per Lick (ul) & 1.03 & $0.99^{*}$ & & 1.15 & $1.29^{*}$ \\
Initial Lick Rate & 191.44 & 241 & & 279.25 & 313.80 \\
Burst Count & $33.78^{*}$ & $13.20^{*}$ & & $17.60^{*}$ & $4.70^{*}$ \\
Mean Burst Size & 39.81 & $31.43^{*}$ & & 46.86 & $72.85^{*}$ \\
Burst Size: 1st Half & 43.42 & 46.04 & & 62.78 & $116.57^{*}$ \\
Burst Size: 2nd Half & 36.08 & 15.87 & & 25.23 & 32.42 \\
Intra-burst Lick Rate (ms) & $132.16^{*}$ & 127.72 & & $105.46^{*}$ & 116.91 \\
Primary Lick Rate (ms) & $113.36^{*}$ & $113.63^{*}$ & & $94.85^{*}$ & $97.72^{*}$ \\
Number of Visits & 6.56 & 2.90 & & 5.63 & 1.50 \\
Latency to First Lick (s) & 0.13 & 0.11 & & 0.38 & 0.99 \\
\hline
\end{tabular}

Notes: Pink cells indicate significant group (control vs. CTA) differences (factorial ANOVA, strain X group, followed by Bonferroni test, $p \leq 0.05$ ), as expected in CTA formation (e.g., Baird, et al., 2005). Gray cells indicate significant group differences, but not consistent with results seen in rats. Asterisks indicate significant strain differences (compared within groups only). Abbreviations: $\mathrm{CTA}=$ conditioned taste aversion; $\mathrm{ms}=$ milliseconds; $\mathrm{s}=$ seconds; $\mathrm{ul}=$ microliter. 
Table 3-6. Microstructure: high-dose generalization.

\begin{tabular}{llllll}
\hline Measure & \multicolumn{2}{c}{ C57BL /6J } & & \multicolumn{2}{c}{ DBA/2J } \\
\cline { 2 - 3 } \cline { 5 - 6 } & Control & CTA & & Control & CTA \\
\hline Lick Count & 1428 & 375.5 & & $739^{*}$ & 357.10 \\
Volume per Lick (ul) & 1.12 & 0.78 & & 1.32 & 0.73 \\
Initial Lick Rate & 247.33 & 6.60 & & 147.20 & 2.00 \\
Burst Count & 22.22 & 11.90 & & 11.20 & 14.50 \\
Mean Burst Size & 65.35 & 26.04 & & 70.71 & 22.38 \\
Burst Size: 1st Half & 62.25 & 16.67 & & 76.69 & 15.04 \\
Burst Size: 2nd Half & 68.51 & 41.63 & & 65.44 & 30.38 \\
Intra-burst Lick Rate (ms) & 138.50 & 200.16 & & 106.53 & 181.44 \\
Primary Lick Rate (ms) & $114.52^{*}$ & $118.07^{*}$ & & $94.02^{*}$ & $91.29^{*}$ \\
Number of Visits & 7.11 & 6.40 & & 5.50 & 5.50 \\
Latency to First Lick (s) & 0.12 & 56.03 & & 0.15 & 60.87 \\
\hline
\end{tabular}

Notes: Pink cells indicate significant group (control vs. CTA) differences (factorial ANOVA, strain X group, followed by Bonferroni test, $p \leq 0.05$ ), as expected in CTA formation (e.g., Baird, et al., 2005). Gray cells indicate significant group differences, but not consistent with results seen in rats. Asterisks indicate significant strain differences (compared within groups only). Abbreviations: $\mathrm{CTA}=$ conditioned taste aversion; $\mathrm{ms}=$ milliseconds; $\mathrm{s}=$ seconds; $\mathrm{ul}=$ microliter. 
These changes are not in line with previous data, but do demonstrate alterations at the microstructural level in these mice. Although it is likely a number of these results are due to malaise (for example decreased mean licks and increased intraburst lick rate), it is still possible that some of these changes indicate acquisition of an aversion. During generalization, D2 CTA mice show significant decreases in lick count, volume per lick, initial lick rate, burst size (throughout the $1^{\text {st }}$ and $2^{\text {nd }}$ half), and significant increases in intra-burst lick rate and latency to first lick.

A factorial ANOVA analyzing strain X group, followed by Bonferroni test, indicated several strain differences in licking microstructure. During conditioning, B6 controls exhibited significantly higher lick counts, burst counts, intra-burst lick rate, and primary lick rate, compared to D2 controls. Again, as seen in the low-dose experiment, these strain differences are most likely associated in inherent strain differences in lick rate, not differences in CTA. B6 CTA mice also showed significantly higher lick counts, burst counts, and primary lick rate; and significantly lower volume per lick, and burst size. Many of these strain differences are due to effects seen in D2 CTA mice, some of which do not match previous literature (gray cells). One possible explanation is that D2 CTA mice took so few licks to $0.24 \mathrm{M} \mathrm{LiCl}$, it resulted in just a few bursts in which all the licks occurred - increasing the mean burst size as well.

Following generalization, B6 controls and CTA mice show significantly higher primary lick rate compared to D2, as expected between strains. No other strain differences were found in this comparison following generalization. However, D2 CTA mice do show more characteristics of a CTA than B6 CTA mice, including decreased burst size for the entire 20 min generalization session, compared to just the first half, seen by B6 mice.

\section{Discussion}

When investigating conditioned taste aversion, there are a number of factors that must be considered. First, and perhaps most importantly, is the method of conditioning. It has been shown that results in a CTA study can vary due to method of delivery of the unconditioned stimulus. Shafe et al (1998) explores this point and shows that when rats are conditioned via intra-oral cannulas, electrolytic lesions in the amygdala result in elimination of an aversion (Schafe, G. E. et al. 1998). However, when conditioned using bottle presentation of the conditioned stimulus, CTA learning was attenuated, but not eliminated, following the same lesions in the amygdala (Schafe, G. E. et al. 1998). Further, Shafe et al (1998) concluded that the strength of the aversions in their experiments was similar, despite method of conditioning. Another study conducted by Spray et al (2000) investigated conditioning method as it relates to c-Fos induction following a CTA. This study compared intra-oral and bottle presentation of the conditioned stimulus (Spray, K. J. et al. 2000). As was shown in Shafe's study, strength of the aversion did not differ between conditioning methods (Schafe, G. E. et al. 1998; Spray, K. J. et al. 2000). However, increases in c-Fos activation, as a result of CTA, were only seen in animals conditioned intraorally (Spray, K. J. et al. 2000). Together, these studies clearly demonstrate the 
effects of conditioning method on the outcome of a CTA experiment and should be considered when comparing studies.

In the present study, we used a paradigm similar to those by Spray and colleagues (2000) that allows the animal to drink from a bottle. However, the present study presented the bottle via a lickometer instead of a larger bottle presented in a cage. Another difference between the two studies is that Spray and colleagues (2000) conducted the CTA test 10 days after conditioning (compared to the following day in our study), and possibly accounted for the lack of c-Fos changes compared to the I/O method (Spray, K. J. et al. 2000). Therefore, comparing studies directly regarding CTA results is complex as many details vary.

A second important factor to consider when investigating CTA is timing, or number of trials. It has been shown that the strength of a CTA varies according to the number of trials - the more trials, the stronger the CTA. This is also related to c-Fos activation, as Navarro et al (2000) have shown that the amount of c-Fos induced following CTA correlates to the strength of the aversion formed. Navarro et al (2000) showed more c-Fos was elicited in the NST, PBN, and CNA, following 3 trials compared to controls. However, following a single conditioning trial, c-Fos increases were only seen in the NST (Navarro, M. et al. 2000). Further, latency to reject the stimulus was shorter in animals following 3 trials of conditioning versus a single trial, behaviorally confirming the differing strengths of aversion (Navarro, M. et al. 2000). In the study presented here, mice were conditioned with a single trial of conditioning, accomplished by selfadministration of $\mathrm{LiCl}$ solution.

A third issue to address is whether the suppression in licks is due to a conditioned taste aversion, or to lingering malaise from the $\mathrm{LiCl}$. Baird et al (2005) have already shown that a CTA can be formed in the first 8 minutes, and that decreased response is not due to sickness. Rats were presented with $\mathrm{LiCl}$ for 8 minutes, then a second stimulus for another 8 minutes. When presented with $\mathrm{NaCl}$ or $\mathrm{LiCl}$ for the last 8 minutes, intake was significantly decreased, while when presented with sucrose or water for the last 8 minutes, intake was not significantly decreased (Swank, M. W. et al. 1995; Baird, J. P. et al. 2005). This study demonstrates that suppression of licks throughout our 20 minute trial is most likely due to formation of a CTA. However, as will be addressed in further detail below, the microstructure data from our experiments suggests it is still unclear whether a full CTA has formed during conditioning, or if the changes seen are simply due to malaise. For example, results such as a decrease in burst count could easily be due to formation of a CTA, or a subsequent effect of a decrease in overall licks - the fewer licks taken, the fewer opportunities for bursts as well.

To confirm that the decrease in licks to $\mathrm{NaCl}$ the following day is not due to malaise, unpublished results show that following a CTA formed via the selfadministration model used here, the CTA specifically generalizes to $\mathrm{NaCl}$, a similar-tasting salt to $\mathrm{LiCl}$. In this experiment, mice were conditioned via selfadministration with $\mathrm{LiCl}$. The following day, the mice were given a variety of 
stimuli, including, $\mathrm{NaCl}, \mathrm{MgCl}$ (magnesium chloride) sucrose, and water. The results showed avoidance (by a significant decrease in licks compared to controls) only to $\mathrm{NaCl}$ (unpublished data, Boughter Lab). Had the mice been ill, a decrease in response to the other stimuli would have been observed as well. Therefore, avoidance of the $\mathrm{NaCl}$ solution on day 4 (generalization) of the present study is reasonable evidence of a CTA, and not lingering malaise.

In our study, we used a self-administration paradigm to condition an aversion. While previous studies used bottles as a conditioning method, the unconditioned stimulus continued to be delivered via i.p. injection (Swank, M. W. et al. 1995; Grabus, S. D. et al. 2004). The method used in our experiments presents both the unconditioned and conditioned stimulus via bottles. This selfadministration paradigm was first used by Loy and Hall (2002), who demonstrated that self-administration of $\mathrm{LiCl}$ resulted in a conditioned taste aversion to salt, which then generalized to similar-tasting $\mathrm{NaCl}$ (Loy, I. et al. 2002). Baird et al (2005) also used this paradigm and showed that not only does a CTA form, and generalize to $\mathrm{NaCl}$, but that this occurs in a very rapid timeframe. This model is reasoned to be a more accurate animal model of conditioned taste aversion learning as it allows for time-dependent analysis of formation, generalization, and extinction of CTA as it would occur naturally, rather than following the standard pairing of ingested stimulus with injection.

To address the effectiveness of the paradigm itself, it appears clear that a single, oral self-administered conditioning trial is sufficient to condition an aversion. In our results, we saw a decrease in mean licks in the first couple of minutes, indicating the mice are learning to avoid the stimulus. Due to the fact that the licking continues sporadically throughout the trial, and that Baird et al (2005) have already shown malaise is not impairing their ability to consume fluids, we feel this acquisition of the conditioned taste aversion is taking place due to our microstructure results, though, we are not clear whether the CTA is completely formed during this trial or just in process.

Figure 3-1 shows a summary of the behavior lick data collected here. Although these results show a strain difference in mean licks to water, it is not clear what the cause of this effect is. D2 mice are known to have a faster lick rate, yet they are the strain with fewer licks. We are not able to determine if this is a result of differing thirst levels between the strains, quicker satiation by D2 mice, or if D2 mice are able to detect some taste in the distilled water. However, the comparisons made in mean licks for these experiments were mainly between controls and CTA mice between strains, making this difference in water licking a non-confounding issue. For example, it is obvious that mice drinking $\mathrm{LiCl}$ during conditioning have significantly fewer licks compared to controls. Also, on generalization day, it is again clear that mice with a CTA have fewer licks to $\mathrm{NaCl}$ than controls. Alone, these results suggest that a CTA was formed by both strains. Regarding the low-dose and high-dose experiments, both strains showed conditioning of an aversion in response to both doses of $\mathrm{LiCl}$. However, both $\mathrm{B} 6$ and D2 mice did appear to show an increase in their aversion, as seen in comparisons in Figure 3-1. 


\section{Microstructure}

Analyzing licking microstructure offers insights into feedback from both gustatory and visceral factors during the course of an ingested meal. Parameters used to define "bursts" (a clustering of licks surrounded by pauses) vary somewhat from study to study, but changes in burst size (licks per burst) and count (number of bursts) have been shown in response to palatable substances and caloric feedback (Davis, J. D. et al. 1992; Davis, J. D. et al. 1993; Spector, A. C. et al. 1998a; Eisen, S. et al. 2001; Baird, J. P. et al. 2005). For example, in studies by Davis and Perez (1993) burst size (defined in that study as the number of licks in a sequence separated by intervals of less than $250 \mathrm{~ms}$ ) and cluster size (defined as the number of licks in a sequence separated by intervals of less than $500 \mathrm{~ms}$ ) increased as sucrose concentrations increased. Other studies showed similar results: one study defined a burst using $1 \mathrm{~s}$ intervals (same as the present study) and concluded that increasing sucrose concentrations resulted in increased burst size (Spector, A. C. et al. 1998a), while a second study again showed increased burst and cluster size with increasing maltose concentrations (Davis, J. D. et al. 1992). Alternatively, burst size decreases linearly with increasing concentrations of naturally aversive tastants (Spector, A. C. et al. 1998b). Together, these studies suggest that burst size or cluster size, even when measured using varying intervals, is influenced by taste - specifically palatability.

Burst duration is also affected as a result of gastrointestinal feedback. As satiety increases toward the end of meals, pauses on average tend to grow longer in duration (Davis, J. D. 1996). Eisen et al (2001) gave rats gastric infusions of 3, 6, and $12 \mathrm{ml}$ of milk or saline. Results showed that $12 \mathrm{ml}$ of solution, whether saline or milk, inhibited intake, suggesting the inhibition was due to the volume of fluid in the stomach or to the rate of infusion (Eisen, S. et al. 2001). This study agrees with other experiments that show gastric preloads and satiety factors decrease burst size, number, and rate of ingestion (Davis, J. D. et al. 1995; Kaplan, J. M. et al. 1997; Baird, J. P. et al. 1999; Eisen, S. et al. 2001; Baird, J. P. et al. 2005). In rats, visceral distress following the ingestion of $\mathrm{LiCl}$ results in decreased burst size, increased number of bursts, and increase in pauses (Baird, J. P. et al. 2005). However, in this study, the authors posit that these changes were not due merely to visceral distress, but to a qualitative change in hedonic value of the stimulus following rapid CTA. A greater number of smaller bursts (leading to more pauses, as pause count $=$ number of bursts -1 ) were interpreted as a "stop-andgo" or more hesitant pattern of ingestion that was similar to ingestion of naturally aversive stimuli such as quinine. Another measure we examined in our study was the intra-burst lick rate, defined as the average ILI $<1 \mathrm{~s}$. It is important to distinguish this measure from the primary lick rate (MPI - mean primary interval), which is defined as the mean ILI between 60 and 160 ms (Boughter, J. D., Jr. et al. 2007b). MPI is genetically determined among strains of mice, is thought to reflect a "hard-wired" output of an intrinsic pattern generator, and has been shown to be impervious to sensory or environmental manipulation (Horowitz, G. P. et al. 1977; Boughter, J. D., Jr. et al. 2007b; Travers, J. B. et al. 2007; Shires, C. B. et al. 2011). On the other hand, the intra-burst lick rate includes longer duration ILIs, and is affected by gastric feedback. Rats drinking LiCl possessed a much higher proportion of long-duration (> 250 - $1000 \mathrm{~ms}$ ) ILIs 
within bursts than those drinking $\mathrm{NaCl}$. As in the aforementioned changes to burst-pause structure, this higher intra-burst mean ILI was thought to be reflective of a hesitant pattern of ingestion (Baird, J. P. et al. 2005). Finally, we also measured the frequency and size of "visits", which were defined as sequences of licks bounded by intervals of $60 \mathrm{~s}$.

\section{Lick Bursts}

In the present study, burst size, burst count, ILI distribution, and local lick rate (MPI) were analyzed. We saw a decrease in burst count in most groups over the 20 min trial, as shown in Tables 3-3 through 3-6. At low-dose conditioning and generalization, both strains demonstrated decreases in burst count compared to controls. At high-dose conditioning and generalization, B6 mice showed a significant decrease in burst count compared to controls, and D2 mice showed a marked decrease during conditioning. In addition, mice possessed a gradual decrease in burst size over time - mice in all groups experienced satiety, but mice drinking $\mathrm{LiCl}$ were also becoming ill and so showed a more drastic decrease over time (data not shown). For example, $\mathrm{B} 6$ controls drinking $0.12 \mathrm{M} \mathrm{NaCl}$ go from an average of 54.42 licks per burst to 33.92 licks per burst in the last 5 minutes of the trial. This is in striking contrast to B6 CTA mice that go from an average burst size of 80.13 down to 11.69 by the end of the trial. Similar results are seen in D2 mice (data not shown).

Next we compared burst size between groups (controls to CTA mice in each strain, and B6 to D2 mice), as Baird et al (2005) did in several experiments in rats. Baird and colleagues (2005) reported various results based on whether it was acquisition or generalization, and a single or multiple conditioning trial. When rats were conditioned with multiple trials ( 3 trials of access to $\mathrm{LiCl}$ ) and then subjected to generalization tests (another 3 trials with access to $\mathrm{NaCl}$ ), the experimenters saw an increase in burst count but decrease in burst size in both acquisition and generalization (Baird, J. P. et al. 2005). However, a second experiment used single-trial conditioning by giving rats access to $\mathrm{LiCl}$ for the first 8 minutes of the test trial, followed by $\mathrm{NaCl}$ for the next 8 minutes (Baird, J. P. et al. 2005). Here, the same effect of more numerous, yet smaller, bursts was seen during the $8 \mathrm{~min}$ conditioning trial, but a decrease in both burst size and number was seen during the generalization trial to $\mathrm{NaCl}$ and $\mathrm{LiCl}$ (Baird, J. P. et al. 2005). Further, no effect on burst number or size was seen when the generalization stimulus was water or sucrose (Baird, J. P. et al. 2005). In our study, we found no effect on burst size using $0.12 \mathrm{M}$ solutions, but did see a decrease in burst size in B6 and D2 CTA mice, on generalization day, in response to $0.24 \mathrm{M} \mathrm{NaCl}$. Interestingly, we saw a decrease in burst count following conditioning with $\mathrm{LiCl}$ and generalization $(\mathrm{LiCl}-\mathrm{NaCl})$ at both doses $(0.12 \mathrm{M}$ and $0.24 \mathrm{M})$. This was true for both strains, with the exception of D2 CTA mice following generalization with $0.24 \mathrm{M} \mathrm{NaCl}$. Although our results match those of Baird et al (2005) regarding generalization of a CTA, we see the opposite in conditioning, with decreased burst count. While this measure alone may suggest the presence of an aversion in the conditioning trial, it is important to note the 
lack of other microstructural changes during this trial, leading to the conclusion that this effect was due to malaise from $\mathrm{LiCl}$.

\section{Lick Rate}

We assessed both the mean primary ILI (MPI), as well as the mean intraburst ILI in all groups. As mentioned earlier, experimental manipulations such as sensory deafferentation, increased thirst, or using different taste stimuli rarely result in any change in the inherent lick frequency of mice, which is determined by a central pattern generator (Horowitz, G. P. et al. 1977; Boughter, J. D., Jr. et al. 2007b; Shires, C. B. et al. 2011). B6 mice possess a slower primary lick rate, as reflected by an average MPI around $120 \mathrm{~ms}$, whereas D2 are faster lickers, with an average MPI of about $95 \mathrm{~ms}$ (Boughter, J. D., Jr. et al. 2007b). Results from the current experiments were consistent with these earlier studies: B6 mice had a higher MPI than D2 mice, and mice in both the low- and high-dose CTA groups had unaltered MPIs on either conditioning or generalization day. Therefore, data that showed D2 taking significantly fewer licks compared to controls or to B6 mice was not due to lick rate - if D2 mice lick faster, it would be expected to see more drinking from this strain, not less. Therefore, this further suggests that the suppression in licks is due to a conditioned taste aversion, and not to the rate of licking.

Also, intra-burst ILI was shifted to significantly higher values on generalization day in both strains and in both the low- and high-dose groups. This shift in mean values was due to a higher proportion of longer-duration ILIs, or "micropauses", reflective of hesitant licking, and since these occurred on generalization day, a reliable hallmark of CTA formation and expression. Interestingly, D2 but not B6 mice had significantly elevated mean intra-burst ILIs on conditioning day, suggesting that perhaps actual CTA formation occurs during this session for D2 mice. We broke ILIs down into the following ranges: 0$159 \mathrm{~ms}, 160-319 \mathrm{~ms}, 320-999 \mathrm{~ms}$, and 1000+ ms. Most ILIs fall into this first category (Figures 3-4 to 3-5 and 3-8 to 3-9). During conditioning D2 mice possessed much larger increases in the 160-319 ms ILI range for both experiments. Since values about twice as long as the average MPI occur in this range, it is possible that this increase represents "skipped" or missed licks.

During generalization, ILI distribution was more altered: B6 CTA mice show a small increase in ILIs in the range $160-319 \mathrm{~ms}$ at $0.12 \mathrm{M} \mathrm{LiCl}$; but in response to $0.24 \mathrm{M} \mathrm{LiCl}$, the ILI distribution was wildly altered, with large increases in ILIs over 160. D2 CTA mice showed a more marked increase in ILIs from $160-319 \mathrm{~ms}$ following $0.12 \mathrm{M} \mathrm{LiCl}$, and a severe alteration of distribution following $0.24 \mathrm{M} \mathrm{LiCl}$. Again, such changes in licking behavior appear to be more accurately indicative of the presence and strength of a CTA. 


\section{Strain Comparison}

In summary, we tested C57BL/6J and DBA / 2J mice in 2 separate experiments, with different concentrations, and acquired numerous data points to be analyzed. First, it seems clear that the paradigm indeed resulted in conditioning an aversion. This was seen by decreased licks, burst count, burst size, and change in microstructure as discussed above. Tables 3-3 - 3-6 illustrate the possible strain differences in the acquisition and generalization of a CTA. D2 mice show more characteristics of a CTA during both conditioning and generalization compared to B6. However, it is unclear whether the microstructural changes seen in conditioning are purely due to acquisition, or lingering effects of malaise. A future study comparing licking microstructure in mice injected with $\mathrm{LiCl}$ and mice licking $\mathrm{LiCl}$ could offer clarity to whether our results are due to malaise or CTA acquisition. For example, if mice were injected with $\mathrm{LiCl}$ immediately before being placed in a lickometer offering water, any alterations in licking behavior would be due to the malaise. If results from such a test were different from the results presented here, it would suggest our results pointed to effects of acquisition. However, dissecting learning and memory processes occurring at this time would be a much more complex idea to test in the future.

The second point of this study was to examine possible strain differences in CTA in these particular mice. Previous studies have shown that B6 and D2 mice differ in learning and memory - and which strain performs the task better depends on the type of task, such as Morris water maze or place avoidance. Being that conditioned taste aversion is a form of classical conditioning, which is a method of learning previously discussed as resulting in strain differences between B6 and D2 mice, it would be expected to see such strain differences in CTA as well (Garcia, J. et al. 1974). In addition, the tasks D2 mice are known to out-perform B6 are indeed classical conditioning situations including place avoidance (conditioned with bites from aggressive mouse), avoidance task (lever press to avoid shock), and conditioned taste aversion (conditioned with i.p. $\mathrm{LiCl}$ ) (Bovet, D. et al. 1969; Ingram, D. K. 1982; Siegfried, B. et al. 1989; Risinger, F. O. et al. 2000; Squire, L. R. 2004). Due to the amount of analyses conducted, it is difficult to state whether there is a clear strain difference strictly based on behavior. Using the lower, $0.12 \mathrm{M}$, concentration of $\mathrm{LiCl}$, we saw equivalent mean licks, but strain differences in microstructure. Baird et al (2005) discuss the possibility that microstructural analysis is a more sensitive measure. Due to our results, we would agree such is the case, and perhaps measures such as ILI distribution and local lick rate are more indicative of not only the existence of a conditioned taste aversion, but of the strength of one. The increase in intervals between licks and slower rate of licking seem to offer more insight into the animal's behavioral response to the stimulus than simply measuring mean licks alone. For example, D2 mice exhibited longer ILIs, increased burst count and burst size, and even a decrease in volume per lick throughout our data. These measures suggest a hesistant, stop-and-go behavior of the mice. Our mice were water deprived, with minimal supplements each week, resulting in thirsty and motivated drinkers. It makes sense that mice would not halt all drinking, but instead, be more hesitant and drawn out about consuming the aversive fluid. 
Longer ILIs represent longer pauses, and a decrease in volume per lick represents a lack of solid contact between the tongue and sipper tube. All of these results point to hesistancy in responding to $\mathrm{NaCl}$ on generalization day evidence of a conditioned taste aversion.

There was also an interesting trend in the data that suggested D2 controls, drinking $0.24 \mathrm{M} \mathrm{NaCl}$, were possibly aversive to the stimulus. At a closer look, D2 mice show a striking observation - the controls, drinking $0.24 \mathrm{M} \mathrm{NaCl}$ are more similar to D2 mice being conditioned with $0.12 \mathrm{M} \mathrm{LiCl}$, and show the same sharp decrease as conditioned D2 mice in both experiments. The microstructure results show D2 controls appear to be conditioning an aversion to the higher concentration of $\mathrm{NaCl}$. During generalization, where mice are expressing the conditioned aversion, D2 controls from the high-dose group show no difference in burst count compared to conditioned mice. In fact, they show the same burst count as D2 mice conditioned with both $0.12 \mathrm{M}$ and $0.24 \mathrm{M} \mathrm{LiCl}$ (Tables 3-3 through 3-6). These observations should be considered in these results, as it is possible D2 mice can condition an aversion to $0.24 \mathrm{M} \mathrm{NaCl}$ - albeit it a weak one, as not all microstructural data points to this. Local lick rate, and other data from generalization are mixed regarding these controls. Further, due to such unexpected results, a second control group was tested with both strains, and all data remained consistent, ruling out any possibility of mistakes in testing.

Our data support the hypothesis that mice generate a CTA following a single-trial of self-administered $\mathrm{LiCl}$ at both $0.12 \mathrm{M}$ and $0.24 \mathrm{M} \mathrm{LiCl}$ concentrations based on the evidence provided in changes seen in microstructure and decreases in mean licks following a CTA. However, evidence suggests that the CTA is only expressed in a subsequent test session (in our case $24 \mathrm{~h}$ later); behavioral changes during $\mathrm{LiCl}$ licking on the conditioning day were indicative of malaise rather than learning. Secondly, our hypothesis that strain differences exist in CTA between B6 and D2 is correct, even if subtle, with D2 acquiring a stronger CTA compared to B6. This was evident in the minute-by-minute analysis where D2 mice showed significantly fewer licks compared to their controls earlier in the conditioning trial, and for a longer time in the generalization trial. This suggests the D2 mice may experience the malaise of $\mathrm{LiCl}$ sooner than $\mathrm{B} 6$ in the conditioning trial, leading to an abrupt halt of licking, and that they subsequently form a stronger CTA. The strength of the CTA can be seen in the length of time the mice avoid the stimulus in the generaliation trial, and D2 avoid it longer as was shown in the results section. Lastly, at the higher $\mathrm{LiCl}$ concentration, our hypothesis was correct that it amplified the CTA results, but mostly for B6. However, due to the borderline aversiveness to $0.24 \mathrm{M} \mathrm{NaCl}$ by $\mathrm{D} 2$ mice, and the already stronger aversion to $0.12 \mathrm{M} \mathrm{LiCl}$ compared to B6, amplification of the CTA was not as apparent in this strain. 


\title{
CHAPTER 4. IMMUNOHISTOCHEMICAL DETECTION OF C-FOS, TO DETERMINE ANATOMICAL BRAIN AREAS RESPONSIBLE FOR STRAIN DIFFERENCES SEEN IN ACQUISITION AND EXTINCTION OF A CONDITIONED TASTE AVERSION
}

\author{
Introduction
}

\section{Immediate Early Genes}

Immediate early genes (IEG) are commonly used in combination with immunohistochemistry techniques as a method of marking activated neurons. In our studies, we used c-Fos, the most commonly used, and therefore well established, IEG. Sensory stimuli, such as taste, lead to synaptic activation (Yamamoto, T. et al. 1994) of responding neurons. Once activated, a series of secondary mechanisms take place, ultimately resulting in activation of the immediate early gene, c-Fos. As an IEG, c-Fos is a transcription factor, thereby signaling the DNA to proceed with making the protein Fos. By using antibodies specifically made to recognize c-Fos, one is able to label specific sets of neurons responding to the stimulus being applied. Also, since c-Fos is a transcription factor, and resides in the nucleus, it allows for single-cell level of staining, and hence identification of activated neurons.

Some limitations do apply to using c-Fos, but most have been addressed or can be controlled for. Previously, there were technical issues concerning c-Fos antibody specificity - where the antibody would bind to homologous proteins also in the Fos family (Bures, J. et al. 1998). The antibody used in these studies, (cFos, Santa Cruz Biotechnology, Santa Cruz, California) is more specific. The second common problem researchers had with c-Fos related to use of the antibody in various species. For example, those working with avian strains were having trouble since the available antibodies were only targeted at rodents (Bures, J. et al. 1998). Again, due to advancement in the production of the c-Fos antibodies, this is no longer an issue, and is now available for a variety of species (Bures, J. et al. 1998). A third common concern is that stress has been shown to induce c-Fos (Senba, E. et al. 1997; Trneckova, L. et al. 2006; O'Mahony, C. M. et al. 2010). This makes it critical to ensure that animals are trained and handled properly in order to minimize stress. Also, in our studies, we focus on one area of the brain - the parabrachial nucleus - which is known for visceral (ingestive) and gustatory processing, and the use of Fos staining in these regions is well established (Yamamoto, T. 1993; Yamamoto, T. et al. 1993; Swank, M. W. et al. 1994; Yamamoto, T. et al. 1994; Streefland, C. et al. 1996; Navarro, M. et al. 2000; St Andre, J. et al. 2007; Haino, T. et al. 2010).

\section{Taste and Visceral-evoked c-Fos}

It has previously been shown that the amount of c-Fos elicited in the brain varies according to stimulus, method of application, and wait time before 
perfusions. In addition, several studies have investigated the possible roles of different subnuclei in the PBN (Yamamoto, T. et al. 1993; Yamamoto, T. et al. 1994; Karimnamazi, H. et al. 2002; Yamamoto, T. et al. 2009). Although gustatory and visceral information does overlap in the PBN, making it a key site for conditioned taste aversion, some areas appear to receive more of one input type than the other (see Figure 1-2). For example, the external lateral subnucleus has been established to be primarily a site of visceral input, while the central lateral and waist areas are thought to be primarily gustatory (although none of the areas are exclusively visceral or gustatory). Using dual anterograde tracers injected into the gastric-responsive and oral-responsive areas of the NST, one study showed that most of the labeled neurons were in the more rostral portion of the ELS following visceral stimulation, and following oral stimulation, most traces were seen in central medial and ventral lateral subnuclei near the caudal waist area of the PBN (Karimnamazi, H. et al. 2002). Further, the ELS of the PBN is reported to show neuronal activation representing visceral information, while other subnuclei appear to be associated with other specific taste stimuli (Yamamoto, T. et al. 1994). In a second study, it was determined that the rostral portion of the ELS was an area for general visceral input; the more caudal ELS region represented aversive behavior; the DLS was an area for ingestive behavior; and the central medial subnucleus (CMS) was a region representing the taste of $\mathrm{NaCl}$ (Yamamoto, T. et al. 2009). Lastly, it has been shown that c-Fos activation often correlates to the degree of the response in other brain regions, with an increased response resulting in increased c-Fos activation (Bennett, H. J. et al. 1998; Stephenson, C. P. et al. 1999; Arnold, J. C. et al. 2001; Deurveilher, S. et al. 2006). For example, 3 conditioning trials resulted in more c-Fos in the NST, PBN, and amygdala (Navarro, M. et al. 2000). Therefore, our hypothesis stated that if D2 acquire a stronger CTA than B6, it would be seen in increased c-Fos activation in D2 mice.

One detail in c-Fos protocols that varies is that of timing. Following taste stimulation, other studies vary perfusion times from 30 minutes to 2 hours poststimulation (Swank, M. W. et al. 1995; Navarro, M. et al. 2000; Spray, K. J. et al. 2000; Swank, M. W. 2000; Grancha, M. L. et al. 2002; Chan, C. Y. et al. 2004; Yasoshima, Y. et al. 2006; St Andre, J. et al. 2007; Travers, J. B. et al. 2007; Travers, S. P. et al. 2007). As previously described in Figures 2-1 and 2-2, results from our own lab confirm an optimal time for PBN c-Fos being $2 \mathrm{hr}$ post stimulus. As shown in Figure 2-1, it is evident that there are more stained neurons at $2 \mathrm{~h}$ following intake. This is in agreeance with the vast majority of CTA-related studies that perfuse animals $2 \mathrm{hr}$ post-stimulus in both mice (Swank, M. W. et al. 1994; Koh, M. T. et al. 2003), and rats (Swank, M. W. et al. 1995; Navarro, M. et al. 2000; Spray, K. J. et al. 2000; Grancha, M. L. et al. 2002; Tokita, K. et al. 2007).

\section{Conditioned Taste Aversion in the PBN}

The purpose of the following studies was to test the hypothesis that behavioral differences seen between B6 and D2 mice would be reflected in differing c-Fos expression patterns in the PBN. In order to accurately investigate the role of the parabrachial nucleus in conditioned taste aversion, it is necessary 
to include appropriate groups isolating each condition as much as possible. For each condition, we compared B6 and D2 to one another in their elicited c-Fos response. Table 4-1 explains all test groups and their purpose. In order to see visceral-evoked Fos, we tested two groups with i.p. injections of either $\mathrm{NaCl}$ or $\mathrm{LiCl}$. Mice receiving malaise-inducing $\mathrm{LiCl}$ were expected to show Fos primarily in the external lateral subnucleus, while mice receiving $\mathrm{NaCl}$ were expected to show little to no Fos in response to the injection. Since the method of delivery was via injection, this eliminates any gustatory activation from this test group, allowing for a result showing purely visceral stimulation.

The next set of mice was perfused following conditioning. Controls were conditioned with $0.24 \mathrm{M} \mathrm{NaCl}$, and test mice were conditioned with $0.24 \mathrm{M} \mathrm{LiCl}$. Due to the qualities of $\mathrm{LiCl}$, this group was expected to show activated neurons in response to the gustatory qualities (salty taste) and visceral qualities (malaise) of $\mathrm{LiCl}$. Control mice drinking $\mathrm{NaCl}$ were expected to show mostly a gustatory response, as $\mathrm{NaCl}$ does not elicit any malaise.

The last set of mice was perfused following generalization. Controls were conditioned with $\mathrm{NaCl}$ the day before, as well as on generalization day. CTA mice were conditioned with $\mathrm{LiCl}$ the day before, and then were tested in the lickometer with $\mathrm{NaCl}$, where the CTA generalized to this stimulus. Controls of this group were expected to show activated neurons in response to gustatory stimulation, as again, they are drinking $\mathrm{NaCl}$. However, since $\mathrm{NaCl}$ was a novel tastant during conditioning, there would be a possibility of a slight change in the amount of elicited Fos expected. Mice in this group with a conditioned taste aversion were of key interest, as their response involved gustatory stimulation of the salty taste, but behaviorally the taste would be aversive (e.g. Chapter 3 ). Visceral stimulation should not be applicable here, as no malaise is involved. Any shifts in neuronal activation in the PBN, as seen by Yamamoto (1993), would be expected in this group. (Please see methods for details on all testing.)

\section{Materials and Methods}

\section{Animals}

A total of 70 naïve male mice from inbred strains C57BL/6J (B6) and DBA2/J (D2), purchased from the Jackson Laboratory (Bar Harbor, ME), were used for all experiments. Prior to testing, mice were group-housed according to sex in standard plastic shoebox cages $(28 \times 17.5 \times 13 \mathrm{~cm})$ with ad libitum chow and water. At time of testing, mice were approximately 3-5 months old. Approximately $24 \mathrm{hr}$ prior to testing, mice were water deprived and individually housed with ad libitum chow. Animals were treated according to a protocol approved by the University of Tennessee Health Science Center Institutional Animal Care and Use Committee. Testing groups were of equal number of B6 and D2 mice for all experiments: 10 mice per group, 5 B6 and 5 D2. Groups and testing information can be seen in Table 4-2. 
Table 4-1. Test groups for immunohistochemistry.

\begin{tabular}{|c|c|}
\hline Stimulus & Type of Elicited Response \\
\hline Water & -Control group \\
\hline Visceral i.p. $\mathrm{LiCl}$ & -Visceral stimulation from induced malaise \\
\hline Visceral i.p. $\mathrm{NaCl}$ & -Visceral stimulation control, no malaise \\
\hline $\begin{array}{l}\text { Conditioning/ } \\
\text { Licking } \mathrm{NaCl}\end{array}$ & $\begin{array}{l}\text {-Gustatory stimulation } \\
\text {-Control, no conditioning }\end{array}$ \\
\hline $\begin{array}{l}\text { Conditioning/ } \\
\text { Licking LiCl }\end{array}$ & $\begin{array}{l}\text {-Gustatory stimulation } \\
\text {-Conditioning taking place } \\
\text {-Visceral input from malaise of } \mathrm{LiCl}\end{array}$ \\
\hline $\begin{array}{l}\text { Generalization } \mathrm{NaCl}- \\
\mathrm{NaCl}\end{array}$ & $\begin{array}{l}\text {-Controls for Generalization CTA group } \\
\text {-Effects of non-novel } \mathrm{NaCl} \text { exposure }\end{array}$ \\
\hline $\begin{array}{l}\text { Generalization LiCl- } \\
\mathrm{NaCl}\end{array}$ & $\begin{array}{l}\text {-Conditioned with } \mathrm{LiCl} \text {, have } \mathrm{CTA} \text {, showing aversion to } \\
\mathrm{NaCl} \\
\text {-Gustatory stimulation, possible learning and memory } \\
\text { changes, no malaise }\end{array}$ \\
\hline
\end{tabular}


Table 4-2. Summary of groups, stimulus, and method of application.

\begin{tabular}{lll}
\hline Test Group & Stimulus & Method \\
\hline Water controls & Water & Lickometer \\
Visceral NaCl & $40 \mathrm{ml} / \mathrm{kg}, 0.15 \mathrm{M} \mathrm{NaCl}$ & Intraperitoneal (i.p) \\
Visceral LiCl & $40 \mathrm{ml} / \mathrm{kg}, 0.15 \mathrm{M} \mathrm{LiCl}$ & Intraperitoneal (i.p.) \\
Conditioning controls & $0.24 \mathrm{M} \mathrm{NaCl}$ & Lickometer \\
Conditioning & $0.24 \mathrm{M} \mathrm{LiCl}$ & Lickometer \\
Generalization controls & $0.24 \mathrm{M} \mathrm{NaCl}$ (day 1) - & Lickometer \\
& $0.24 \mathrm{M} \mathrm{NaCl}$ (day 2) & \\
Generalization & $0.24 \mathrm{M} \mathrm{LiCl} \mathrm{(day} \mathrm{1)} \mathrm{-}$ & Lickometer \\
& $0.24 \mathrm{M} \mathrm{NaCl}$ (day 2 & \\
\hline
\end{tabular}

Notes: Test groups were determined in a manner that allowed analyses of effects of taste (conditioning groups), visceral (visceral groups receiving injections), $\mathrm{CTA}$ (conditioning with $\mathrm{LiCl}$ ), or a combination (generalization and conditioning with $\mathrm{LiCl}$ ). A solution of $0.15 \mathrm{M} \mathrm{LiCl}$ was selected for injections based on previous literature and concordance with behavioral data. 


\section{Testing Procedures}

\section{Solutions}

Solutions used for experiments in aim 2 include $0.24 \mathrm{M}$ and $0.15 \mathrm{M} \mathrm{NaCl}$ and $\mathrm{LiCl}$. Injections were done with $0.15 \mathrm{M} \mathrm{LiCl}$ or NaCl, at a dose of $40 \mathrm{ml} / \mathrm{kg}$. This concentration was chosen based upon previous use in CTA experiments using i.p. injections of $\mathrm{LiCl}$. Intake tests were conducted with $0.24 \mathrm{M} \mathrm{NaCl}$ or $\mathrm{LiCl}$. This concentration was chosen based on the results of aim 1, where it appeared mice conditioned a stronger CTA at this concentration compared to $0.12 \mathrm{M} \mathrm{LiCl}$.

Figure 4-1 shows a dose comparison of these stimuli at the different concentrations. For self-administration of solutions, we used lick count, body weight, and amount of $\mathrm{LiCl}$ in the $0.24 \mathrm{M}$ solution to determine dose of $\mathrm{LiCl}$ in terms of $\mathrm{mg} / \mathrm{kg}$. We also converted the amount of $\mathrm{LiCl}$ injected to $\mathrm{mg} / \mathrm{kg}$, and were able to show that the amount of $\mathrm{LiCl}$ ingested in the lickometer is comparable to the amount administered via i.p. injection.

\section{Intraperitoneal Injections}

In order to analyze activated neurons following a strictly visceral response and no taste response, animals were perfused following i.p. injections of either $\mathrm{NaCl}$ or $\mathrm{LiCl}$. Five mice from each strain received an i.p. injection dose of 40 $\mathrm{ml} / \mathrm{kg}$ of a $0.15 \mathrm{M}$ solution of $\mathrm{NaCl}$ (controls) or $\mathrm{LiCl}$. Animals receiving $\mathrm{LiCl}$ would indicate the neuronal activation in specified areas of the PBN in response to visceral malaise induced by the stimulus. Food and water were removed from all animals approximately $1 \mathrm{hr}$ prior to injection, to prevent taste activation. All mice were perfused $2 \mathrm{hrs}$ from time of injection.

\section{Lickometer}

The same self-administration conditioning paradigm used in our behavioral tests was also used in the following experiments. All animals were water deprived $24 \mathrm{hrs}$ prior to day 1 of testing, and were allowed ad libitum food throughout the experiment. The following 2 days, all mice underwent sipper tube training, where each mouse received a single, $20 \mathrm{~min}$ trial of water, to allow them to become familiar with the apparatus. All test trials in the lickometer are single, $20 \mathrm{~min}$, trials. Food was taken from the home cage approximately 1 hour before testing on day of perfusion. Table 4-2 details each group and what stimulus was administered prior to perfusion. Mice in the groups for water controls, and conditioning, were tested and perfused on day 3 of the test paradigm. Mice in the generalization groups were tested on day 4 of the paradigm. 


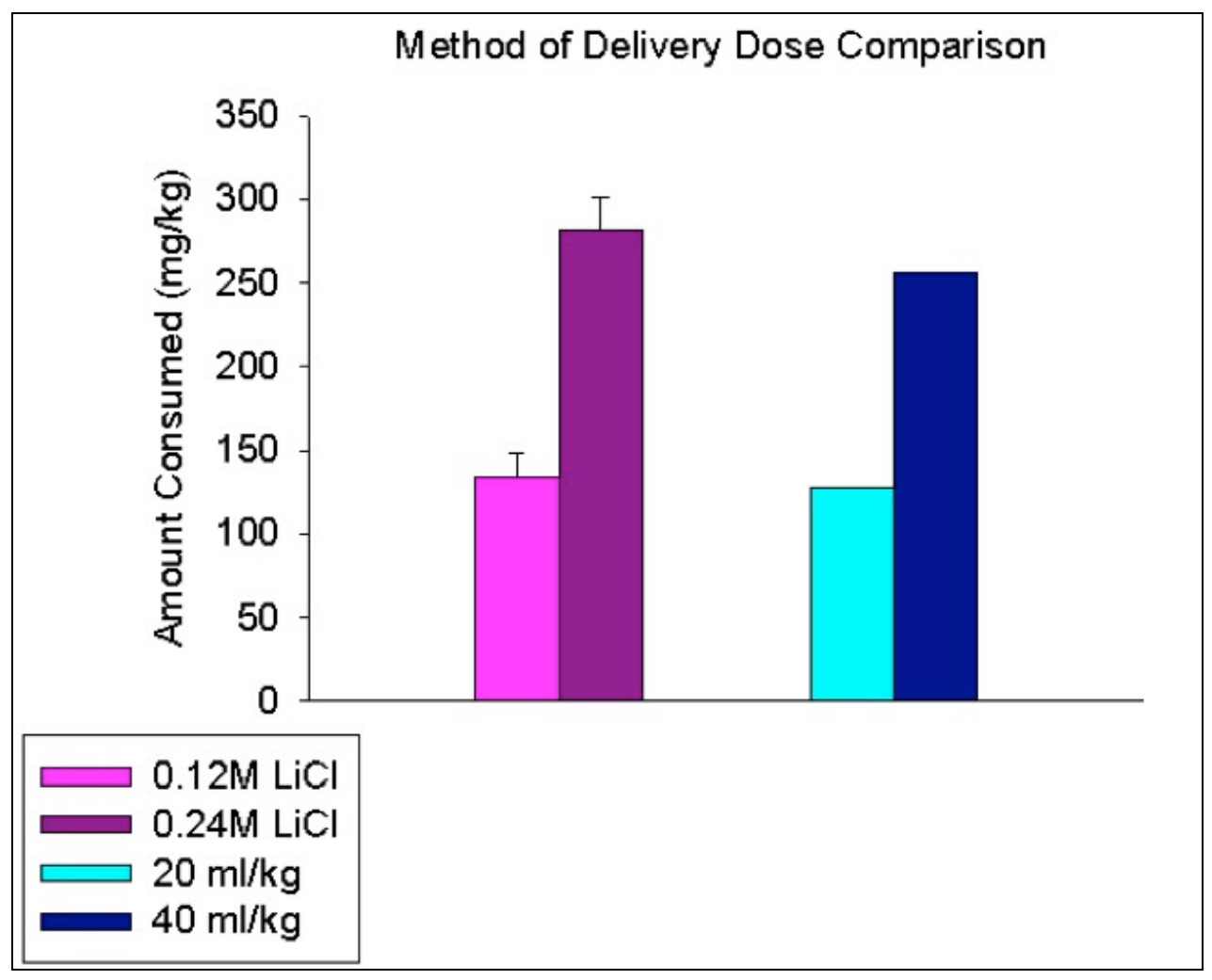

Figure 4-1. Comparison of dose $(\mathrm{mg} / \mathrm{kg})$ mice received of $0.15 \mathrm{M} \mathrm{LiCl}$ injected via i.p. and $0.24 \mathrm{M} \mathrm{LiCl}$ self-administered in lickometer. 


\section{Perfusions and Sectioning}

Following the test trial, mice were returned to their home cages, without food or water. Mice were anesthetized $2 \mathrm{hr}$ from start of testing, via i.p. injections according to previously described methods (Chapter 2). Every other section was selected for Fos protein immunohistochemistry; other sections were stained with cresyl violet to serve as morphological controls. Several sections were stained as controls, to confirm no aberrant staining from either the primary or secondary antibody. Figure 4-2 shows sample images from Fos staining (Figure 4-2A), and tissue processed in the absence of the primary antibody (Figure 4-2C) or secondary antibody (Figure 4-2D). All sections were processed as free-floating tissue at room temperature unless otherwise stated. A summary of the protocol used in these studies can be seen in Table 4-3.

\section{Analysis}

Following preparation of slides, high-resolution microscopic images were made of all sections by A.R.G (using a Leica DMRXA2 microscope equipped with a digital camera and SimplePCI imaging software). These images were given to the lab PI (J.D.B.), who chose representative sections for counting, delineated subnuclei in each section, and assigned each case a number. C-Fos labeling was then quantified blindly by A.R.G. using ImageJ software. Sections from three levels of the PBN (both left and right sides of brain) were selected for counting, for a total of 6 sections per mouse.

These sections were representative of the various key levels in the PBN: caudal, intermediate, and rostral. All sections were selected based on anatomical boundaries and previous work involving various portions of the PBN (Yamamoto, T. et al. 1993; Yamamoto, T. et al. 1994; King, V. M. et al. 2000; Paxinos, G. et al. 2001; Hashimoto, K. et al. 2009). Basically, the PBN was defined in coronal sections extending from a level where Nissl-stained cell bodies were apparent within both the medial $(\mathrm{M})$ and ventral lateral $(\mathrm{VL})$ subnuclei to the section where the brachium completely abuts the mesencephalic nucleus, which is also at about the level of the appearance of the cuneiform nucleus. This stretch occupied roughly $300 \mu \mathrm{m}$ in the mouse brain.

Figure 4-3 shows representations of sections selected for quantification. The caudal PBN receives gustatory input, and previous studies in our lab have noted gustatory-evoked c-Fos expression in the M, VLS and waist region (i.e. cells scattered across the brachium) of mice. Collectively, these subnuclei at this level can be thought of as the "gustatory" region of the PBN. Reinforcing this characterization is the fact that a preponderance of taste-responsive neurons has been isolated in this area in our electrophysiological studies (Tokita and Boughter, unpublished). Caudal sections were chosen where there was a well defined M and VLS, but caudal to the appearance of the external lateral (ELS) or dorsal lateral (DLS) subnuclei. The "intermediate" PBN includes a well-defined DLS, as well as the most rostral portion of the ELS, and is notable as a level that 

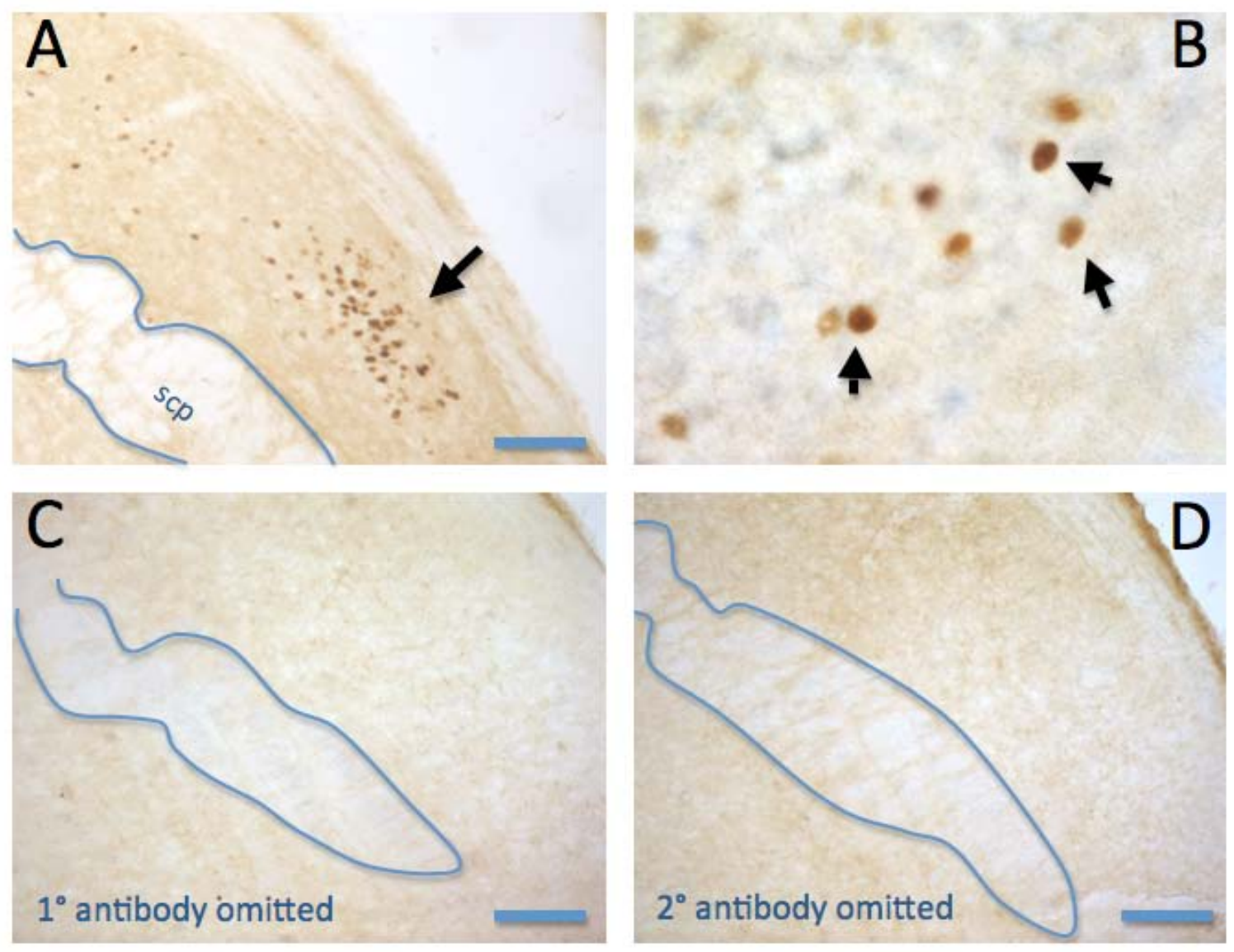

Figure 4-2. c-Fos staining and antibody controls.

Notes: A) c-Fos staining (arrow) in the lateral PBN in a mouse $2 \mathrm{~h}$ following the onset of $\mathrm{LiCl}$ consumption. B) Higher power (63X) image of c-Fos expressing nuclei (arrows). C) No staining was observed when the anti-c-Fos primary was omitted. D) No staining was observed when the biotinylated goat anti-rabbit IgG secondary was omitted. Scp = superior cerebellar peduncle, scale bars $=100$ $\mu \mathrm{m}$. 
Table 4-3. Immunohistochemistry steps for labeling c-Fos.

\begin{tabular}{ll}
\hline Histology Step & Time \\
\hline Following perfusions, brains placed in $10 \%$ formalin, stored $4^{\circ} \mathrm{C}$ & $\mathrm{N} / \mathrm{A}$ \\
Brains placed in $30 \%$ sucrose & $24-48 \mathrm{hr}$ \\
Sectioning done at $40 \mu \mathrm{m}$ on sliding microtome & $\mathrm{N} / \mathrm{A}$ \\
Floating sections placed in 0.1M PBS & $\mathrm{N} / \mathrm{A}$ \\
Wash: 0.1M PBS, 3 times & $10 \mathrm{~min}$ each \\
Pretreatment: $3 \% \mathrm{H}_{2} \mathrm{O}_{2}$ solution & $30 \mathrm{~min}$ \\
Wash: 0.1M PBS, 3 times & $10 \mathrm{~min}$ each \\
Blocking: normal goat serum solution & $1.5 \mathrm{hr}$ \\
Primary: primary antibody, c-Fos & Overnight \\
Wash: next morning, 0.1M PBS, 7 times & $6 \mathrm{~min}$ each \\
Secondary: biotin-goat-anti-rabbit & $2 \mathrm{hr}$ \\
Wash: 0.1M PBS, 3 times & $10 \mathrm{~min}$ each \\
ABC: placed in avidin biotin complex solution & $1 \mathrm{hr}$ \\
Wash: 0.1M PBS, 2 times & $10 \mathrm{~min}$ each \\
DAB: diaminobenzidine solution for staining & $5-10 \mathrm{~min}$ \\
\hline
\end{tabular}



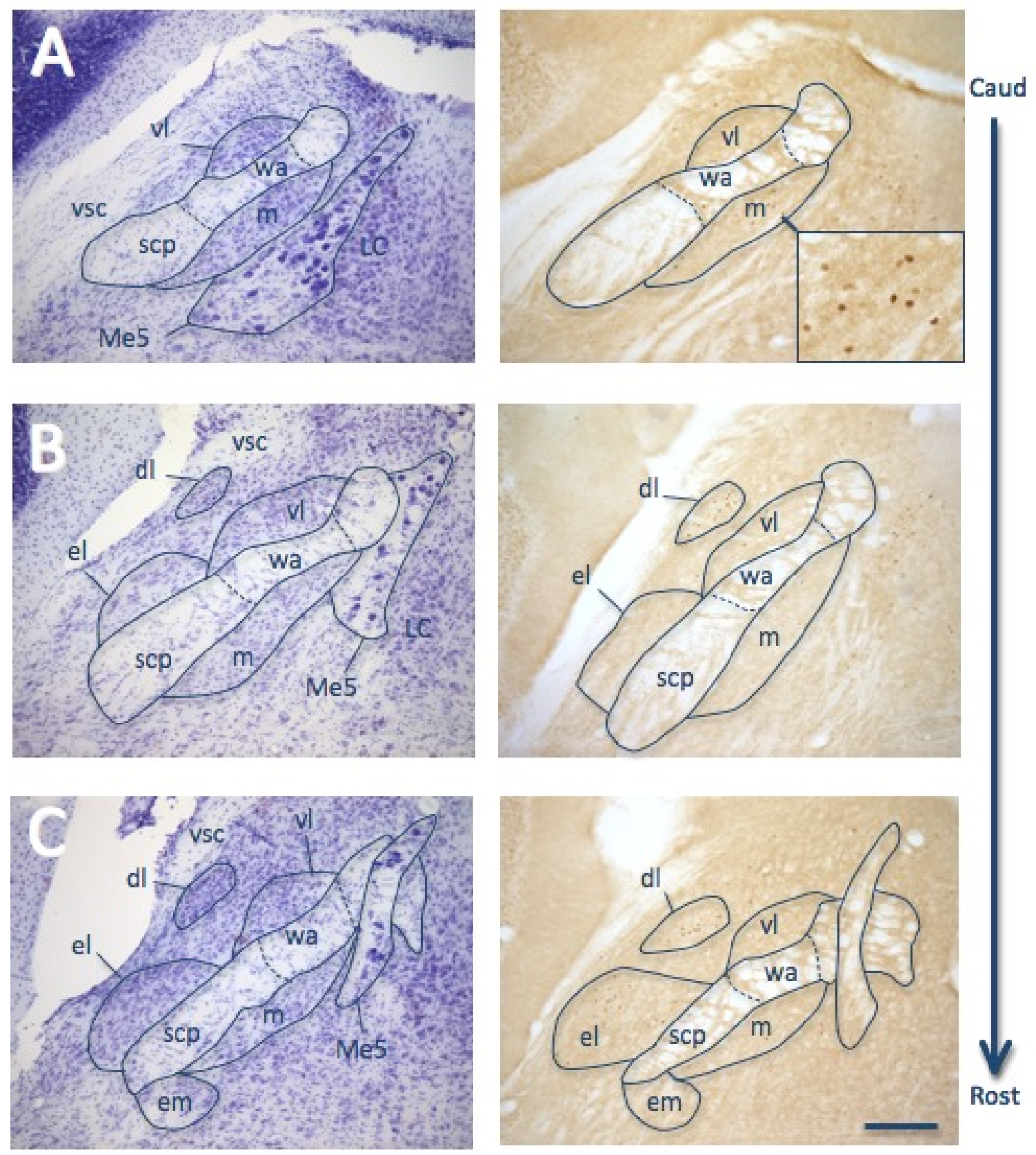

Figure 4-3. Representative sections of the PBN used for quantification.

Notes: Sections from 3 levels of the PBN of an individual B6 mouse after $\mathrm{LiCl}$ consumption. Consecutive c-Fos stained and nissl-stained sections are shown for caudal (A), intermediate (B), and rostral (C) levels. c-Fos staining is shown on the right. Nissl-stained sections used to delineate subnuclei shown on left. Inset in (A) shows c-Fos expressing nuclei from the medial $(\mathrm{m})$ subnucleus at higher magnification. Total distance from (A) left to (C) right equals $\sim 280 \mu \mathrm{m}$. Scale bar $=200 \mu \mathrm{m}$. (wa $=$ waist; $\mathrm{vl}=$ ventral lateral; $\mathrm{m}=$ medial; $\mathrm{dl}=$ dorsal lateral; $\mathrm{el}=$ external lateral; Me5 = mesencephalic; $\mathrm{LC}=$ locus coeruleus). 
receives both gustatory and visceral inputs. Prior studies in our lab demonstrate that tasting of palatable compounds such as sucrose and MSG evoke a cluster of c-Fos-positive nuclei in the DLS in the mouse. Finally, sections from the rostral PBN reflect those regions primarily involved in visceral processing, especially in the ELS. Quantifying the number of Fos labeled neurons in major subnuclei (known to have a role in gustatory and / or visceral processing) in each of these levels of the PBN, allowed a comprehensive overview of the role of the PBN in CTA acquisition and generalization.

\section{Results}

\section{Overall}

Quantification of c-Fos activation following 6 different test conditions was analyzed in the following experiments: conditioning $(\mathrm{NaCl}$ or $\mathrm{LiCl})$, generalization (CTA or controls), and visceral (i.p. $\mathrm{NaCl}$ or $\mathrm{LiCl}$ ). Counts were made in three different levels in 6 subnuclei (depending on level), as shown in Figure 4-3. A series of Figures, 4-4 to 4-8, show representative plots of where Fospositive nuclei were confirmed following several test conditions. Briefly, Fos was seen mostly in the ELS following i.p. LiCl; in the DLS following $\mathrm{NaCl}$ intake; and equally in the DLS and ELS following LiCl intake.

A quantitative summary of all Fos counts is shown in Figures 4-9 (B6) and 4-10 (D2). In both figures, all test groups of each strain are represented. The results of c-Fos quantification were analyzed statistically by test condition (visceral, conditioning, and generalization), and shown in more detail below.

\section{Visceral}

B6 and D2 mice were injected intraperitoneally with either $0.15 \mathrm{M} \mathrm{LiCl}$ or $0.15 \mathrm{M} \mathrm{NaCl}$, at a dose of $40 \mathrm{ml} / \mathrm{kg}$. Two hours post injection, mice were perfused and tissue was processed for c-Fos labeled neurons. A 2 (strain) $\times 2$ (treatment) $\mathrm{x}$ 6 (subnuclei) repeated measures ANOVA was conducted to analyze neuronal activation throughout the PBN following visceral stimulation, followed by a 2 (strain) $\times 2$ (treatment) factorial ANOVA (Figure 4-11). The repeated measures ANOVA revealed significant effects of treatment (more Fos following $\mathrm{LiCl}$ injection) $[\mathrm{F}(1,16)=12.780, p \leq .003]$, and subnucleus and treatmenet $[\mathrm{F}(5,80)=$ $65.027, p \leq .00001]$, and subnucleus, strain, and treatment $[\mathrm{F}(5,80)=4.9354, p \leq$ $.0006]$ were found.

A $2 \times 2$ factorial ANOVA in the ELS resulted in significant effects of strain $[\mathrm{F}(1,16)=9.5267, p \leq .05]$, and treatment $[\mathrm{F}(1,16)=63.198, p \leq .000001]$. D2 mice showed more c-Fos activation compared to $\mathrm{B} 6$, and $\mathrm{LiCl}$ resulted in more c-Fos than $\mathrm{NaCl}$. Bonferroni tests revealed that both $\mathrm{B} 6$ and $\mathrm{D} 2$ mice receiving $\mathrm{LiCl}$ injections had significantly more activation in the ELS compared to mice 


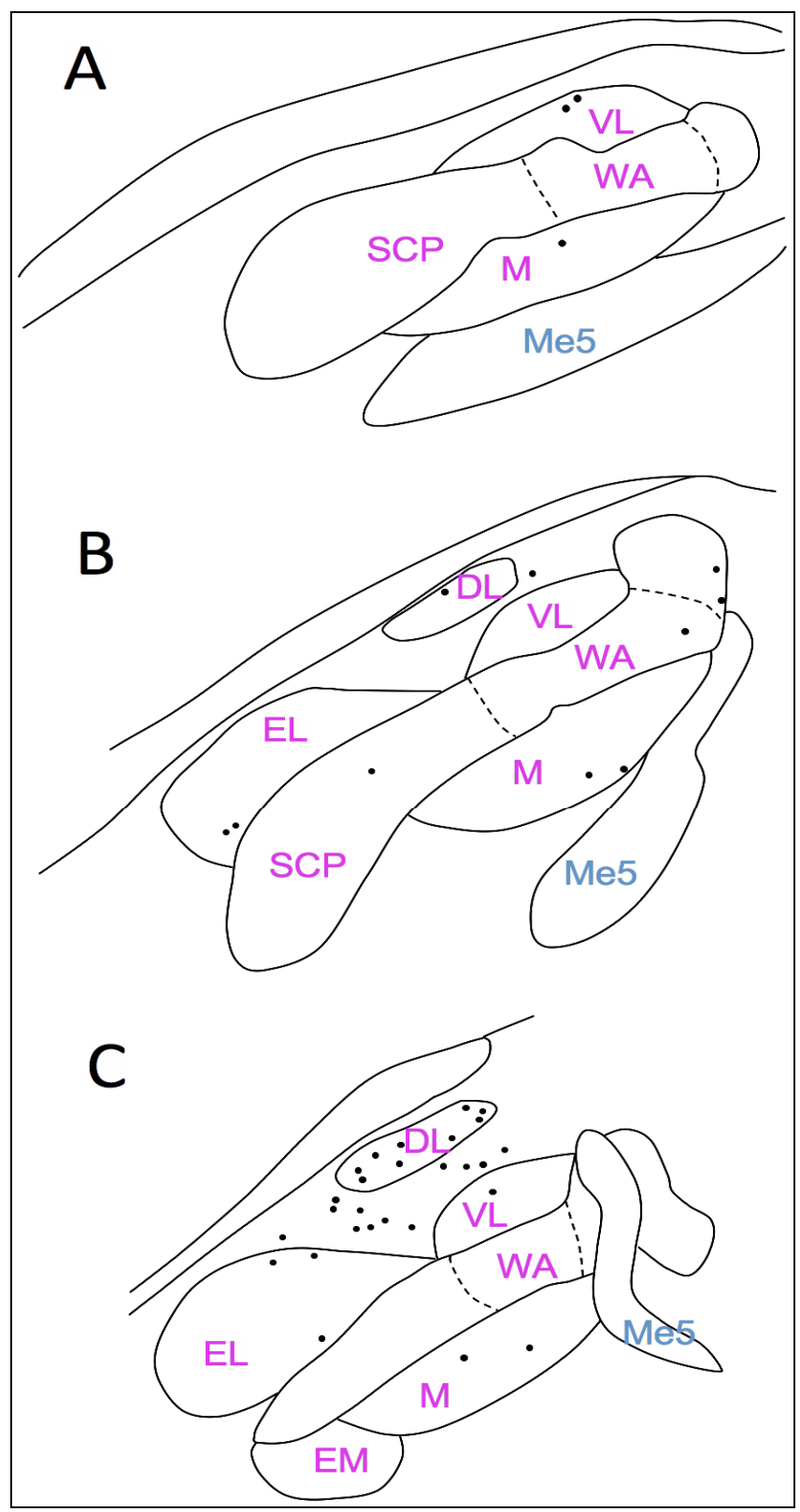

Figure 4-4. Plots of c-Fos quantification (labeling) in the PBN following water intake.

Notes: Shown are representative sections from a single B6 mouse in caudal (A), intermediate (B), and rostral (C) levels. Dots represent labeled nuclei in the PBN. Water evoked only sparse c-Fos in this mouse, including in the rostral level, in the lateral PBN and DLS (C). Abbreviations: $\mathrm{DL}=$ dorsal lateral; $\mathrm{VL}=$ ventral lateral; $\mathrm{WA}=$ waist; $\mathrm{M}=$ medial; $\mathrm{SCP}=$ superior cerebellar peduncle; $\mathrm{EL}=$ external lateral; $\mathrm{EM}=$ external medial; $\mathrm{Me} 5=$ mesencephalic tract. 


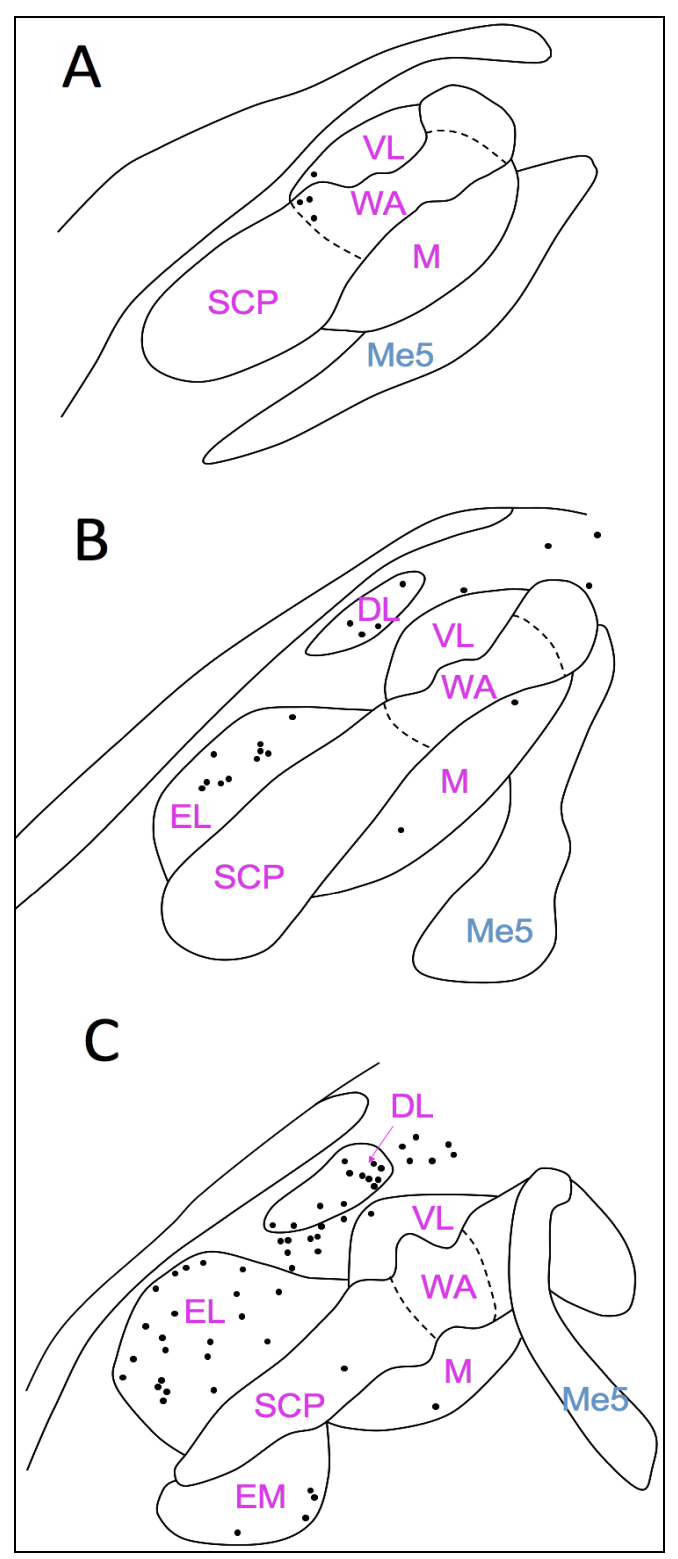

Figure 4-5. Plots of c-Fos quantification in the PBN following i.p. $\mathrm{NaCl}$.

Notes: Shown are representative sections from a single B6 mouse in caudal (A), intermediate (B), and rostral (C) levels. I.p. $\mathrm{NaCl}$ evoked c-Fos mostly in the rostral PBN, scattered laterally across the ELS and DLS, as expected following a visceral stimulation.

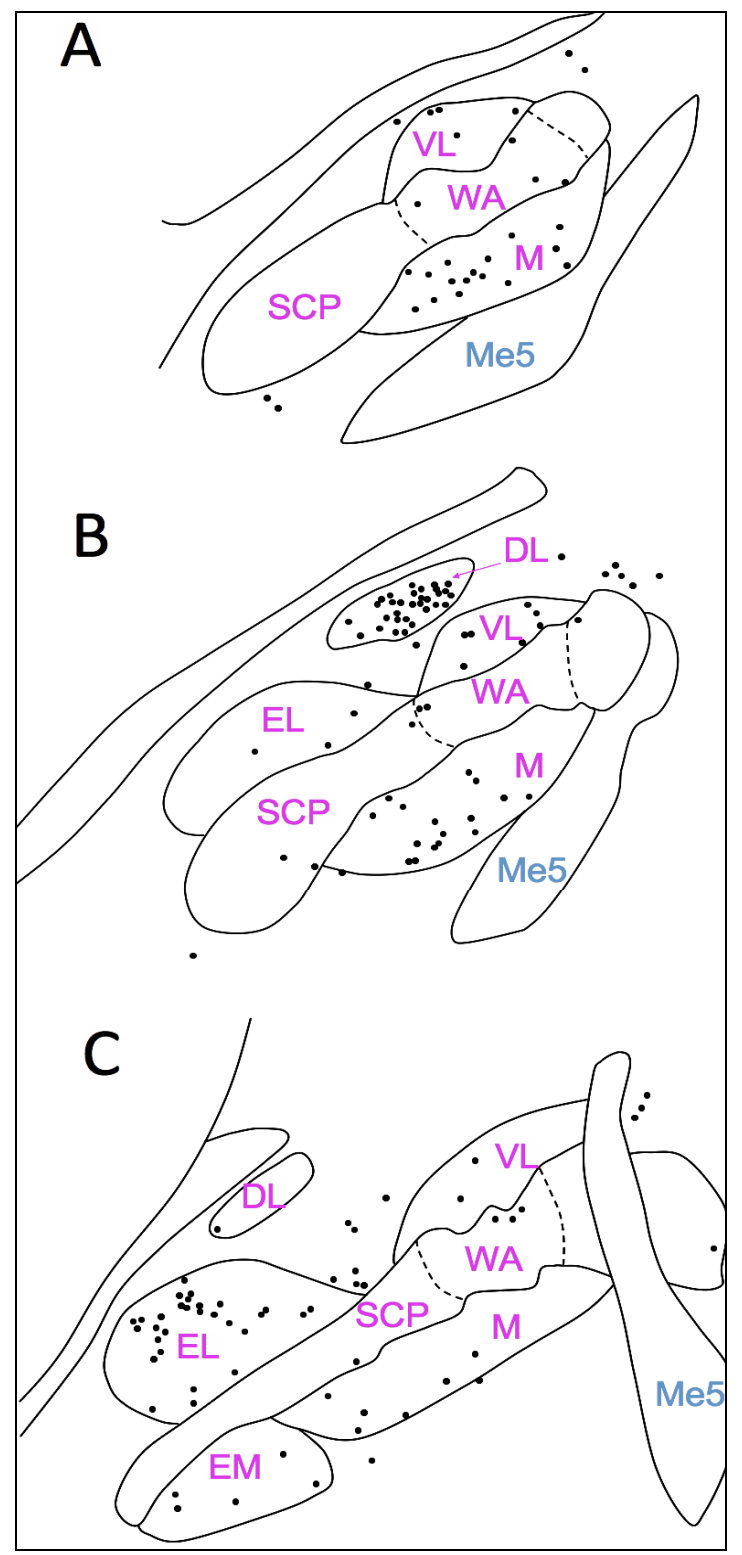

Figure 4-6. Plots of c-Fos quantification in the PBN following $\mathrm{NaCl}$ intake.

Notes: Shown are representative sections from a single B6 mouse in caudal (A), intermediate (B), and rostral (C) levels. $\mathrm{NaCl}$ intake indicated c-Fos in the DLS, an area of the PBN associated with intake, salt taste, and palatable taste. 


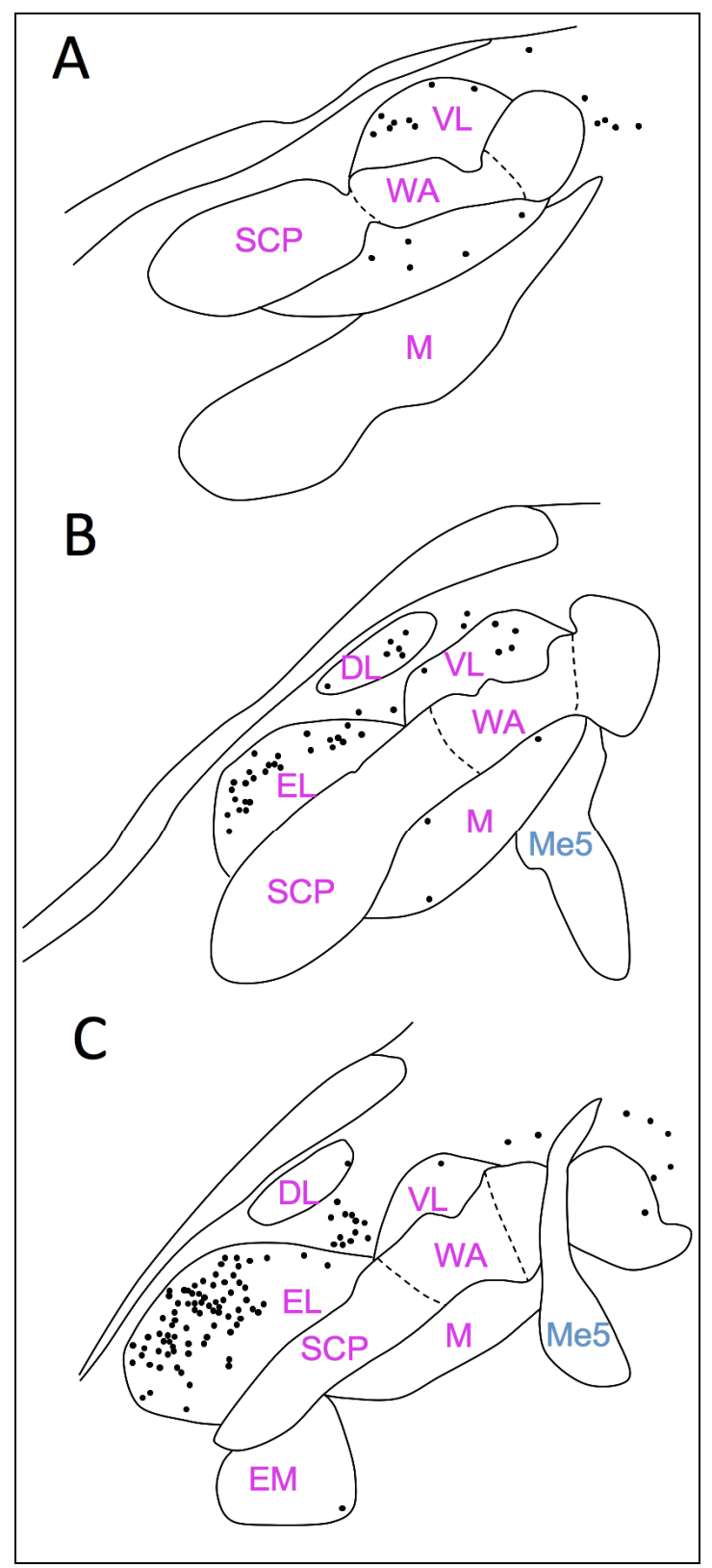

Figure 4-7. Plots of c-Fos quantification in the PBN following i.p. LiCl.

Notes: Shown are representative sections from a single B6 mouse in caudal $(\mathrm{A})$, intermediate $(\mathrm{B})$, and rostral (C) levels. Following i.p. $\mathrm{LiCl}$, Heavy c-Fos was detected in the rostral PBN, in the ELS, indicative of the visceral effects (malaise) of $\mathrm{LiCl}$.

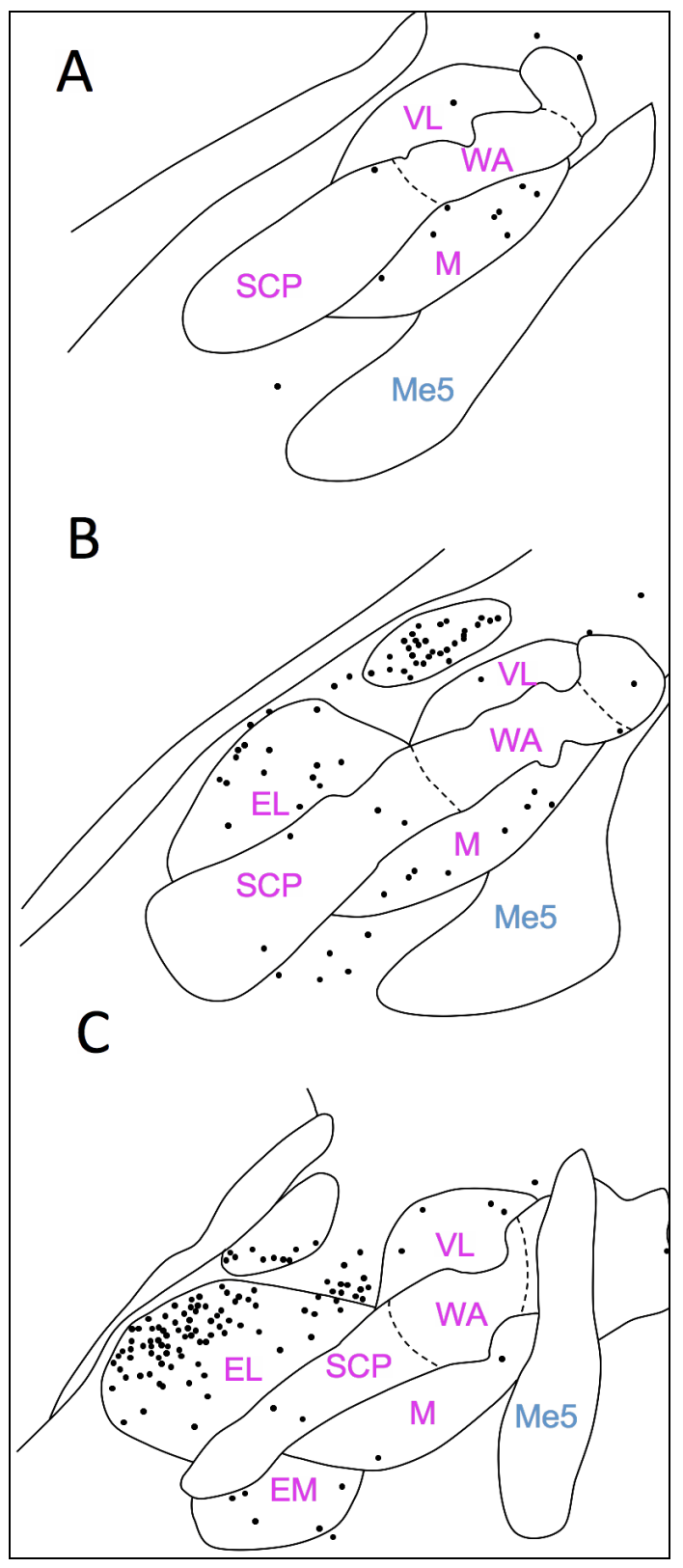

Figure 4-8. Plots of c-Fos quantification in the PBN following LiCl intake.

Notes: Shown are representative sections from a single B6 mouse in caudal (A), intermediate (B), and rostral (C) levels. Following $\mathrm{LiCl}$ intake, heavy c-Fos was detected in both the DLS and ELS - indicative of both the taste and visceral effects of $\mathrm{LiCl}$. 


\section{Figure 4-9. Summary of c-Fos quantification for B6 mice.}

Notes: Average number of Fos-positive neurons for each subnucleus in the PBN. Mice were perfused following intake of Water, $\mathrm{NaCl}$, or LiCl. Visceral Fos was determined following i.p. injections of $\mathrm{NaCl}$ or $\mathrm{LiCl}$. $\mathrm{NaCl}-\mathrm{NaCl}$ (controls) and $\mathrm{LiCl}-\mathrm{NaCl}$ (CTA) represent generalization groups that were conditioned either with $\mathrm{NaCl}$ (controls) or LiCl (CTA) and perfused on day 4 following $\mathrm{NaCl}$. Increases in activation are apparent in the medial and dorsal lateral subnuclei following $\mathrm{LiCl}, \mathrm{NaCl}$, and $\mathrm{NaCl}-\mathrm{NaCl}$ intake. The ELS shows clear increased activation following $\mathrm{LiCl}$ intake and injections. 


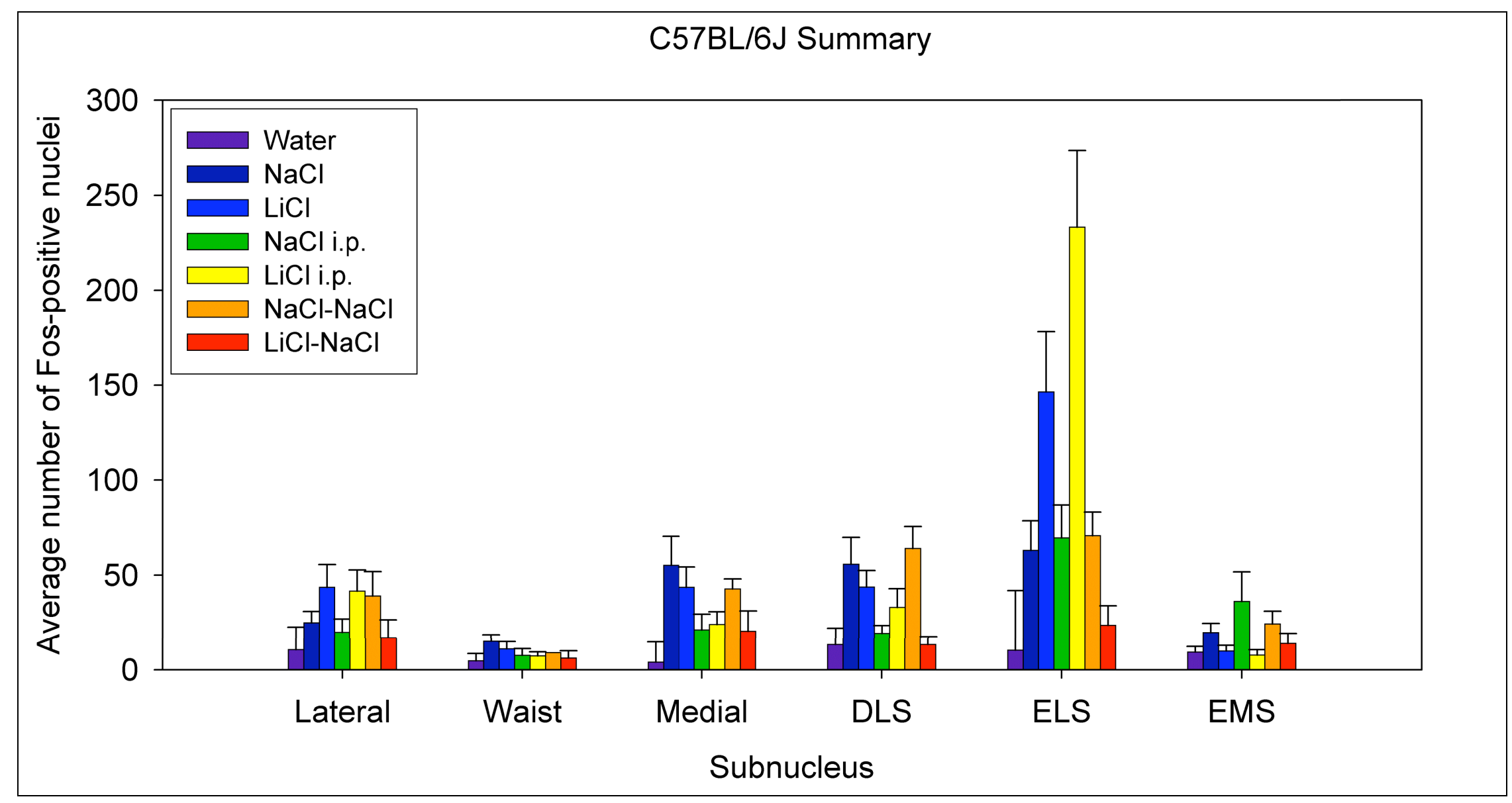




\section{Figure 4-10. Summary of c-Fos quantification for D2 mice.}

Notes: Average number of Fos-positive neurons for each subnucleus in the PBN. Mice were perfused following intake of Water, $\mathrm{NaCl}$, or $\mathrm{LiCl}$. Visceral Fos was determined following i.p. injections of $\mathrm{NaCl}$ or $\mathrm{LiCl}$. $\mathrm{NaCl}-\mathrm{NaCl}$ (controls) and $\mathrm{LiCl}-\mathrm{NaCl}$ (CTA) represent generalization groups that were conditioned either with $\mathrm{NaCl}$ (controls) or $\mathrm{LiCl}$ (CTA) and perfused on day 2 following $\mathrm{NaCl}$. 


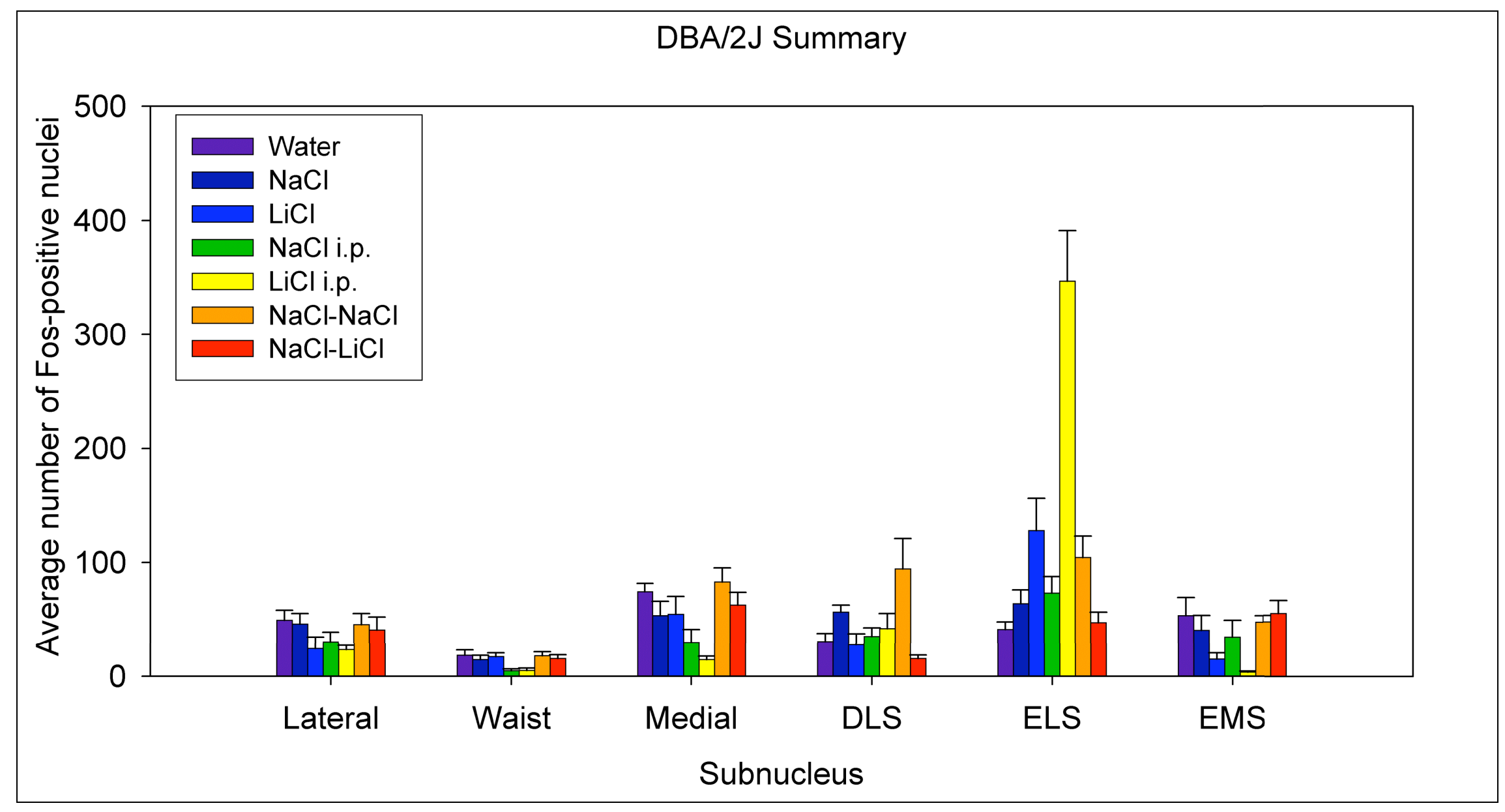




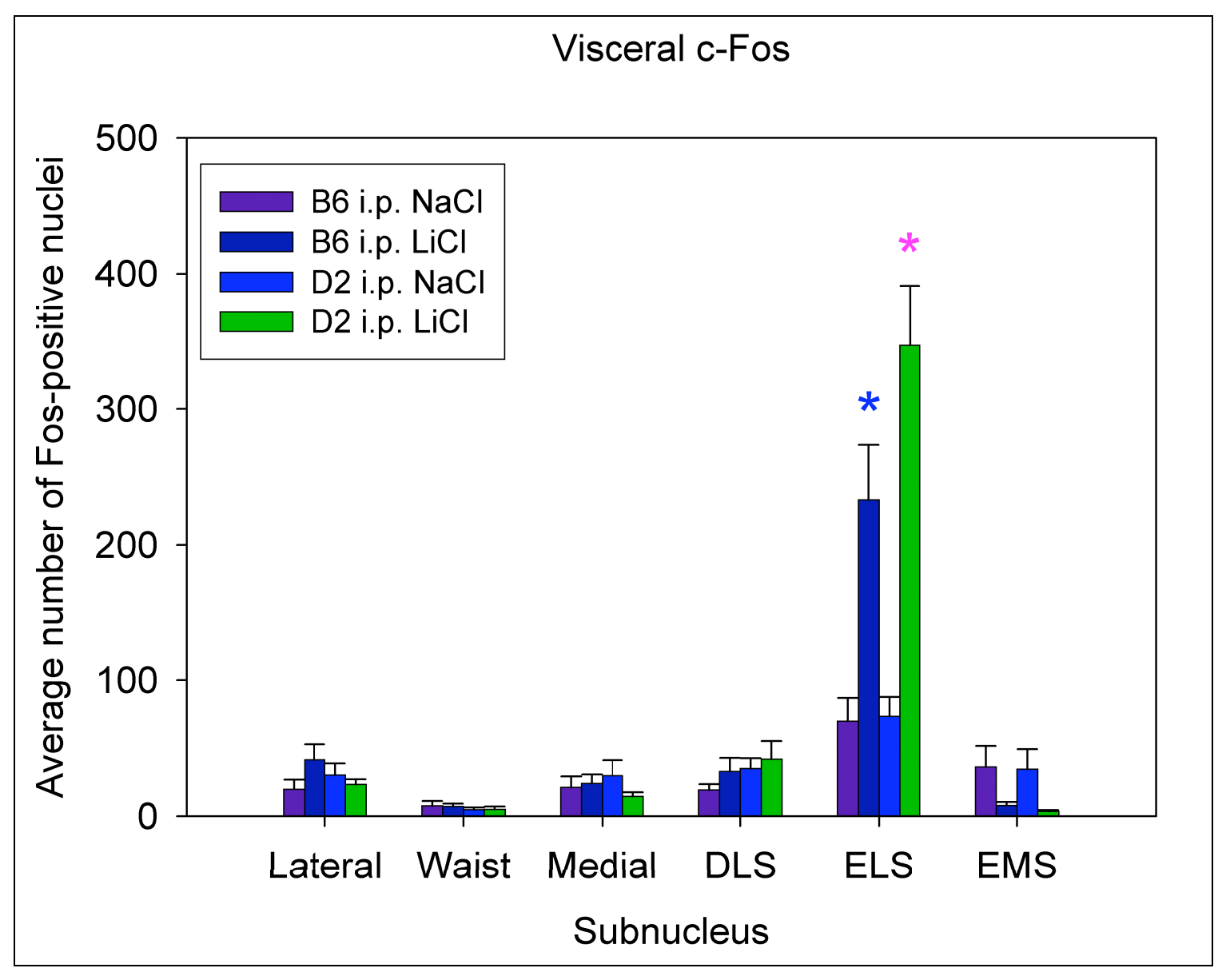

Figure 4-11. Comparisons of c-Fos expression following intraperitoneal injections of $\mathrm{NaCl}$ or $\mathrm{LiCl}$.

Notes: Average number of c-Fos positive neurons in various subnuclei of the PBN following i.p. injections of either $\mathrm{LiCl}$ or $\mathrm{NaCl}(40 \mathrm{ml} / \mathrm{kg}$ of $0.15 \mathrm{M}$ solutions) in $\mathrm{B} 6$ and D2 mice. Both B6 and D2 mice receiving $\mathrm{LiCl}$ injections expressed significantly more c-Fos activation in the ELS (B6, $p \leq .03 ; \mathrm{D} 2, p \leq .00007)$ compared to their respective controls. Blue asterisk marks significance between test groups, within B6 (ELS, $p \leq .004)$; pink asterisk marks significance between test groups, within D2 (ELS, $p \leq .00002)$. 
receiving $\mathrm{NaCl}$ injections (B6, $p \leq .004 ; \mathrm{D} 2, p \leq .00002)$. In the external medial subnucleus (EMS), there was also a significant effect of treatment $[\mathrm{F}(1,16)=$ $4.9004, p \leq .04]$, with more Fos following $\mathrm{NaCl}$ injections.

\section{Conditioning}

On day 3 of testing, B6 and D2 mice were given access to either $0.24 \mathrm{M}$ $\mathrm{NaCl}$, or $0.24 \mathrm{M} \mathrm{LiCl}$ to condition an aversion to the salty taste of the stimulus. It was expected that c-Fos activation in response to $\mathrm{NaCl}$ consumption would be predominantly a gustatory response. A 2 (strain) $\times 2$ (treatment) $\times 6$ (subnuclei) repeated measures ANOVA was conducted to analyze neuronal activation throughout the PBN following conditioning (controls conditioned with $0.24 \mathrm{M}$ $\mathrm{NaCl}$; CTA mice conditioned with $0.24 \mathrm{M} \mathrm{LiCl}$ ), followed by a 2 (strain) $\times 2$ (treatment) factorial ANOVA (Figure 4-12).

The repeated measures ANOVA revealed a significant effect of subnucleus $[\mathrm{F}(5,95)=34.569, p \leq .00001]$ and an interaction of subnucleus and treatment $(\mathrm{NaCl}$ or $\mathrm{LiCl}$ intake) $[\mathrm{F}(5,95)=11.109, p \leq .00001]$.

The $2 \times 2$ factorial analysis revealed a significant effect of treatment in the $\operatorname{DLS}[\mathrm{F}(1,19)=4.4190, p \leq .05]$, ELS $[\mathrm{F}(1,19)=9.3251, p \leq .006]$, and $\operatorname{EMS}[\mathrm{F}(1,19)=$ $5.0603, p \leq .04]$. These effects were due to more Fos following $\mathrm{NaCl}$ in the DLS and EMS, and more Fos following $\mathrm{LiCl}$ in the ELS.

\section{Generalization}

On day 4 testing, mice were allowed access to drinking $0.24 \mathrm{M} \mathrm{NaCl}$. Mice with a conditioned taste aversion were conditioned the previous day with $0.24 \mathrm{M}$ $\mathrm{LiCl}$, and controls with $0.24 \mathrm{M} \mathrm{NaCl}$. A 2 (strain) x 2 (treatment) x 6 (subnuclei) repeated measures ANOVA was conducted to analyze neuronal activation throughout the PBN following generalization (the previous day, controls were conditioned with $\mathrm{NaCl}$; CTA mice were conditioned with $\mathrm{LiCl}$ ), followed by a 2 (strain) x 2 (treatment) factorial ANOVA (Figure 4-13).

The repeated measures ANOVA revealed significant effects of strain (more activation in D2 mice) $[\mathrm{F}(1,17)=11.144, p \leq .004]$, treatment (more activation in controls compared to CTA mice) $[\mathrm{F}(1,17)=13.344, p \leq .002]$, and subnucleus $[\mathrm{F}(5,85)=15.425, p \leq .000001]$, as well as a significant interaction of subnucleus and treatment $[\mathrm{F}(5,85)=9.2278, p \leq .000001]$. Bonferroni comparisons showed no significant differences between D2 controls and D2 CTA mice, or between B6 controls and B6 CTA mice, at any subnucleus.

A $2 \times 2$ analysis of the each subnucleus revealed several effects throughout the PBN. A strain effect was found in the waist $[\mathrm{F}(1,17)=6.9747, p \leq .02]$, medial 


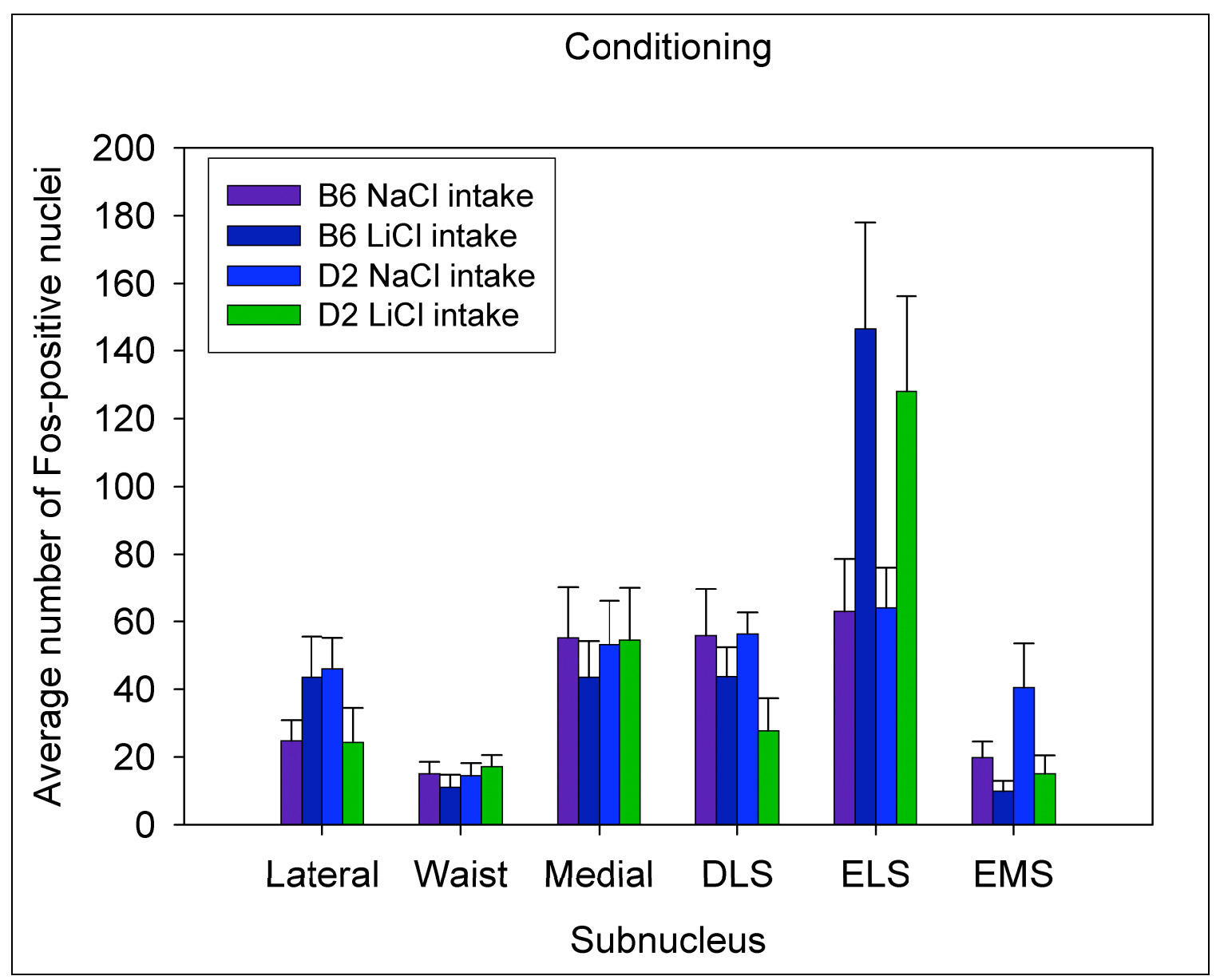

Figure 4-12. Comparisons of c-Fos expression following $\mathrm{NaCl}$ or $\mathrm{LiCl}$ intake in $\mathrm{B} 6$ and $\mathrm{D} 2$ mice.

Notes: Average number of Fos positive neurons following conditioning with either $0.24 \mathrm{M} \mathrm{NaCl}$ or $0.24 \mathrm{M} \mathrm{LiCl}$. Overall, there was significantly more Fos in the DLS and EMS following $\mathrm{NaCl}$ intake, and more Fos in the ELS following $\mathrm{LiCl}$ intake. No strain effects were found for conditioning. 


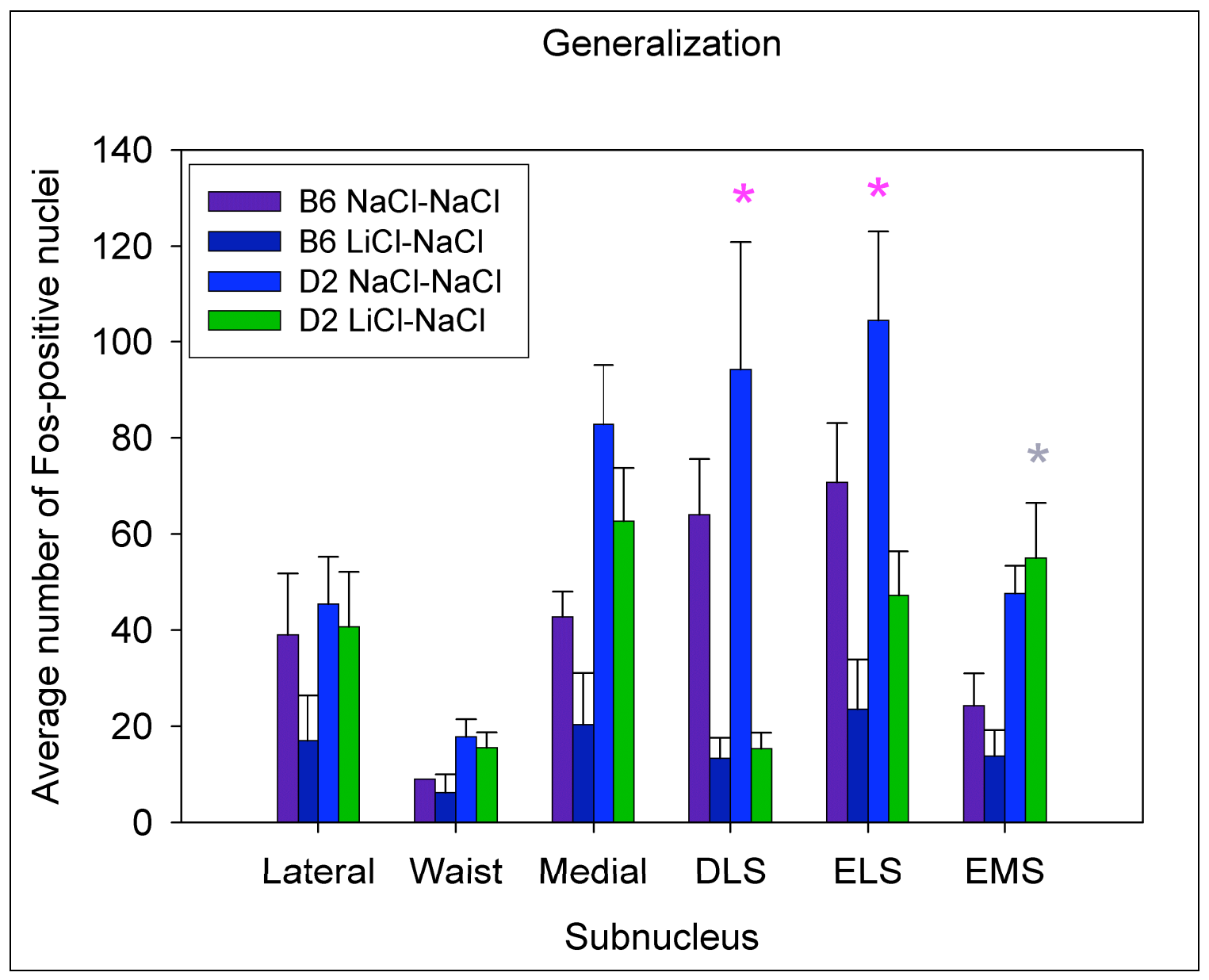

Figure 4-13. Comparison of c-Fos expression following generalization.

Notes: Comparison of c-Fos expression following generalization in B6 and D2 mice. Overall, more activation was seen following controls $(\mathrm{NaCl}-\mathrm{NaCl})$ compared to CTA ( $\mathrm{LiCl}-\mathrm{NaCl})$ mice, as well as in $\mathrm{D} 2$ compared to $\mathrm{B} 6$ miceD2 controls exhibited more c-Fos activation in the DLS and ELS compared to D2 CTA mice. Pink asterisks mark significance between test groups, within the D2 strain (DLS, $p \leq .004$; ELS, $p \leq .03$ ). B6 mice were not shown to significantly differ in any subnucleus when comparing controls to CTA mice. Gray asterisk marks significant difference between B6 and D2 CTA groups in the EMS $(p \leq .009)$. 
$[\mathrm{F}(1,17)=13.998, p \leq .001]$, external lateral $[\mathrm{F}(1,17)=4.8832, p \leq .04]$, and external medial $[\mathrm{F}(1,17)=14.994, p \leq .001]$ subnuclei. All of these effects were due to higher activation in these subnuclei in D2 mice compared to B6 mice. There was an effect of treatment found in the DLS $[\mathrm{F}(1,17)=21.699, p \leq .0002]$, and ELS $[\mathrm{F}(1,17)=16.227, p \leq .0009]$, driven by more Fos in control mice (previously conditioned with $\mathrm{NaCl}$ ) compared to CTA mice (previously conditioned with $\mathrm{LiCl}$ ). Bonferroni comparisons further revealed significantly more Fos in the DLS and ELS in D2 controls compared to D2 CTA mice (DLS, $p \leq .004$; ELS, $p \leq .03$ ). Also, D2 CTA mice showed significantly more Fos in the EMS compared to B6 CTA mice $(p \leq .009)$.

\section{Conditioning to Generalization}

A previous study done in rats has shown that following a CTA, a shift in neuronal activation can be seen, as the previously palatable substance (saccharin), is then considered unpalatable (Yamamoto, T. 1993). In order to investigate whether this occurred in our experiments, we compared the number of Fos positive neurons from conditioning day to the counts on generalization day for each strain. A 2 (test day, conditioning or generalization) $\times 2$ (treatment (controls $/ \mathrm{NaCl}$ or $\mathrm{CTA} / \mathrm{LiCl}) \times 6$ (subnuclei) repeated measures ANOVA was conducted, followed by a 2 (test day) $\times 2$ (treatment) factorial ANOVA for each subnucleus. B6 data is shown in Figure 4-14 and D2 data is shown in Figure 4-15.

The repeated measures ANOVA showed a significant effect of subnucleus $[\mathrm{F}(5,85)=27.944, p \leq .000001]$, as well as significant interactions of subnucleus and test day $[\mathrm{F}(5,85)=6.0747, p \leq .00007]$, subnucleus and treatment $[\mathrm{F}(5,85)=$ $3.5184, p \leq .006]$, and subnucleus, test day, and treatment $[\mathrm{F}(5,85)=7.8520, p \leq$ $.000001]$.

As shown in Figure 4-14, the $2 \times 2$ analysis for B6 mice revealed a significant effect of treatment $[\mathrm{F}(1,17)=10.212, p \leq .005]$. Bonferroni tests showed a significant difference between controls and CTA mice following generalization $(p \leq .02)$. In the ELS, a significant effect of test day $[\mathrm{F}(1,17)=7.1875, p \leq .02]$, and an interaction between test day and treatment $[\mathrm{F}(1,17)=9.2540, p \leq .007]$ was found. Bonferroni tests revealed a significant difference in CTA mice from conditioning to generalization $(p \leq .002)$.

In Figure 4-15, a 2 × 2 analysis for D2 mice showed a significant effect of treatment in the DLS $[\mathrm{F}(1,19)=16.852, p \leq .0006]$. Bonferroni comparisons revealed generalization controls had significantly more Fos in the DLS compared to generalization CTA mice $(p \leq .003)$. A significant interaction of test day and treatment was found in the ELS $[\mathrm{F}(1,19)=10.555, p \leq .004]$, with significantly more Fos following conditioning with $\mathrm{LiCl}$ compared to generalization the following day (same mice) $(p \leq .03)$. Finally, a significant effect of test day was 


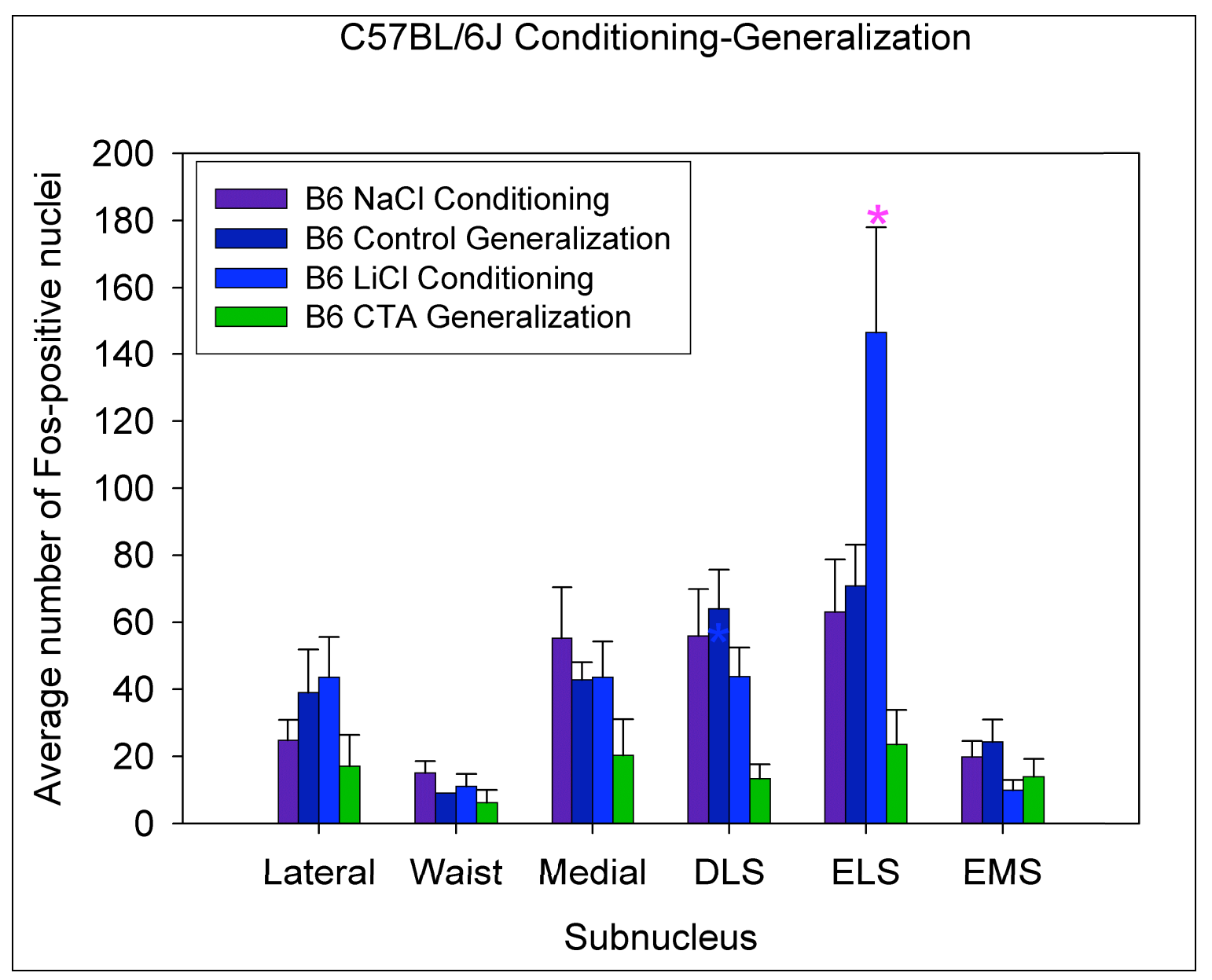

Figure 4-14. Amount of c-Fos expression on conditioning day compared to generalization day in $\mathrm{C} 57 \mathrm{BL} / 6 \mathrm{~J}$ mice.

Notes: Comparisons of c-Fos expression in B6 mice from conditioning day to generalization day in controls and CTA mice. In the DLS, generalization controls had significantly more Fos activation compared to generalization CTA mice ( $p \leq$ .02 , blue asterisk). In the ELS, there was significantly more Fos following conditioning with $\mathrm{LiCl}$ compared to generalization the following day (in same mice) ( $p \leq .002$, pink asterisk). 


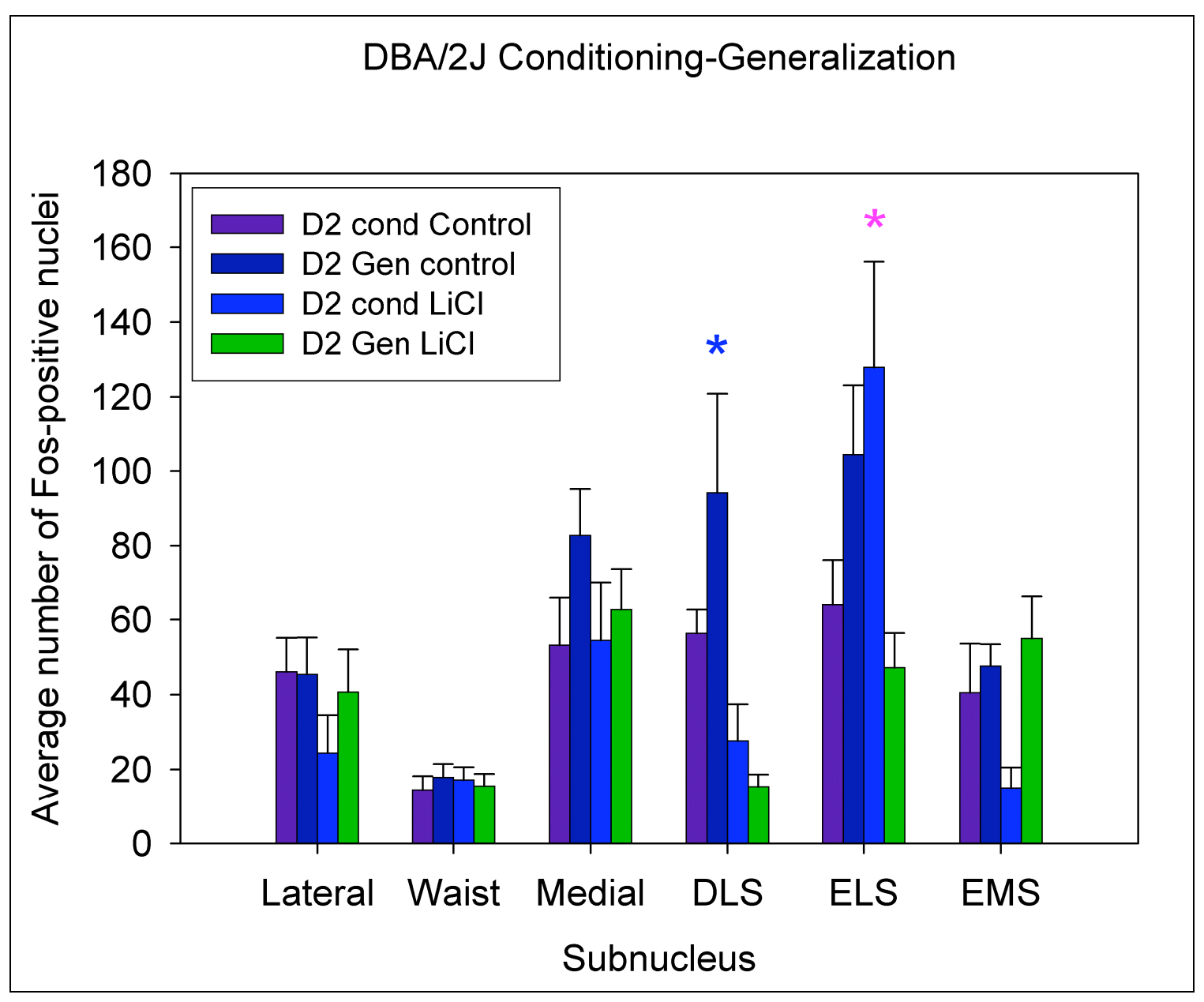

Figure 4-15. Amount of c-Fos expression on conditioning day compared to generalization day in DBA/2J mice.

Notes: Comparisons of c-Fos expression from conditioning (day 3, $\mathrm{LiCl}$ ) and generalization (day 4, NaCl) in controls and CTA D2 mice. Following generalization, significantly more Fos was found in the DLS in controls compared to CTA mice ( $p \leq .003$, blue asterisk). In the ELS, significantly more Fos was seen following conditioning with $\mathrm{LiCl}$ compared to generalization the following day (in same mice) ( $p \leq .03$, pink asterisk). 
found in the EMS $[\mathrm{F}(1,19)=5.6674, p \leq .03]$, with more Fos following generalization compared to conditioning.

\section{Total Fos}

A final analysis was conducted to compare overall, total Fos labeling between B6 and D2 mouse strains (Figure 4-16). For overall Fos counts, comparisons were made via a one-way ANOVA for each analysis. No strain differences were discovered following i.p. $\mathrm{NaCl}$ or $\mathrm{LiCl}$, or conditioning with $\mathrm{NaCl}$ or LiCl. Total Fos counts differed between B6 and D2 controls following generalization, however the finding was determined not significant via a Bonferroni post hoc test, although close $(p=.05)$. Lastly, as was initially hypothesized based on learning and memory differences between B6 and D2 mice, a significant strain difference was found between B6 and D2 CTA mice following generalization $[F(1,10)=6.02, p \leq .03]$, with $\mathrm{D} 2$ exhibiting significantly more Fos overall than B6.

\section{Discussion}

Anatomical studies are frequently used to determine areas, or populations, of neurons that respond to specific stimuli. For example, there have been a number of taste studies that have used c-Fos activation as a marker to determine where neurons are responding to a stimulus (Yamamoto, T. 1993; Yamamoto, T. et al. 1993; Houpt, T. A. et al. 1994; Swank, M. W. et al. 1994; Yamamoto, T. et al. 1994; Houpt, T. A. et al. 1996; Streefland, C. et al. 1996; Chan, C. Y. et al. 2004; Koh, M. T. et al. 2005; St Andre, J. et al. 2007; Yamamoto, T. et al. 2009; Haino, T. et al. 2010). In the studies presented here, we used immunohistochemical techniques to label the immediate early gene, c-Fos, as a method of identifying neurons responding to either a visceral stimulus, or a stimulus presented in a lickometer. In addition, this method was also used to compare two inbred mouse strains at the neuronal level for genetic differences underlying aspects of conditioned taste aversion. Figure 4-17 shows a comparison of our results to the hypothesis proposed by Yamamoto (1993) (based on his own work) where convergence of visceral (gastrointestinal) and gustatory stimulation may occur (Figure 1-2). Following i.p. injection of $\mathrm{LiCl}$, in both strains we generally saw heavy c-Fos labeling in the ELS, mainly in the rostral portion and a smaller amount in the caudal region. There was also very light activation in the DLS. This pattern of labeling is similar to that proposed by Yamamoto (1993). Following ingestion of $\mathrm{LiCl}$, we saw heavy activation in the rostral ELS (due to malaise), a smaller amount in the caudal ELS, and a small amount in the DLS (positive hedonics, due to salty taste of $\mathrm{LiCl}$ ). Lastly, following generalization, where mice showed an aversion to $\mathrm{NaCl}$, we saw decreased activation in the ELS (no malaise on this test day) and a decrease in the DLS. The decrease in the DLS may represent decreased palatability of $\mathrm{NaCl}$. These results appear to vary slightly from the idea that aversion would be represented by c-Fos in the PBN, as we actually see a decrease in this region. 
Figure 4-16. Total c-Fos amounts in the PBN in B6 and D2 mice following visceral, conditioning, and generalization testing.

Notes: Results of total number of Fos-positive nuclei counted in B6 and D2 mice following test conditions. A) Total Fos in control mice following i.p. $\mathrm{NaCl}$. B) Total Fos in control mice following $\mathrm{NaCl}$ intake/ conditioning. C) Total Fos in control mice (conditioned with $\mathrm{NaCl}$ ) following generalization. D) Total Fos in mice following i.p. LiCl. E) Total Fos in mice following intake/ conditioning with $\mathrm{LiCl}$. No strain differences were found in test groups shown in panels A-E. F) Total Fos in CTA mice following generalization. This is only condition in which a significant difference was found between strains in amount of overall Fos in the PBN. D2 mice show a significantly higher number of activated neurons in the PBN compared to B6. 


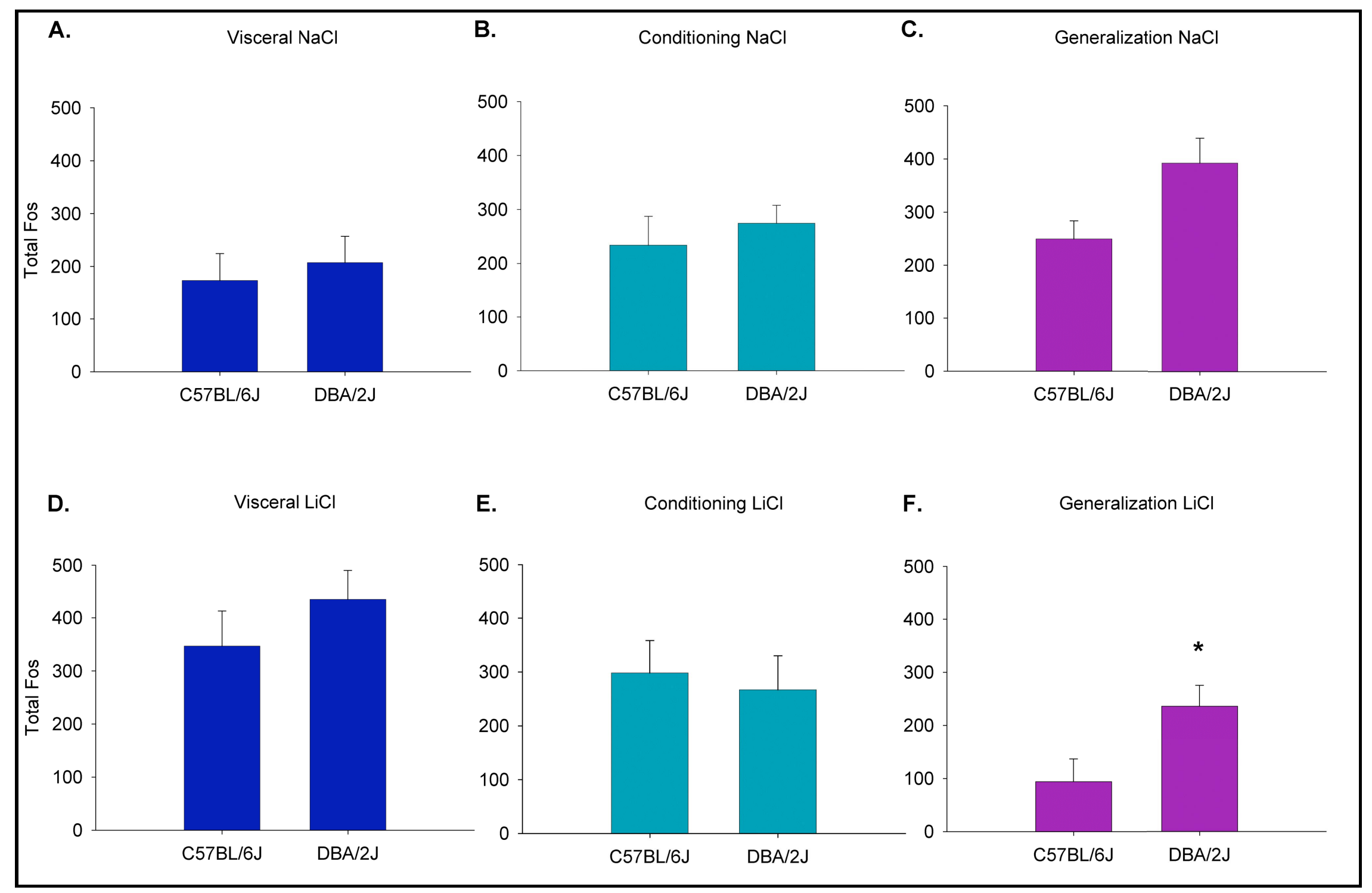




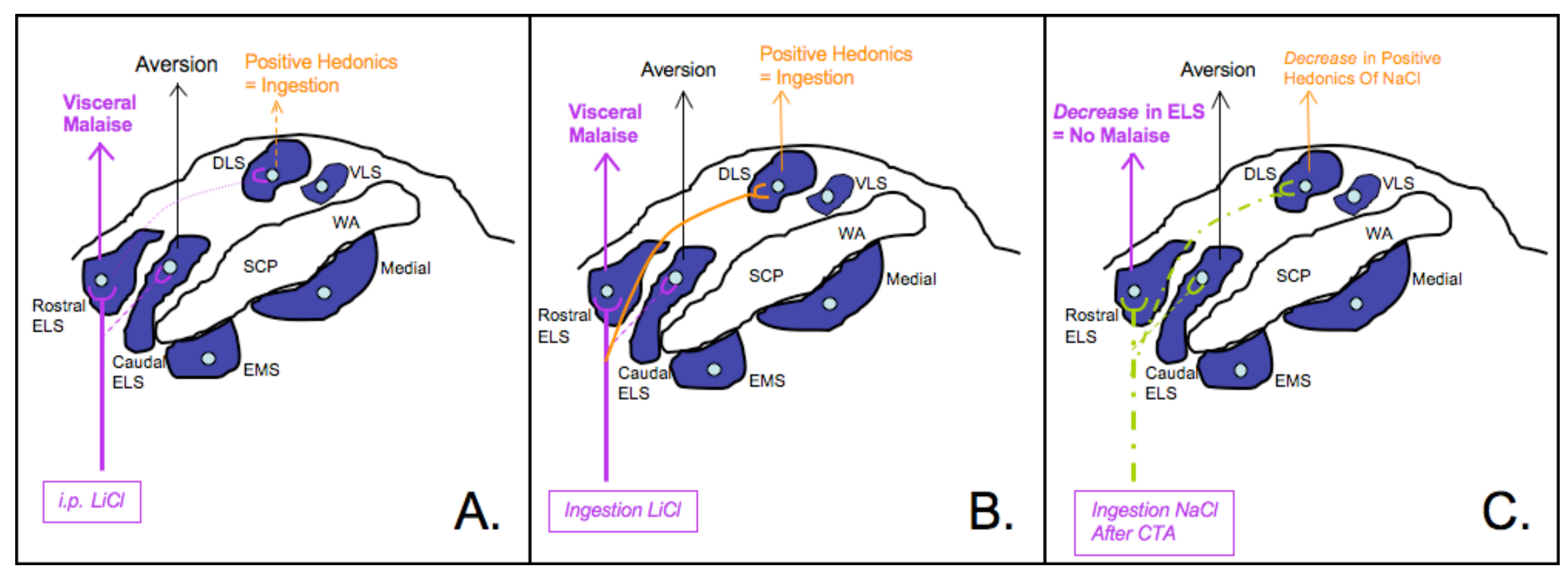

Figure 4-17. Illustration of c-Fos labeling results following stimulation by injection, conditioning, and generalization.

Notes: Schematic showing c-Fos results following i.p. $\mathrm{LiCl}$ (A), self-administration of $\mathrm{LiCl}$ (B), and self-administration of $\mathrm{NaCl}$ after conditioning with $\mathrm{LiCl}$ (C) based on hypothesis of convergence and previous work by Yamamoto (1993). 
However, it is key to remember that c-Fos activation is related to excitation of neurons, not inhibition (Sheng, M. et al. 1990; Hughes, P. et al. 1995; St Andre, J. et al. 2007).

Navarro et al (2000) have previously shown that c-Fos expression varies with the strength of aversion - the stronger the aversion, the more Fos expression. As discussed in Chapter 2, our own study showed increased Fos expression following a stronger dose of $\mathrm{LiCl}$, indicating expression was a representation of the visceral response (Figure 2-2). Based on these findings, one would expect D2 mice to reveal more Fos positive neurons in the ELS compared to B6, if the D2 mice were experiencing a higher degree of malaise. Based on this reasoning, our results suggest B6 and D2 mice appear to respond equally (in the $\mathrm{PBN}$ ) to illness induced by $\mathrm{LiCl}$ injection. Therefore, if the amount of c-Fos elicited by a purely visceral stimulation does not vary between B6 and D2, this suggests that other strain differences in CTA are not due to D2 mice simply becoming more ill.

In order to investigate strain differences following conditioning, B6 and $\mathrm{D} 2$ mice were compared in the amounts of elicited c-Fos after intake of $\mathrm{NaCl}$ or $\mathrm{LiCl}$. A previous study concluded that formation of a conditioned taste aversion occurs in less than 9 minutes in rats (Baird, J. P. et al. 2005). Our anatomical results indicated no strain effects on conditioning. However, D2 LiCl mice did possess decreased neuronal activation in the DLS compared to D2 controls. Since the DLS is associated with palatability and ingestion (Yamamoto, T. et al. 1993; Yamamoto, T. et al. 2009), it is possible the decrease seen in D2 mice is due to decreased mean licks (ingestive behavior) or formation of an aversion (decrease in palatability). When considered along with the B6 results, which also show a decrease in mean licks and no decrease in DLS Fos, this constitutes possible evidence of a CTA formation. However, due to the transient nature of c-Fos expression and the fact that activation is the result of neuronal excitation only, it is difficult to pinpoint from these results a point of formation. We can speculate that the decrease in Fos is due to inhibitory signals as a result of an aversion, but there is no way of confirming this hypothesis with the given data, so future studies would be needed to separate such signals and analyze a specific timeline of CTA formation.

On generalization day, mice that had been conditioned the previous day with $\mathrm{LiCl}$ were allowed to self-administer $\mathrm{NaCl}$ - the act of avoiding the $\mathrm{NaCl}$ demonstrates the generalization from $\mathrm{LiCl}$ to $\mathrm{NaCl}$. Our results showed that $\mathrm{D} 2$ mice expressed more c-Fos overall compared to B6 following generalization. These results were specific to the waist, medial, external lateral, and external medial subnuclei. There was also a significant effect of treatment, where higher activation was seen in the PBN following controls ( $\mathrm{NaCl}-\mathrm{NaCl})$ compared to CTA mice (LiCl-NaCl). D2 mice had increased activation in the DLS and ELS in controls compared to mice with a CTA. It is possible that this lack of activation in the DLS compared to controls is due to lack of palatability of $\mathrm{NaCl}$ due to an aversion. This would match results previously seen where palatability shifted from the DLS to the ELS following a conditioned taste aversion to saccharin (Yamamoto, T. et al. 1994). The decrease in the ELS in activation (compared to 
controls) could simply be a result of fewer licks, or as mentioned above, could be the result of inhibitory signals resulting from a CTA, therefore leading to what appears to be less neuronal activation. Lastly, there was a strain difference specific to the EMS, where more Fos was seen in D2 CTA mice compared to B6 CTA mice. There are several possibilities for this effect discussed in more detail below.

Lastly, an analysis was done to investigate changes occurring from one phase of CTA to the next by comparing results from conditioning (day 3) and generalization (day 4). First, to rule out any possible confounding issues revolving around novelty of the tastant, controls of neither strain exhibited changes in Fos labeling from day 3 to day 4. Second, CTA mice of both strains revealed a significant drop in Fos labeling in the ELS on day 4 (compared to day 3 , conditioning), but this is due to the malaise being experienced during conditioning, while during generalization the malaise was absent. Finally, only a significant effect of test day was found in the EMS for D2 mice. This effect was seen above in analysis of the generalization data and there are several possible explanations.

As it is extremely unlikely that there is lingering malaise on test day 4, it is possible this increase in Fos in the EMS (compared to B6) is associated with aversion. In fact, it has been suggested the EMS specifically plays a role in retention of a CTA (Di Lorenzo, P. M. 1988; Flynn, F. W. et al. 1991a; Flynn, F. W. et al. 1991b; Reilly, S. et al. 1993; Bures, J. et al. 1998). If this is true, and D2 mice exhibit more neuronal activation in this region following a conditioned taste aversion compared to B6, it is possible this result is evidence that D2 mice develop stronger aversions, as better retention would be expected to be preceded by a stronger memory of a learning event. However, in Figure 4-15, when comparing the change in neuronal activation from conditioning to generalization, it appears to be a decreased response in the EMS to $\mathrm{LiCl}$ conditioning that is driving this effect in D2 mice. Therefore, it is more likely that the increased Fos we see in the EMS in D2 mice compared to B6 is due to other signals related to licking; Figure 4-13 shows that the amount of Fos in the EMS following generalization of CTA mice appears comparable to that of controls on either test day, decreasing the likelihood that this is an effect of learning. 


\section{CHAPTER 5. FINAL SUMMARY AND OVERALL CONCLUSIONS}

The experiments described above were focused on determining if differences in conditioned taste aversion (CTA) existed between two common and well-studied inbred strains of mice, C57BL/6J (B6) and DBA/2J (D2). CTA is a form of single trial learning, dependent on the integration of taste and visceral sensation (gastric malaise). In the experiments of this thesis, I utilized both behavioral and anatomical methods to compare the strains. For both experiments, a naturalistic model of CTA was used: When rodents consume a solution of $\mathrm{LiCl}$, they have been shown to develop an aversion to the salty taste of this solution. However, there is uncertainty if the taste-based aversion develops rapidly following intake, as has been claimed for rats (Baird et al., 2005), or if it is manifested some time later, following the cessation of malaise. Moreover, it is unknown whether or not there are genetic-based differences among inbred strains in this form of CTA.

A previous study comparing B6 and D2 mice in acquisition and extinction of a CTA showed D2 mice had a greater resistance to extinction (Ingram, D. K. 1982). They suggested the difference was due to a stronger CTA formed by D2 mice, although their measures (of sucrose consumption) did not yield such differences (Ingram, D. K. 1982). However, our experiments included analyses of licking microstructure, which offers a more in depth comparison of strains regarding behavior in a CTA paradigm. As previously discussed, D2 mice have been shown to respond more to other conditioning tasks (for example as place avoidance), compared to B6 mice (Siegfried, B. et al. 1989). These studies suggest D2 mice form stronger aversions than B6, and therefore I hypothesized that B6 and D2 mice would exhibit differences in licking behavior during both conditioning and generalization phases of CTA. As shown in Table 1-1, it has previously been demonstrated that D2 mice perform better in a subset of learning and memory, including classical conditioning. Since conditioned taste aversion is one example of classical conditioning, it was expected that D2 mice would develop the aversion faster, and develop a stronger aversion, than B6 mice.

I uncovered behavioral evidence to support this hypothesis. However, our behavioral data suggest that the effects seen following conditioning are likely due to malaise, not to a full conditioned taste aversion, as Baird (2005) concluded. However, the results clearly show a CTA the following day during the generalization trial. At the lower dose $(0.12 \mathrm{M})$, on conditioning day, both strains initially licked $\mathrm{LiCl}$ at a rate equivalent to that of the control stimulus, $0.12 \mathrm{M} \mathrm{NaCl}$, confirming that these stimuli possess a similar taste. Within a few minutes, mice from both strains abruptly stopped licking $\mathrm{LiCl}$, whereas control mice continued to lick $\mathrm{NaCl}$ throughout the 20-minute trial. However, microstructure analysis suggested that the structure of licking appeared mainly normal until cessation. Some small changes, such as a shift to longer intra-burst lick rate, only appeared in D2 mice, suggesting they were perhaps more sensitive to the malaise-inducing effects of $\mathrm{LiCl}$. In contrast to conditioning, in the generalization session CTA mice of both strains initially avoided licking $\mathrm{NaCl}$ 
relative to controls. Licking behavior appear to be comparable to controls only after 2-6 minutes (depending on which experiment), and microstructural analyses showed hallmarks of CTA, including reduced volume per lick and elevated intra-burst lick rate, as reflected by a greater number of longer duration inter-lick intervals (ILIs). These alterations are reflective of hesitant consumption behavior, expected when the stimulus is perceived as aversive. The effects appeared greater in D2 CTA mice, which also possessed significantly reduced burst size, and which showed a lower initial lick rate than B6 mice.

As expected, the effects of $\mathrm{LiCl}$-induced malaise and / or CTA were more robust when a higher concentration of $\mathrm{LiCl}(0.24 \mathrm{M})$ was used. Intake of $\mathrm{NaCl}$ (control mice) or $\mathrm{LiCl}$ (CTA mice) was equivalent only in the first minute in both strains; by minute three, licking of $\mathrm{LiCl}$ was completely suppressed and remained so for the duration of the session. This is likely due to malaise. In the generalization session, CTA mice expressed a strong aversion to $\mathrm{NaCl}$, including significant changes on almost all microstructural variables. These changes include longer intervals, smaller bursts, and other measures that together, represent pauses and hesistancy in the behavioral response to the stimulus. For example, if a mouse has a CTA, but is thirsty due to water deprivation, it might take a few licks at a time, but take longer pauses because it doesn't like the solution. Finally, CTA effects appeared to be stronger in D2 mice than in B6 mice, suggesting D2 mice formed a stronger aversion.

In a recent study with Sprague-Dawley rats, Baird and colleagues (2005) concluded that a conditioned taste aversion was fully developed and expressed within the first 8 minutes of the conditioning trial. In this experiment, the rats were placed in a lickometer and presented with $0.12 \mathrm{M} \mathrm{LiCl}$ for 8 minutes, followed by $\mathrm{LiCl}, \mathrm{NaCl}$, water, or sucrose (Baird, J. P. et al. 2005). Microstructural analysis demonstrated hesitant licking behavior to either $\mathrm{LiCl}$ or $\mathrm{NaCl}$, including reduced lick volume, number of licks, and burst size, as compared to normal consumption of sucrose or water. The hesitant behavior to the salty stimuli was similar to that displayed by rats in response to the bitter compound quinine, leading the authors to conclude that the hedonic identity (positive or negative/ palatable or unpalatable) of the salts had rapidly switched from neutral/appetitive to aversive: meaning CTA formation was complete. However, this conclusion may not be entirely accurate, as 4 rats in the study were noted to have not consumed anything further during the second 8 minute trial. In other rats, water was consumed, but significantly less as compared to controls; and sucrose was consumed, although no controls were provided for this group. Furthermore, the authors report, but do not explain, that there was a significant increased latency to lick in trial 2 (generalization), even to water or sucrose (rats conditioned with $\mathrm{NaCl}$, latency to lick to water, $9 \mathrm{~ms}$; rats conditioned with $\mathrm{LiCl}$, latency to lick to water, $63 \mathrm{~ms}$ ). Therefore, if the rats possess a greater latency to begin the new trial, regardless of the stimulus, it is likely that they are still suffering malaise induced from the $\mathrm{LiCl}$. We conclude that it remains unclear whether they truly measured a CTA after just 8 minutes. Our data on generalization day does indeed match the findings from this particular study (Baird, J. P. et al. 2005) - including decreased mean licks, decreased volume per lick, increased latency to lick, and decreased number of bursts and burst size. 
However, we did not see most of these effects during conditioning, leading us to conclude that the cessation in licking was likely a result of the malaise being experienced. We conclude that the CTA was not yet complete, and that the following day during the generalization trial, the mice expressed a fully learned aversion, as shown in results in Chapter 3.

One important limitation in our studies involves the total amount of behavior produced by mice. As shown in the summary figures, control mice produce a maximum average lick count of $1200-1500$ licks to $\mathrm{NaCl}$ in a 20 minute trial on either day 3 (Conditioning) or Day 4 (Generalization). Rats, being a much larger animal, can easily double or triple this count in a shorter period of time. It is possible that subtle microstructural changes could have been seen in the conditioning trial had there been more data points to work with. How fast can a CTA actually form? The answer to this question is still open. Traditional paradigms (that pair flavor or taste exposure with i.p. $\mathrm{LiCl}$ delivery) use at least a $24 \mathrm{hr}$ time gap between conditioning and generalization testing. An important obstacle is the fact that decreases or alterations in consummatory behavior may be caused by either sickness or learning. Various studies have shown oral rejection behavior increases within $10-15$ minutes following i.p. injection of $\mathrm{LiCl}$ (Spector, A. C. et al. 1988; Eckel, L. A. et al. 1996; Houpt, T. A. et al. 1999). However, it is still possible that either malaise or learning contribute to the aversion seen in these studies.

Interestingly, at the higher dose of $\mathrm{NaCl}, \mathrm{D} 2$ controls decreased their lick counts, showing signs that the stimulus was no longer as palatable as it was to the B6 mice. However, when comparing D2 controls consuming $0.12 \mathrm{M}$ and $0.24 \mathrm{M} \mathrm{NaCl}$, there was no difference in mean lick counts. When comparing microstructure from these controls to other groups, there are only a few measures that are decreased (i.e., burst size). Lastly, when analyzing the anatomical results, following generalization, both D2 controls and CTA mice show increases in the same subnuclei compared to B6: the medial and external medial subnuclei. These two subnuclei may play a role in decreased palatability, and have also been shown to be critical to CTA retention (Sakai, N. et al. 1994; Bures, J. et al. 1998).

The second main focus of these studies was to use a neuronal marker to label activated neurons within the PBN, an area shown to be critical for CTA formation and expression, and compare these patterns of activation between B6 and D2 mice. No previous study has examined potential strain differences at the neuronal level for CTA. Additionally, comparing intake- (either on conditioning or generalization day) and visceral-evoked c-Fos allowed me to investigate whether or not CTA acquisition and expression reflected a unique neuronal "footprint" within the PBN. I quantified the number of Fos-positive nuclei within several key subnuclei of the PBN, and across several different rostralcaudal levels: ventral lateral (VLS), dorsal lateral (DLS), medial (M), waist, external lateral (ELS), and external medial (EMS). In summary, both strains generally exhibited an increase in Fos in particular subnuclei based on the stimulus, and these increases fell in line with previous studies. For example, following i.p. injection of $\mathrm{LiCl}$ in both strains, large amounts of Fos-positive 
nuclei were detected in the ELS, as compared to i.p. $\mathrm{NaCl}$ controls. Both $\mathrm{NaCl}$ and $\mathrm{LiCl}$ intake resulted in c-Fos expression within the DLS on conditioning day, expected since these stimuli have a similar salty taste to the mice, and appetitive stimuli, including salty-tasting stimuli, have been shown to evoke Fos in this region (Yamamoto, T. et al. 1994; Hashimoto, K. et al. 2009). However, only intake of $\mathrm{LiCl}$ drove c-Fos expression in the ELS, consistent with this stimulus producing malaise. When comparing B6 and D2 mice directly in terms of c-Fos quantification in subnuclei, no strain differences were found in visceral stimulation, $\mathrm{NaCl}$ or $\mathrm{LiCl}$ intake/conditioning. However, D2 mice showed significantly more Fos in the external medial subnucleus, compared to B6, following generalization. As was previously discussed, studies have shown that the lateral and medial portions of the PBN play separate roles; the lateral PBN plays a role in acquisition, and the medial PBN, particularly the external medial region (Di Lorenzo, P. M. 1988; Flynn, F. W. et al. 1991a; Flynn, F. W. et al. 1991b; Reilly, S. et al. 1993; Bures, J. et al. 1998), plays a role in retention (Sakai, N. et al. 1994; Bures, J. et al. 1998). Therefore, as previously discussed, this strain difference in the EMS possibly reflects a strain difference in CTA retention (and therefore strength of the aversion developed). However, the results of the studies presented here suggest that although there is a strain difference in this subnucleus, the amount of Fos elicited by D2 CTA mice following generalization actually appears to be comparable to their controls never exposed to $\mathrm{LiCl}$, and that therefore the effect we see is due to other, unknown signals.

Results showing that D2 CTA mice exhibited significantly less Fos in the DLS and ELS following generalization, we believe is due to decreased licks during the trial - as the mice are avoiding $\mathrm{NaCl}$ in the beginning portion of the trial, leading to an overall decrease in total licks. Since the DLS is associated with palatability and intake, a decrease in this subnucleus may represent a shift towards unpalatability of the stimulus, or it may represent less activation due to fewer licks. Since the ELS is associated with visceral and aversive properties of the stimulus, a decrease in the region may be due to less intake to stimulate the visceral response seen in controls. Arguing against this possibility is that when we constructed a scatter plot of individual c-Fos totals and licks for both strains and all groups, we did not see a significant correlation $(\mathrm{r}=0.28 ; p \leq 0.05)$. In other words, mice receiving $\mathrm{LiCl}$ on the conditioning day showed the same results the following day when receiving $\mathrm{NaCl}$ - on both days these mice had low lick counts relative to control groups, but only following generalization did the CTA mice have low Fos. Therefore, since lick count did not appear to correlate to Fos expression, it is possible that decreased neuronal activation in the ELS following the generalization test is a result of increased inhibitory signals to the ELS as a result of a CTA.

In regards to the water control group for the anatomical study, we did observe significant differences in Fos between strains. We also saw this same strain difference in our behavioral results (Figure 3-1), where D2 mice show fewer licks to water than B6. It is unclear what the cause of this effect is. When the strains were combined, there was not a significant correlation between the number of licks and Fos $(\mathrm{r}=0.24, p \leq 0.05)$. It is unclear if $\mathrm{D} 2$ mice are able to 
detect a taste from some component of the distilled water, or if there is an underlying genetic difference in visceral response (for example, stimulation caused by expanding of the stomach when eating or drinking). However, based on our results, B6 and D2 mice showed no differences in visceral or intake response. Further, these same results can rule out that the increased Fos is due to learning that took place in the apparatus itself, as again, we saw no such differences in $\mathrm{NaCl}$ intake. To test this further, a study comparing Fos levels and mean licks, in both strains, from all 3 days of water, could help answer this question - to determine if by day 3 , the Fos is representing a learned task with a familiar tastant.

In conclusion, we first hypothesized that D2 mice would make a stronger association between malaise and taste faster than B6 mice. Behaviorally, this was supported by our results, especially seen in microstructural data showing more changes characteristic of CTA in D2 than B6. It is important to note that licking analyses in mice are limited by the number of licks they take in a single trial (compared to rats, who take many more licks, providing much larger data sets to work with). Therefore, the strain differences seen in the behavioral results are subtle.

Our second hypothesis was that any differences between these two strains, whether in visceral response, taste reactivity, or developing an aversion, would be seen in differences in the amount of neuronal activation (marked via cFos). The method for this hypothesis was also confirmed, as we showed c-Fos does increase following a stronger dose of i.p. LiCl. However, we did not find consistent evidence of strain differences at the neuronal level following visceral stimulation (i.p. $\mathrm{LiCl}$ or $\mathrm{NaCl}$ ) or conditioning $(\mathrm{LiCl}$ or $\mathrm{NaCl}$ ). We did find evidence of a strain effect following generalization though, with D2 mice expressing overall more c-Fos throughout the PBN than B6. Although D2 mice have a faster lick rate, they actually had fewer licks overall compared to B6, yet more c-Fos. This suggests that the difference in c-Fos patterns is not due to inherent lick rates, but to differences in forming a CTA. There was evidence of a CTA at the neuronal level, based on c-Fos activation - both B6 and D2 mice with a CTA do show a marked decrease in Fos (compared to controls) in the DLS and ELS following the generalization test (although the decrease in B6 mice was not found to be significant). Most likely, the DLS shows a decrease in activation due to the salty taste of $\mathrm{NaCl}$ being determined unpalatable now that mice have a CTA.

In D2 mice, it is possible we see the same shift from palatable to unpalatable that Yamamoto (1993) saw in the PBN. In his study, the shift was from the DLS to ELS (Yamamoto, T. et al. 1993) - in our study, D2 mice show a decrease in the DLS with a simultaneous increase in the ELS. It is possible that we see the shift to the EMS instead of the ELS due to differences between rats and mice, or due to testing methods. Also, the decrease in the ELS could be due to less stimulation, although we found no correlation of mean licks and amount of c-Fos in the PBN, arguing against this possibility. Lastly, it is also possible that following a conditioned taste aversion, signals to the DLS and other subnuclei are inhibitory instead of excitatory. This hypothesis would explain why we see 
much less c-Fos in general following generalization, and why we see less c-Fos in particular regions previously mentioned. If a taste shifts from being pleasant to unpleasant, it is reasonable that signals to the DLS, a region associated with palatability, would weaken while signals to EMS, a region associated with aversive stimuli, would strengthen. Further studies need to be done to explore this hypothesis of inhibitory signals following a CTA. It has been shown that areas of the limbic forebrain, including the lateral hypothalamus and amygdala send inhibitory signals back to PBN to modulate taste. A combination of methods would be needed to test this - for example, one could record from neurons in specific subnuclei in the PBN while administering a tastant to the animal's tongue. If these recordings were compared before and after a CTA, one would expect to see a weakened or absent response of neurons in the DLS following a CTA. Other experiments could include combinations of lesions, cFos, and other tracers to determine the existence of inhibition in the PBN following CTA.

While the cause of the results in the EMS remains uncertain, the effects found in the anatomical study do support the subtle, yet significant, strain differences seen in the behavioral study. Following conditioning, we only saw cFos where expected - in the ELS due to malaise and in the DLS due to the salty taste of $\mathrm{LiCl}$. There were no other patterns or subnuclei responding heavily during conditioning, which supports conclusions from the behavior studies that we do not see a CTA that day, only malaise. Lastly, it is important to note that we did see overall effects of strain in several conditions in the anatomical analysis (specifically following generalization), and therefore conclude that we found strain differences related to CTA in B6 and D2 mice at the neuronal level.

In addition, this evidence of a strain difference in neuronal response following CTA suggests that these two strains are processing information required to form and maintain an aversion differently or at different rates. Whether the difference is due to learning processes, sensitivity to aversive factors, or where taste and learning information is integrated, remains unclear and requires further research. One possibility we ruled out here is that D2 mice experience more malaise than B6 mice. One future study could be a series of extinction studies, following various numbers of conditioning trials. This could create a timeline of the two strains, showing how long each strain maintains the aversion after single, or $2+$ conditionings trials. It would be expected D2 mice would retain the memory longer than B6 based on our results here and in combination with previous literature. A second study could follow protocols laid out here, and investigate other brain regions, such as the amygdala or forebrain. Lastly, comprehensive studies comparing Fos throughout the brain following various behavioral learning paradigms could help determine the neuronal processing of learning and memory in B6 and D2 mice. 


\section{LIST OF REFERENCES}

Ammassari-Teule, M., Hoffmann, H. J. and Rossi-Arnaud, C. (1993). "Learning in inbred mice: Strain-specific abilities across three radial maze problems." Behav Genet 23(4): 405-412.

Arnold, J. C., Topple, A. N., Mallet, P. E., Hunt, G. E. and Mcgregor, I. S. (2001). "The distribution of cannabinoid-induced fos expression in rat brain: Differences between the lewis and wistar strain." Brain Res 921(1-2): 240255.

Baird, J. P., Grill, H. J. and Kaplan, J. M. (1999). "Effect of hepatic glucose infusion on glucose intake and licking microstructure in deprived and nondeprived rats." Am J Physiol 277(4 Pt 2): R1136-1143.

Baird, J. P., St John, S. J. and Nguyen, E. A. (2005). "Temporal and qualitative dynamics of conditioned taste aversion processing: Combined generalization testing and licking microstructure analysis." Behav Neurosci 119(4): 983-1003.

Balogh, S. A., Radcliffe, R. A., Logue, S. F. and Wehner, J. M. (2002). "Contextual and cued fear conditioning in $c 57 \mathrm{bl} / 6 \mathrm{j}$ and $\mathrm{dba} / 2 \mathrm{j}$ mice: Context discrimination and the effects of retention interval." Behav Neurosci 116(6): 947-957.

Balogh, S. A. and Wehner, J. M. (2003). "Inbred mouse strain differences in the establishment of long-term fear memory." Behav Brain Res 140(1-2): 97106.

Bennett, H. J. and Semba, K. (1998). "Immunohistochemical localization of caffeine-induced c-fos protein expression in the rat brain." J Comp Neurol 401(1): 89-108.

Bolivar, V. J., Pooler, O. and Flaherty, L. (2001). "Inbred strain variation in contextual and cued fear conditioning behavior." Mamm Genome 12(8): 651-656.

Bothe, G. W., Bolivar, V. J., Vedder, M. J. and Geistfeld, J. G. (2004). "Genetic and behavioral differences among five inbred mouse strains commonly used in the production of transgenic and knockout mice." Genes Brain Behav 3(3): 149-157.

Boughter, J. D., Jr. and Bachmanov, A. A. (2007a). "Behavioral genetics and taste." BMC Neurosci 8 Suppl 3: S3.

Boughter, J. D., Jr., Baird, J. P., Bryant, J., St John, S. J. and Heck, D. (2007b). "C57bl/6j and dba/2j mice vary in lick rate and ingestive microstructure." Genes Brain Behav 6(7): 619-627. 
Boughter, J. D., Jr., Raghow, S., Nelson, T. M. and Munger, S. D. (2005). "Inbred mouse strains $c 57 \mathrm{bl} / 6 \mathrm{j}$ and $\mathrm{dba} / 2 \mathrm{j}$ vary in sensitivity to a subset of bitter stimuli." BMC Genet 6: 36.

Boughter, J. D., Jr., St John, S. J., Noel, D. T., Ndubuizu, O. and Smith, D. V. (2002). "A brief-access test for bitter taste in mice." Chem Senses 27(2): 133142.

Bovet, D., Bovet-Nitti, F. and Oliverio, A. (1969). "Genetic aspects of learning and memory in mice." Science 163(863): 139-149.

Brown, R. E., Schellinck, H. M., Gunn, R. K., Wong, A. A. and O'leary, T. P. (2011). Visual ability and spatial, motor and olfactory learning and memory in 14 inbred strains of mice., MPD:Brown2.

Brown, R. E. and Wong, A. A. (2007). "The influence of visual ability on learning and memory performance in 13 strains of mice." Learn Mem 14(3): 134144.

Bures, J., Bermudez-Rattoni, F. and Yamamoto, T. (1998). Conditioned taste aversion. Memory of a special kind. Oxford, Oxford University Press.

Calder, A. J., Lawrence, A. D. and Young, A. W. (2001). "Neuropsychology of fear and loathing." Nat Rev Neurosci 2(5): 352-363.

Chan, C. Y., Yoo, J. E. and Travers, S. P. (2004). "Diverse bitter stimuli elicit highly similar patterns of fos-like immunoreactivity in the nucleus of the solitary tract." Chem Senses 29(7): 573-581.

Chang, F. C. and Scott, T. R. (1984). "Conditioned taste aversions modify neural responses in the rat nucleus tractus solitarius." J Neurosci 4(7): 1850-1862.

Clark, E. W. and Bernstein, I. L. (2009). "Establishing aversive, but not safe, taste memories requires lateralized pontine-cortical connections." Behav Brain Res 197(2): 356-363.

Curtis, K. S., Sved, A. F., Verbalis, J. G. and Stricker, E. M. (1994). "Lithium chloride-induced anorexia, but not conditioned taste aversions, in rats with area postrema lesions." Brain Res 663(1): 30-37.

D'hooge, R. and De Deyn, P. P. (2001). "Applications of the morris water maze in the study of learning and memory." Brain Res Brain Res Rev 36(1): 60-90.

Davis, J. D. (1996). "Deterministic and probabilistic control of the behavior of rats ingesting liquid diets." Am J Physiol 270(4 Pt 2): R793-800.

Davis, J. D. and Perez, M. C. (1993). "Food deprivation- and palatability-induced microstructural changes in ingestive behavior." Am J Physiol 264(1 Pt 2): R97-103. 
Davis, J. D. and Smith, G. P. (1992). "Analysis of the microstructure of the rhythmic tongue movements of rats ingesting maltose and sucrose solutions." Behav Neurosci 106(1): 217-228.

Davis, J. D., Smith, G. P. and Kung, T. M. (1995). "Abdominal vagotomy attenuates the inhibiting effect of mannitol on the ingestive behavior of rats." Behav Neurosci 109(1): 161-167.

Davis, M. (1992). "The role of the amygdala in fear and anxiety." Annu Rev Neurosci 15: 353-375.

Davis, M. and Whalen, P. J. (2001). "The amygdala: Vigilance and emotion." $\mathrm{Mol}$ Psychiatry 6(1): 13-34.

Deurveilher, S., Lo, H., Murphy, J. A., Burns, J. and Semba, K. (2006). "Differential c-fos immunoreactivity in arousal-promoting cell groups following systemic administration of caffeine in rats." I Comp Neurol 498(5): 667-689.

Di Lorenzo, P. M. (1988). "Taste responses in the parabrachial pons of decerebrate rats." J Neurophysiol 59(6): 1871-1887.

Ding, H. K., Teixeira, C. M. and Frankland, P. W. (2008). "Inactivation of the anterior cingulate cortex blocks expression of remote, but not recent, conditioned taste aversion memory." Learn Mem 15(5): 290-293.

Eckel, L. A. and Ossenkopp, K. P. (1996). "Area postrema mediates the formation of rapid, conditioned palatability shifts in lithium-treated rats." Behav Neurosci 110(1): 202-212.

Eisen, S., Davis, J. D., Rauhofer, E. and Smith, G. P. (2001). "Gastric negative feedback produced by volume and nutrient during a meal in rats." Am I Physiol Regul Integr Comp Physiol 281(4): R1201-1214.

Flynn, F. W., Grill, H. J., Schulkin, J. and Norgren, R. (1991a). "Central gustatory lesions: Ii. Effects on sodium appetite, taste aversion learning, and feeding behaviors." Behav Neurosci 105(6): 944-954.

Flynn, F. W., Grill, H. J., Schwartz, G. J. and Norgren, R. (1991b). "Central gustatory lesions: I. Preference and taste reactivity tests." Behav Neurosci 105(6): 933-943.

Foynes, M. M. and Riley, A. L. (2004). "Lithium-chloride-induced conditioned taste aversions in the lewis and fischer 344 rat strains." Pharmacol Biochem Behav 79(2): 303-308.

Garcia, J., Hankins, W. G. and Rusiniak, K. W. (1974). "Behavioral regulation of the milieu interne in man and rat." Science 185(4154): 824-831. 
Grabus, S. D., Glowa, J. R. and Riley, A. L. (2004). "Morphine- and cocaineinduced c-fos levels in lewis and fischer rat strains." Brain Res 998(1): 2028.

Grancha, M. L., Navarro, M., Cubero, I., Thiele, T. E. and Bernstein, I. L. (2002). "Induction of a brainstem correlate of conditioned taste aversion expression: Role of the pontine parabrachial nucleus." Behav Brain Res 131(1-2): 205-209.

Grill, H. J., Spector, A. C., Schwartz, G. J., Kaplan, J. M. and Flynn, F. W. (1987). Evaluating taste effects on ingestive behavior. Feeding and drinking. Toates, F. M. and Rowland, N. E. New York, Elsevier: 151-158.

Haino, T., Hironaka, S., Ooka, T., Tokita, K., Kubota, Y., Boughter, J. D., Jr., Inoue, T. and Mukai, Y. (2010). "Orosensory deprivation alters tasteelicited c-fos expression in the parabrachial nucleus of neonatal rats." Neurosci Res 67(3): 228-235.

Harder, D. B., Capeless, C. G., Maggio, J. C., Boughter, J. D., Gannon, K. S., Whitney, G. and Azen, E. A. (1992). "Intermediate sucrose octa-acetate sensitivity suggests a third allele at mouse bitter taste locus soa and soarua identity." Chem Senses(17): 391-401.

Harris, J. A. (1998). "Using c-fos as a neural marker of pain." Brain Res Bull 45(1): $1-8$.

Hashimoto, K., Obata, K. and Ogawa, H. (2009). "Characterization of parabrachial subnuclei in mice with regard to salt tastants: Possible independence of taste relay from visceral processing." Chem Senses 34(3): 253-267.

Hermann, G. E., Kohlerman, N. J. and Rogers, R. C. (1983). "Hepatic-vagal and gustatory afferent interactions in the brainstem of the rat." J Auton Nerv Syst 9(2-3): 477-495.

Holmes, A., Wrenn, C. C., Harris, A. P., Thayer, K. E. and Crawley, J. N. (2002). "Behavioral profiles of inbred strains on novel olfactory, spatial and emotional tests for reference memory in mice." Genes Brain Behav 1(1): 5569.

Horowitz, G. P., Stephan, F. K., Smith, J. C. and Whitney, G. (1977). "Genetic and environmental variability in lick rates of mice." Physiol Behav 19(4): 493496.

Houpt, T. A. and Berlin, R. (1999). "Rapid, labile, and protein synthesisindependent short-term memory in conditioned taste aversion." Learn Mem 6(1): 37-46. 
Houpt, T. A., Philopena, J. M., Joh, T. H. and Smith, G. P. (1996). "C-fos induction in the rat nucleus of the solitary tract correlates with the retention and forgetting of a conditioned taste aversion." Learn Mem 3(1): 25-30.

Houpt, T. A., Philopena, J. M., Wessel, T. C., Joh, T. H. and Smith, G. P. (1994). "Increased c-fos expression in nucleus of the solitary tract correlated with conditioned taste aversion to sucrose in rats." Neurosci Lett 172(1-2): 1-5.

Hughes, P. and Dragunow, M. (1995). "Induction of immediate-early genes and the control of neurotransmitter-regulated gene expression within the nervous system." Pharmacol Rev 47(1): 133-178.

Ingram, D. K. (1982). "Lithium chloride-induced taste aversion in c57bl/6j and dba/2j mice." J Gen Psychol 106(2d Half): 233-249.

Ishiwatari, Y. and Bachmanov, A. A. (2009). "A high-throughput method to measure nacl and acid taste thresholds in mice." Chem Senses 34(4): 277293.

Johnson, L. R. (2006). Physiology of the gastrointestinal tract. Burlington, MA, Elsevier Academic Press.

Kaplan, J. M., Donahey, J., Baird, J. P., Simansky, K. J. and Grill, H. J. (1997). "Dfenfluramine anorexia: Dissociation of ingestion rate, meal duration, and meal size effects." Pharmacol Biochem Behav 57(1-2): 223-229.

Karimnamazi, H., Travers, S. P. and Travers, J. B. (2002). "Oral and gastric input to the parabrachial nucleus of the rat." Brain Res 957(2): 193-206.

King, V. M. and Apps, R. (2000). "Somatotopical organization of fos-like immunoreactivity in rat cervical spinal cord following noxious stimulation of the forelimb." Neuroscience 101(1): 179-188.

Koh, M. T. and Bernstein, I. L. (2005). "Mapping conditioned taste aversion associations using c-fos reveals a dynamic role for insular cortex." Behav Neurosci 119(2): 388-398.

Koh, M. T., Clarke, S. N., Spray, K. J., Thiele, T. E. and Bernstein, I. L. (2003). "Conditioned taste aversion memory and c-fos induction are disrupted in riibeta-protein kinase a mutant mice." Behav Brain Res 143(1): 57-63.

Kosten, T. and Contreras, R. J. (1989). "Deficits in conditioned heart rate and taste aversion in area postrema-lesioned rats." Behav Brain Res 35(1): 9-21.

Ladowsky, R. L. and Ossenkopp, K. P. (1986). "Conditioned taste aversions and changes in motor activity in lithium-treated rats. Mediating role of the area postrema." Neuropharmacology 25(1): 71-77. 
Ledoux, J. E. (2000). "Emotion circuits in the brain." Annu Rev Neurosci 23: 155184.

Lewis, S. R., Ahmed, S., Dym, C., Khaimova, E., Kest, B. and Bodnar, R. J. (2005). "Inbred mouse strain survey of sucrose intake." Physiol Behav 85(5): 546556.

Loy, I. and Hall, G. (2002). "Taste aversion after ingestion of lithium chloride: An associative analysis." Q J Exp Psychol B 55(4): 365-380.

Lush, I. E. (1984). "The genetics of tasting in mice. Iii. Quinine." Genet Res 44(2): 151-160.

Maren, S. (2001). "Neurobiology of pavlovian fear conditioning." Annu Rev Neurosci 24: 897-931.

Maren, S. (2003). "What the amygdala does and doesn't do in aversive learning." Learn Mem 10(5): 306-308.

Mcfadyen, M. P., Kusek, G., Bolivar, V. J. and Flaherty, L. (2003). "Differences among eight inbred strains of mice in motor ability and motor learning on a rotorod." Genes Brain Behav 2(4): 214-219.

Mcgaugh, J. L. (1989). "Involvement of hormonal and neuromodulatory systems in the regulation of memory storage." Annu Rev Neurosci 12: 255-287.

Meachum, C. L. and Bernstein, I. L. (1990). "Conditioned responses to a taste conditioned stimulus paired with lithium chloride administration." Behav Neurosci 104(5): 711-715.

Navarro, M., Spray, K. J., Cubero, I., Thiele, T. E. and Bernstein, I. L. (2000). "Cfos induction during conditioned taste aversion expression varies with aversion strength." Brain Res 887(2): 450-453.

Nelson, T. M., Munger, S. D. and Boughter, J. D., Jr. (2003). "Taste sensitivities to prop and ptc vary independently in mice." Chem Senses 28(8): 695-704.

O'Mahony, C. M., Sweeney, F. F., Daly, E., Dinan, T. G. and Cryan, J. F. (2010). "Restraint stress-induced brain activation patterns in two strains of mice differing in their anxiety behaviour." Behav Brain Res 213(2): 148-154.

Orsini, C., Buchini, F., Conversi, D. and Cabib, S. (2004). "Selective improvement of strain-dependent performances of cognitive tasks by food restriction." Neurobiol Learn Mem 81(1): 96-99.

Paxinos, G. and Franklin, K. B. J. (2001). The mouse brain in stereotaxic coordinates. Hong Long, Academic Press. 
Paylor, R., Baskall-Baldini, L., Yuva, L. and Wehner, J. M. (1996). "Developmental differences in place-learning performance between c57bl/6 and $\mathrm{dba} / 2$ mice parallel the ontogeny of hippocampal protein kinase c." Behav Neurosci 110(6): 1415-1425.

Paylor, R., Tracy, R., Wehner, J. and Rudy, J. W. (1994). "Dba/2 and c57bl/ 6 mice differ in contextual fear but not auditory fear conditioning." Behav Neurosci 108(4): 810-817.

Purves, D. (2008). Neuroscience. Sunderland, Sinauer.

Rabin, B. M., Hunt, W. A. and Lee, J. (1983). "Attenuation of radiation- and druginduced conditioned taste aversions following area postrema lesions in the rat." Radiat Res 93(2): 388-394.

Reilly, S., Grigson, P. S. and Norgren, R. (1993). "Parabrachial nucleus lesions and conditioned taste aversion: Evidence supporting an associative deficit." Behav Neurosci 107(6): 1005-1017.

Rinaman, L., Stricker, E. M., Hoffman, G. E. and Verbalis, J. G. (1997). "Central cfos expression in neonatal and adult rats after subcutaneous injection of hypertonic saline." Neuroscience 79(4): 1165-1175.

Risinger, F. O. and Cunningham, C. L. (2000). "Dba/2j mice develop stronger lithium chloride-induced conditioned taste and place aversions than c57bl/6j mice." Pharmacol Biochem Behav 67(1): 17-24.

Ritter, S., Mcglone, J. J. and Kelley, K. W. (1980). "Absence of lithium-induced taste aversion after area postrema lesion." Brain Res 201(2): 501-506.

Sakai, N., Tanimizu, T., Sako, N., Shimura, T. and Yamamoto, T. (1994). Effects of lesions of the medial and lateral parabrachial nuclei on acquisition and retention of conditioned taste aversion. Olfaction and taste xi. Kurihara, K., Suzuki, N. and Ogawa, H. Tokyo, Springer-Verlag: 495-496.

Sakai, N. and Yamamoto, T. (1997). "Conditioned taste aversion and c-fos expression in the rat brainstem after administration of various uss." Neuroreport 8(9-10): 2215-2220.

Schafe, G. E., Fitts, D. A., Thiele, T. E., Ledoux, J. E. and Bernstein, I. L. (2000). "The induction of c-fos in the nts after taste aversion learning is not correlated with measures of conditioned fear." Behav Neurosci 114(1): 99106.

Schafe, G. E., Thiele, T. E. and Bernstein, I. L. (1998). "Conditioning method dramatically alters the role of amygdala in taste aversion learning." Learn Mem 5(6): 481-492. 
Senba, E. and Ueyama, T. (1997). "Stress-induced expression of immediate early genes in the brain and peripheral organs of the rat." Neurosci Res 29(3): 183-207.

Sheng, M. and Greenberg, M. E. (1990). "The regulation and function of c-fos and other immediate early genes in the nervous system." Neuron 4(4): 477-485.

Shimura, T., Norgren, R., Grigson, P. S. and Norgren, R. (1997). "Brainstem lesions and gustatory function: I. The role of the nucleus of the solitary tract during a brief intake test in rats." Behav Neurosci 111(1): 155-168.

Shires, C. B., Saputra, J. M., Stocks, R. M. S., Sebelik, M. E. and Boughter, J. D., Jr. (2011). "Effects of sensory or motor nerve deafferentation on oromotor function in mice." Otolaryngol Head Neck Surg Epub ahead of print.

Siegfried, B. and Frischknecht, H. R. (1989). "Place avoidance learning and stressinduced analgesia in the attacked mouse: Role of endogenous opioids." Behav Neural Biol 52(1): 95-107.

Spector, A. C., Breslin, P. and Grill, H. J. (1988). "Taste reactivity as a dependent measure of the rapid formation of conditioned taste aversion: A tool for the neural analysis of taste-visceral associations." Behav Neurosci 102(6): 942-952.

Spector, A. C., Klumpp, P. A. and Kaplan, J. M. (1998a). "Analytical issues in the evaluation of food deprivation and sucrose concentration effects on the microstructure of licking behavior in the rat." Behav Neurosci 112(3): 678694.

Spector, A. C., Norgren, R. and Grill, H. J. (1992). "Parabrachial gustatory lesions impair taste aversion learning in rats." Behav Neurosci 106(1): 147-161.

Spector, A. C. and St John, S. J. (1998b). "Role of taste in the microstructure of quinine ingestion by rats." Am J Physiol 274(6 Pt 2): R1687-1703.

Spray, K. J., Halsell, C. B. and Bernstein, I. L. (2000). "C-fos induction in response to saccharin after taste aversion learning depends on conditioning method." Brain Res 852(1): 225-227.

Squire, L. R. (2004). "Memory systems of the brain: A brief history and current perspective." Neurobiol Learn Mem 82(3): 171-177.

St Andre, J., Albanos, K. and Reilly, S. (2007). "C-fos expression in the rat brain following lithium chloride-induced illness." Brain Res 1135(1): 122-128.

Stephenson, C. P., Hunt, G. E., Topple, A. N. and Mcgregor, I. S. (1999). "The distribution of 3,4-methylenedioxymethamphetamine "Ecstasy"-induced c-fos expression in rat brain." Neuroscience 92(3): 1011-1023. 
Streefland, C., Farkas, E., Maes, F. W. and Bohus, B. (1996). "C-fos expression in the brainstem after voluntary ingestion of sucrose in the rat." Neurobiology (Bp) 4(1-2): 85-102.

Swank, M. W. (2000). "Conditioned c-fos in mouse nts during expression of a learned taste aversion depends on contextual cues." Brain Res 862(1-2): 138-144.

Swank, M. W. and Bernstein, I. L. (1994). "C-fos induction in response to a conditioned stimulus after single trial taste aversion learning." Brain Res 636(2): 202-208.

Swank, M. W., Schafe, G. E. and Bernstein, I. L. (1995). "C-fos induction in response to taste stimuli previously paired with amphetamine or licl during taste aversion learning." Brain Res 673(2): 251-261.

Tokita, K., Shimura, T., Nakamura, S., Inoue, T. and Yamamoto, T. (2007). "Involvement of forebrain in parabrachial neuronal activation induced by aversively conditioned taste stimuli in the rat." Brain Res 1141: 188-196.

Travers, J. B., Herman, K., Yoo, J. and Travers, S. P. (2007). "Taste reactivity and fos expression in gad1-egfp transgenic mice." Chem Senses 32(2): 129-137.

Travers, J. B. and Norgren, R. (1986). "Electromyographic analysis of the ingestion and rejection of sapid stimuli in the rat." Behav Neurosci 100(4): 544-555.

Travers, S. P. and Travers, J. B. (2007). "Taste-evoked fos expression in nitrergic neurons in the nucleus of the solitary tract and reticular formation of the rat." J Comp Neurol 500(4): 746-760.

Trneckova, L., Armario, A., Hynie, S., Sida, P. and Klenerova, V. (2006). "Differences in the brain expression of c-fos mrna after restraint stress in lewis compared to sprague-dawley rats." Brain Res 1077(1): 7-15.

Upchurch, M. and Wehner, J. M. (1988). "Differences between inbred strains of mice in morris water maze performance." Behav Genet 18(1): 55-68.

Welzl, H., D'adamo, P. and Lipp, H. P. (2001). "Conditioned taste aversion as a learning and memory paradigm." Behav Brain Res 125(1-2): 205-213.

Whitney, G., Harder, D. B., Gannon, K. S. and Maggio, J. C. (1991). Congenic lines differing in ability to taste sucrose octaacetate. New York, Marcel Dekker.

Yamamoto, T. (1993). "Neural mechanisms of taste aversion learning." Neurosci Res 16(3): 181-185. 
Yamamoto, T., Matsuo, R., Kiyomitsu, Y. and Kitamura, R. (1989). "Taste responses of cortical neurons in freely ingesting rats." J Neurophysiol 61(6): 1244-1258.

Yamamoto, T., Shimura, T., Sakai, N. and Ozaki, N. (1994). "Representation of hedonics and quality of taste stimuli in the parabrachial nucleus of the rat." Physiol Behav 56(6): 1197-1202.

Yamamoto, T., Shimura, T., Sako, N., Sakai, N., Tanimizu, T. and Wakisaka, S. (1993). "C-fos expression in the parabrachial nucleus after ingestion of sodium chloride in the rat." Neuroreport 4(11): 1223-1226.

Yamamoto, T., Takemura, M., Inui, T., Torii, K., Maeda, N., Ohmoto, M., Matsumoto, I. and Abe, K. (2009). "Functional organization of the rodent parabrachial nucleus." Ann N Y Acad Sci 1170: 378-382.

Yasoshima, Y., Sako, N., Senba, E. and Yamamoto, T. (2006). "Acute suppression, but not chronic genetic deficiency, of c-fos gene expression impairs longterm memory in aversive taste learning." Proc Natl Acad Sci U S A 103(18): 7106-7111.

Zhu, X. O., Brown, M. W. and Aggleton, J. P. (1995). "Neuronal signalling of information important to visual recognition memory in rat rhinal and neighbouring cortices." Eur J Neurosci 7(4): 753-765. 


\section{VITA}

I, April Rebecca Glatt, was born in 1981, and am native of Memphis, TN. My high school education was completed at Immaculate Conception High School and undergraduate was completed at Christian Brothers University. I graduated from CBU with a Bachelor of Arts in Psychology, and a minor in religious studies, and I graduated Magna Cum Laude in 2003. After a one-year break, I was accepted and enrolled at UTHSC to pursue graduate level education within the Integrated Program of Biomedical Sciences. In 2005 I joined the graduate student executive council and was elected Honor Council President. In 2006 I was elected Graduate Student Executive Committee (GSEC) President and also served as the graduate representative for the Student Government Association. During this time, I also served as a student representative on the curriculum committee and graduate studies committee. After my term as president, I remained actively involved as Vice President and subsequently as a student representative for GSEC.

Within the IPBS program, I chose to pursue research in the Neuroscience track and joined the lab of Dr. John Boughter. Initially I worked on a project concerning the taste of nicotine and it's contribution to intake. For my second project I was given the opportunity to develop and create a research plan based on my own ideas, and subsequently pursued research that investigated the connection between taste, obesity, and ghrelin. Several years later the project was ended for various reasons and I switched my dissertation work to conditioned taste aversion. My final project, presented here, looked at conditioned taste aversion in inbred mice to determine possible differences, lending to future studies of genetics in the field of learning and memory.

I was enrolled at UTHSC from 2004-2011, at which time I completed requirements for a PhD in Neuroscience. In the end, I had been an author on 3 papers with 2 others in the making, written and presented 7 posters and abstracts at conferences, including the Association of Chemoreception Sciences, and received 6 travel awards. 